NBER WORKING PAPER SERIES

\title{
BIAS IN CABLE NEWS: PERSUASION AND POLARIZATION
}

Gregory J. Martin

Ali Yurukoglu

Working Paper 20798

http://www.nber.org/papers/w20798

\author{
NATIONAL BUREAU OF ECONOMIC RESEARCH \\ 1050 Massachusetts Avenue \\ Cambridge, MA 02138 \\ December 2014
}

Previously circulated as "Bias in Cable News: Real Effects and Polarization." We thank Tom Clark, Greg Crawford, Ruben Enikopolov, Matthew Gentzkow, Ben Golub, Marit Hinnosaar, Kei Kawai, Robin Lee, Claire Lim, Paul Oyer, Ariel Pakes, Jesse Shapiro, Michael Sinkinson, Gaurav Sood, and seminar and workshop participants at the BFI Media and Communications Conference, Boston College, Boston University, Columbia, Emory, Harvard, NYU Stern, Stanford, USC Marshall, the Wallis Political Economy Conference, the Workshop on Media Economics, and Zurich for comments and suggestions, and Carlos Sanchez-Martinez for excellent research assistance. The views expressed herein are those of the authors and do not necessarily reflect the views of the National Bureau of Economic Research.

NBER working papers are circulated for discussion and comment purposes. They have not been peer-reviewed or been subject to the review by the NBER Board of Directors that accompanies official NBER publications.

(C) 2014 by Gregory J. Martin and Ali Yurukoglu. All rights reserved. Short sections of text, not to exceed two paragraphs, may be quoted without explicit permission provided that full credit, including $(\odot$ notice, is given to the source. 
Bias in Cable News: Persuasion and Polarization

Gregory J. Martin and Ali Yurukoglu

NBER Working Paper No. 20798

December 2014, Revised June 2016

JEL No. D72,D83,L82

\begin{abstract}
$\underline{\text { ABSTRACT }}$
We measure the persuasive effects of slanted news and tastes for like-minded news, exploiting cable channel positions as exogenous shifters of cable news viewership. Channel positions do not correlate with demographics that predict viewership and voting, nor with local satellite viewership. We estimate that Fox News increases Republican vote shares by 0.3 points among viewers induced into watching 2.5 additional minutes per week by variation in position. We then estimate a model of voters who select into watching slanted news, and whose ideologies evolve as a result. We quantitatively assess media-driven polarization, and simulate alternative ideological slanting of news channels.
\end{abstract}

Gregory J. Martin

Tarbutton Hall

1555 Dickey Dr.

Atlanta, GA 30322

gregory.martin@emory.edu

Ali Yurukoglu

Graduate School of Business

Stanford University

Stanford, CA 94305

and NBER

ayurukog@stanford.edu 


\title{
Bias in Cable News: Persuasion and Polarization
}

\author{
Gregory J. Martin* and Ali Yurukoglu ${ }^{\ddagger}$
}

May 27, 2016

\begin{abstract}
We measure the persuasive effects of slanted news and tastes for like-minded news, exploiting cable channel positions as exogenous shifters of cable news viewership. Channel positions do not correlate with demographics that predict viewership and voting, nor with local satellite viewership. We estimate that Fox News increases Republican vote shares by 0.3 points among viewers induced into watching 2.5 additional minutes per week by variation in position. We then estimate a model of voters who select into watching slanted news, and whose ideologies evolve as a result. We quantitatively assess media-driven polarization, and simulate alternative ideological slanting of news channels.
\end{abstract}

\section{Introduction}

The 24-hour cable news channels - CNN, the Fox News Channel, and MSNBC - are frequent targets of allegations of media bias. In this paper, we address two questions about cable news. First, how much does consuming slanted news, like the Fox News Channel, alter the propensity of an individual to vote Republican in Presidential elections, if at all? Second, how

*Emory University.

${ }^{\dagger}$ Graduate School of Business, Stanford University and NBER.

${ }^{\ddagger}$ We thank Tom Clark, Greg Crawford, Ruben Enikopolov, Matthew Gentzkow, Ben Golub, Marit Hinnosaar, Kei Kawai, Robin Lee, Claire Lim, Paul Oyer, Ariel Pakes, Jesse Shapiro, Michael Sinkinson, Gaurav Sood, and seminar and workshop participants at the BFI Media and Communications Conference, Boston College, Boston University, Columbia, Emory, Harvard, NYU Stern, Stanford, USC Marshall, the Wallis Political Economy Conference, the Workshop on Media Economics, and Zurich for comments and suggestions, and Carlos Sanchez-Martinez for excellent research assistance. 
intense are consumer preferences for cable news that is slanted towards their own ideology? After measuring these forces, we ask: how much could slanted news contribute to increases in polarization? And, what do these forces imply for the optimal positioning of channels that wish to maximize viewership, or alternatively to maximize influence?

The answers to these questions are key inputs for designing optimal public policy, such as merger policy, for the media sector which has attracted blame for the rise in polarization in the US (Gentzkow, 2016). If consumers simply prefer news that resonates with their preexisting ideology, as in Mullainathan and Shleifer (2005) and Gentzkow and Shapiro (2010), then the news media sector should be treated like any other consumer product. However, if consuming news with a slant also alters the consumer's political behavior, as in DellaVigna and Kaplan (2007), then the existence of slanted news could lead to a polarizing feedback loop: an "echo chamber" where partisans can reinforce and strengthen their initial biases. ${ }^{1}$ Furthermore, an interested party could influence the political process by controlling media outlets as in Prat (2014). ${ }^{2}$ Such concerns led the Federal Communications Commission (FCC) to condition approval of the merger of Comcast Corporation and NBC Universal in 2010 on the requirement that Comcast take steps to promote independent news services. ${ }^{3}$

We propose a new instrument for exposure to media bias to complement estimates based on availability such as DellaVigna and Kaplan (2007): the channel positions of news channels in cable television lineups. We estimate that watching the Fox News Channel for 2.5 additional minutes per week ${ }^{4}$ increases the vote share of the Republican presidential candidate by 0.3 percentage points among voters induced into watching by variation in channel position. The corresponding effect of watching MSNBC for 2.5 additional minutes per week is an imprecise zero.

As with any instrumental variables design, it is critical that the channel positions for Fox News and MSNBC are not chosen to accord with local political tastes. Empirically, we show that Fox News channel position does not predict pre-Fox News political outcomes,

\footnotetext{
${ }^{1}$ Gentzkow and Shapiro (2008) detail the complexities in designing optimal regulatory policy for media markets. Gentzkow and Shapiro (2011) indicate that media consumption tends to be balanced across slanted sources.

${ }^{2}$ Existing evidence from Gentzkow and Shapiro (2010) shows that owner partisanship is not an important determinant of newspaper slant. The sample size is too small to test this hypothesis in the cable news case.

${ }^{3}$ The condition required that Comcast move "independent" news channels such as Bloomberg Television into "news neighborhoods." This effectively required Comcast to move Bloomberg next to channels such as MSNBC and CNN in their channel lineups. The FCC justified the condition "in accordance with the special importance of news programming to the public interest," and did not place any such conditions on non-news programming. See https://apps.fcc.gov/edocs_public/attachmatch/FCC-11-4A1.pdf, paragraph 122.

${ }^{4} 2.5$ minutes per week is the approximate additional time spent watching Fox News associated with a one-standarddeviation decrease in Fox News channel position.
} 
including 1996 county level Republican voting and 1996 political contributions to Republican candidates. Fox News cable positions are also not negatively correlated with the predictablefrom-demographics component of either Republican voting or Fox News viewership. In other words, in areas where demographics would predict the Republican vote share to be high, Fox News is not systematically in lower channel positions. And in areas where demographics would predict Fox News viewership to be high, Fox News is not systematically in lower channel positions. Furthermore, Fox News cable channel position does not predict local viewership of Fox News by satellite subscribers in the same zip code who see a different, nationwide channel lineup.

Our approach to quantifying the preference for like-minded news adapts the method of Gentzkow and Shapiro (2010), who estimate this quantity in the context of newspapers. We measure the relationship between changes in a text-based slant measure over time and the characteristics of viewers of these channels. A key source of variation in this exercise is MSNBC's change in business strategy towards offering more liberal content. Our ideology estimates pick up this format switch - MSNBC closely tracks CNN in the early 2000s, but then moves left following the format switch in 2006. We estimate that Fox News' ideology has been moving further to the right in the most recent years.

We combine the analysis of the influence of slanted news with the demand for slanted news in a structural model that enables the quantification of polarization dynamics and media power. The model features consumer-voters who choose how much time to spend watching the cable news channels; whether to subscribe to cable, satellite or no pay television service; and for whom to vote in presidential elections. Consumers' allocation of time to television channels is governed by their preferences for the channels (which are a function of their ideology, the channels' ideologies, and their demographics), and the availability of the channels (whether the cable operator carries them and, if so, the positions they occupy on the channel lineup). Consumers' ideologies evolve from their initial position depending on how much time they allocate to watching channels of different ideologies. This process culminates in a presidential election in which consumers choose for whom to vote.

We estimate the parameters of the model by simulated indirect inference. The criterion function is the distance between two-stage least squares estimates of voting on demographics and minutes watched of each channel, using channel positions as instrumental variables, in the actual data and in data simulated from the model. In addition to matching the second stage regression coefficients, we also match the first stage (viewership equation) regression coefficients and the OLS regression coefficients. 
We use the estimated model to quantitatively assess the degree of ideological polarization induced by cable news, the effect of the entry of Fox News prior to the year 2000 election, and the level of "media power" (Prat, 2014) possessed by each of the news channels individually as well as a hypothetical conglomerate under unified ownership. We find that cable news does increase polarization among the viewing public, although the magnitude of this increase is modest. Furthermore, the increase in polarization depends critically on the existence of both a persuasive effect and a taste for like-minded news. We estimate that removing Fox News from cable television during the 2000 election cycle would have reduced the overall Republican presidential vote share by 0.46 percentage points. Finally, we find that the cable news channels' potential for influence on election outcomes is large, and would be substantially larger were ownership to become more concentrated.

This paper contributes to the empirical literature on the relationship of news media to political outcomes. ${ }^{5}$ The closest papers to this study are by DellaVigna and Kaplan (2007) and Gentzkow and Shapiro (2010).

DellaVigna and Kaplan (2007) study the effects of Fox News by comparing vote shares in locations with and without cable access to Fox News by November 2000. Our contributions to this strand of the literature are to introduce a new identification strategy based on channel positions, and to update their availability based estimates using more accurate data from Nielsen on Fox News availability. ${ }^{6}$ Channel position variation allows a researcher to examine the effects of cable news in later years where there is negligible variation in availability of these channels, and could be useful for studying the effects of media consumption in other contexts. In terms of results, we estimate a Fox News effect that is statistically positive and quantitatively large as in the DellaVigna and Kaplan (2007) analysis. Indeed, our estimated counterfactual effect of removing Fox News on the change in year 2000 election Republican vote share is 0.46 percentage points, which resonates well with the DellaVigna and Kaplan (2007), updated with more accurate availability data, estimated range of 0.26 to 0.36 percentage points.

\footnotetext{
${ }^{5} \mathrm{~A}$ number of papers have demonstrated that media usage or availability affects behavior. Amongst others, Chiang and Knight (2011) find positive effects of unexpected newspaper endorsements on vote shares for the endorsed candidate, Gentzkow (2006) finds decreased voter turnout from television access, Gerber et al. (2009) find positive effects of newspaper exposure, regardless of slant, on Democratic vote shares in the 2005 Virginia gubernatorial elections. Enikolopov et al. (2011) find that viewing an independent news channel in Russia increased vote shares for the opposition parties and decreased overall turnout in 1999. Lim et al. (2014) find that media coverage can affect criminal sentencing decisions for judges.

${ }^{6}$ In Appendix C, we document that Fox News availability in DellaVigna and Kaplan (2007) is measured with error. Nearly $40 \%$ of the "control group," the locations that they consider as not having cable access to Fox News in 2000, did in fact have cable access to Fox News. 25\% of the control group had Fox News availability since 1998.
} 
Our approach follows Gentzkow and Shapiro (2010) in several dimensions, including the use of text analysis to measure media outlets' slant. Like Gentzkow and Shapiro (2010), we treat ideological slant as a characteristic over which consumers have heterogeneous tastes when choosing media consumption levels. Our contribution is to model media consumption together with voting, to separately measure tastes for like-minded news and the influence of slanted media consumption on consumer ideology. The influence effect also interacts with the existence of tastes for like-minded news. Consumers for whom both effects are present can be induced into a feedback loop in which they consume slanted media, their ideologies then evolve in the direction of the slant, their taste for that slanted media increases, and so on. In this sense, this paper combines the literature on the persuasive effects of the media with the literature on self-selection into consumption of slanted media to explore media-driven polarization and to counterfactually simulate alternative ideological slant strategies by the cable news outlets.

\section{Institutional Overview}

During our study period of 1998-2008, most households had three options for television service: a wire-based cable package, a satellite package, or over-the-air broadcast signals. ${ }^{7}$ In 2000 , most pay television subscribers were cable subscribers, but by 2008 , satellite providers had a market share of about 30\%. The set of channels on cable varies both across providers and within providers across locations. Each of the two nationwide satellite providers, DirecTV and the Dish Network, has their own packages and lineups that are common to all locations. Cable content is produced by media conglomerates such as Viacom, News Corporation, ABC-Disney, or NBC Universal. The cable and satellite providers contract with these firms to offer their content to subscribers.

The foci of this study are the cable news channels. CNN began broadcasting in 1980 as one of the earliest cable channels of any genre. The Fox News Channel (FNC) and MSNBC both entered the market in the mid 1990's. FNC's business strategy from conception was to provide news with a more conservative slant. FNC is now one of the most highly rated cable channels across all genres. MSNBC began as a joint venture between NBC and Microsoft. At the outset, MSNBC did not have any explicit slant. MSNBC changed its business strategy in

\footnotetext{
${ }^{7}$ Some households, for example households in remote rural areas, did not have a cable option. Some households which did not have a direct line of sight due to physical obstructions like tall buildings, trees, or steep slopes, did not have a satellite option. And some households, mostly in urban areas, had two wire-based cable operators. In 2004 about $85 \%$ of US zip codes, accounting for about $67 \%$ of the total population, were served by a single monopolist wire-based cable operator.
} 
the mid-2000's to provide news with a more liberal slant, as detailed in Sanneh (2013).

The channel lineup, or the numerical ordering of channels, that cable subscribers encounter varies by local cable system. The first channel positions are generally allocated to over-theair broadcast affiliates: for example, NBC4 occupies position four in the Washington D.C. area. After the over-the-air channels, the cable channels begin. We assert in this paper that the ordering of a channel in the lineup can have significant effects on the viewership of news channels (though the significant relationship between channel position and viewership holds for all genres, not just news).

Figure 1 plots the relationship between the residual component of ratings - the portion that is not explained by viewer demographics and channel-specific state-year fixed effects and channel position for a set of 34 channels, including both the news channels and other channels that tend to occupy similar positions in cable lineups. There is a clear negative, and very nearly linear, relationship between position and ratings over the range of positions which the news channels typically occupy. Table A28 in Appendix G documents the own-position coefficients on ratings for each of these channels; all are negative and almost all are statistically significant.

The obvious empirical concern is that a channel might be placed in lower positions in localities with high tastes for the channel. We later examine and reject that concern empirically in a variety of ways. Describing the process by which channel positions were determined provides additional support for the claim that channel positions are valid instruments.

The mid-1990's, during which FNC and MSNBC were rolling out, was a tumultuous time for the cable industry. This period saw many systems upgrade from analog to digital equipment, expanding the number of channels cable operators were able to offer. Coincident with this technical advance, a wave of new channels entered cable lineups alongside first-generation channels like CNN, ESPN, and HBO. New channels were often allocated positions sequentially, in the order in which they joined a system. ${ }^{8}$ As a result, the channel positioning of $\mathrm{FNC}$ or MSNBC on a given local system depended on the timing of that system's bilateral negotiations with multiple new channels as well as its decision of when to upgrade. On capacity constrained systems owned by the multiple-system operator TCI in 1996, FNC was reported to have replaced one of as many as twelve different channels (Dempsey (1996)). Combined with the desire to limit changes in positions so as to not confuse customers, these chaotic

\footnotetext{
${ }^{8}$ In Appendix G, we show that channel positions correlate with the best available position in the year before a channel was added.
} 


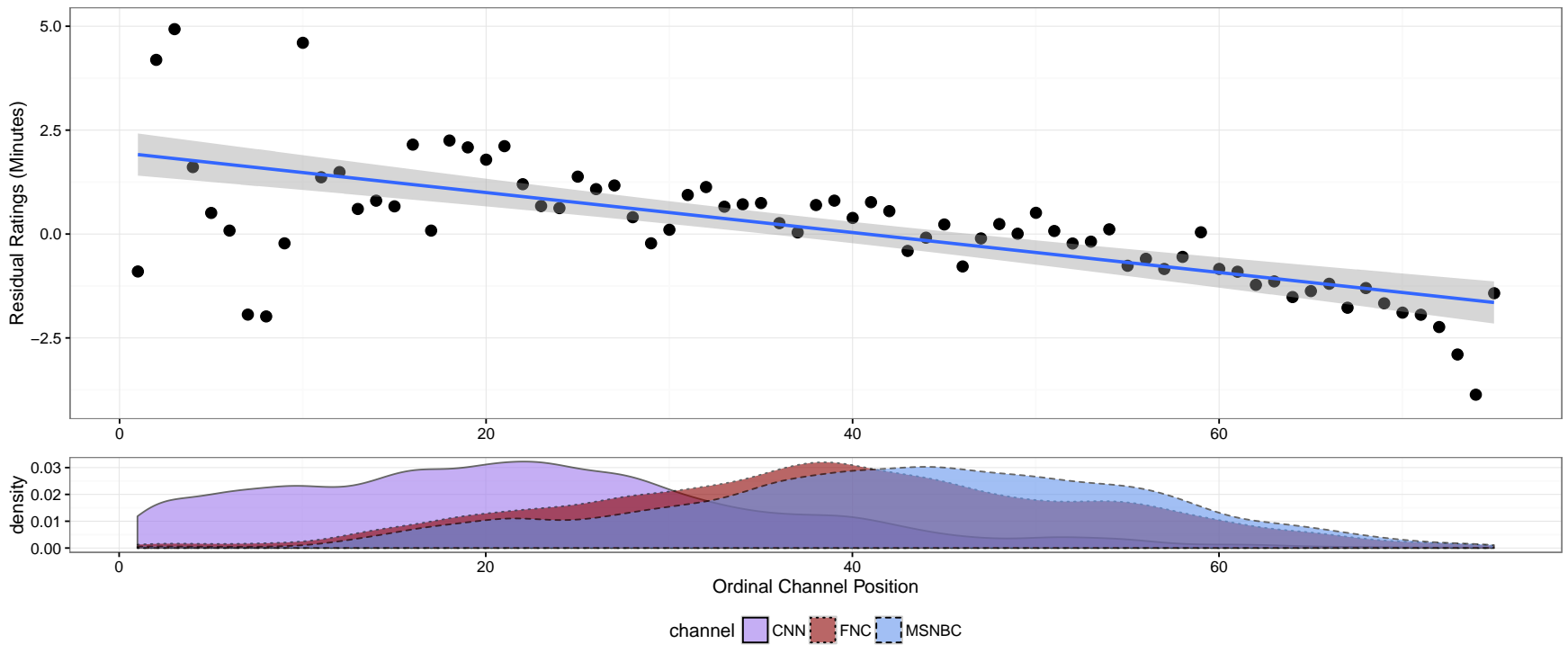

Figure 1: The top panel shows the relationship between the residual component of minutes watched and channel position, in a set of 34 comparable cable channels whose median positions across cable system-years are between 30 and 60 and thus typically occupy similar positions to FNC and MSNBC. Residuals are constructed by regressing minutes watched per week (in the MediaMark individual-level dataset) on the full set of individual demographics plus state-year fixed effects. The predicting regressions are estimated separately for each channel, such that demographic effects and state-specific time trends are allowed to vary by channel. The points in the figure are averages of these residual minutes across all channels located at a given ordinal position. The blue line is the least-squares fit. The bottom panel shows the density of the three news channels' ordinal positions across system-years for comparison.

factors generated persistent cross-system variation in the positioning of FNC and MSNBC. ${ }^{9}$

\section{Data}

We use nine categories of data sets: (1) Nielsen FOCUS data on cable channel lineups by zip code by year, (2) precinct-level voting data from the 2008 Presidential election, (3) individual survey data on intent to vote Republican in 2000, 2004, and 2008 U.S. Presidential elections, (4) Nielsen viewership data at the zip code level for the cable news channels from 2005 to 2008, (5) individual survey data on cable news viewership for 2000 to 2008, (6) County level

\footnotetext{
${ }^{9}$ Some systems have shuffled positions over time as channels went out of business, as channel capacity expanded and as new channels came online. Some local managers pursued a strategy of moving channels with similar content or in the same genre together into "neighborhoods," when possible. In general, however, the ordering of cable channels is highly persistent from year to year: the autoregressive coefficient in a regression of channel position in year $t$ on channel position on the same system in year $t-1$ ranges from 0.94 (MSNBC) to 0.97 (CNN).
} 
presidential election vote share data, (7) U.S. Census demographics by zip code, 1996 political donation data by zip code from the Federal Elections Commissions, and the 2010 religious adherence data by county from the Religious Congregations and Membership Study (RCMS), (8) Broadcast transcripts of cable news from Lexis-Nexis, and (9) the Congressional Record. In Appendix A, we provide details on how we cleaned and joined the data sets.

Cable Lineups: Nielsen FOCUS The Nielsen FOCUS database consists of yearly observations of cable systems. The key variables in this data set are, for each system and year, the availability of CNN, FNC, and MSNBC, the channel positions of CNN, FNC, and MSNBC, when available, and the zip codes served by the system. In Figure 2, we document the availability of each of these news channels by year. CNN was already near-universal by 1998; FNC and MSNBC expanded over the early part of the sample period, reaching the vast majority of cable subscribers by 2002 .

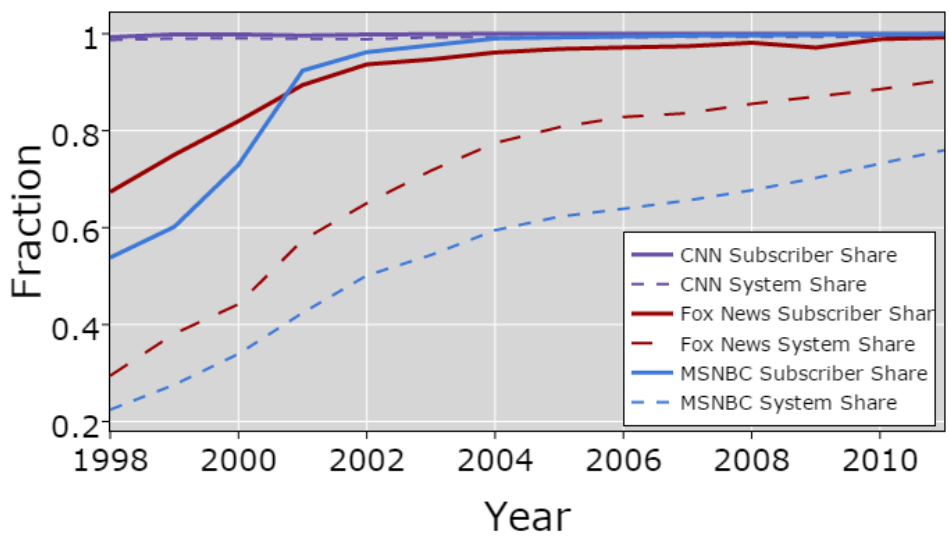

Figure 2: Availability of cable news channels by year. The solid lines represent the fraction of cable subscribers for whom the news channel was carried on their system. The dashed lines represent the fraction of cable systems which carry the news channels. By 2002, nearly all cable subscribers had access to FNC and MSNBC.

Zip Code Level Voting Data and Demographics We use the "Precinct-Level Election Data" from Ansolabehere et al. (2014) which provides votes cast in the 2008 Presidential election for each party, by voting precinct. We aggregate these precinct-level totals up to the zip code level, and compute the two party vote share for each zip code. We combine these with demographic data from the US Census for 2010. These data are summarized in Appendix B, Table A1. 
Individual Voting Data: NAES and CCES The National Annenberg Election Study (NAES) is a large-scale phone survey conducted each presidential election cycle. We use data from the 2000, 2004, and 2008 election cycles, including the confidential zip code field. The key variables are demographic variables such as race, age, and income; zip code; and actual or intent to vote in the current presidential election. These data are summarized in Appendix B, Table A2. For 2008, we add data from the Cooperative Congressional Election Study (CCES) on the same variables that we use from the NAES. In all years, NAES / CCES individuals were matched to their corresponding news channel availability and positioning using their zip code of residence to identify their local cable provider in the Nielsen FOCUS data.

Zip Level Viewership Data: Nielsen Nielsen measures television viewership from a rotating panel of households. We acquired zip code level ratings for CNN, FNC, and MSNBC from the Nielsen Local TV (NLTV) database for the years 2005 through 2008. The Nielsen data also report viewership conditional on being a cable subscriber and conditional on being a satellite subscriber. The measurements come in the units of rating points which indicate what fraction of persons were tuned in to each channel in a given time period. We convert to average hours per week by multiplying the rating by 168 . These data are summarized in Appendix B, Table A3.

Individual Viewership Data: Mediamark and Simmons Mediamark and Simmons are two commercial data vendors who survey individuals on their usage of different brands, including media usage. We use Mediamark for 2000 to 2007, and Simmons for 2008. The key variables for our study are year, zip code, individual demographics, whether the respondent subscribes to cable, satellite, or neither, and the reported number of hours watched per week of CNN, FNC, and MSNBC. These data are summarized in Appendix B, Table A4.

County Level Vote Shares and Demographics We use county level presidential vote shares for the Presidential election in 1996 from the Voting and Elections Collection Database maintained by Congressional Quarterly. We also use zip code level demographic statistics from the 2000 US Census. We construct county-level distributions of household income, age, race, education, and initial ideology, for use in the model in section 5. We also use this data to condition on the pre-Fox News county level Republican vote share in some of our regression specifications. 
Broadcast Transcripts and Congressional Record To quantify the slant of each news channel in each year, we follow Groseclose and Milyo (2005) and Gentzkow and Shapiro (2010) in comparing the language that the channels use to language that Congresspeople use. This procedure does not recognize satire, sub-text, nor tone, and thus likely underestimates the dispersion in slant among the slanted outlets. ${ }^{10}$ We obtained broadcast transcripts for CNN, FNC, and MSNBC from the Lexis-Nexis database for the sample period 1998-2012 by downloading all transcripts per year for each identifiable cable news program from each of the three channels. Appendix E details the procedure we employ.

Each Congressperson has a measure of their ideology, derived from roll-call votes: the DWNOMINATE score of McCarty et al. (1997), which places each Congressperson on the interval $[-1,1]$. More positive scores correspond to more conservative legislators. There are many more two word phrases than Congresspeople, and an ordinary least squares criterion is therefore useless. For each year, we run an Elastic Net (Zou and Hastie, 2005) regularized regression of DW-NOMINATE score of frequency of phrase usage where an observation is a Congressperson. Table 1 shows the most partisan phrases selected by the Elastic Net regression.

We use the estimated coefficients to predict the DW-NOMINATE score for each cable news channel in each year. We then apply a three period moving average smoothing filter. The results are in Figure 3. FNC is consistently more conservative than the other two channels. However, these differences are small compared to differences between Congressmen during the early years. Groseclose and Milyo (2005) find that the difference between CNN and FNC in their sample is about $20 \%$ of the difference between the average Democrat and average Republican. MSNBC closely tracks CNN initially, and then becomes consistently more liberal - though by much less than the gap between CNN and FNC - in the mid-2000's. The estimates also reveal increased polarization of cable news over time. The text based measures produce estimated ideologies for the channels that are more moderate than the median members of each party. In the modelling to come, we allow for consumers to perceive these news channels to be more or less ideologically differentiated, in proportion to these estimates. Indeed, our estimates for this scale factor put FNC very close to the median Republican Congress member.

\footnotetext{
${ }^{10}$ This is one reason why we exclude Comedy Central, which featured two prominent slanted cable news programs, The Daily Show with Jon Stewart and The Colbert Report, from the analysis. Their slant relies heavily on satire and is not as reasonably quantified based on phrase usage. As a separate matter, Comedy Central has other highly viewed shows which are not explicitly political such as South Park, and our data are aggregated to the channel level.
} 


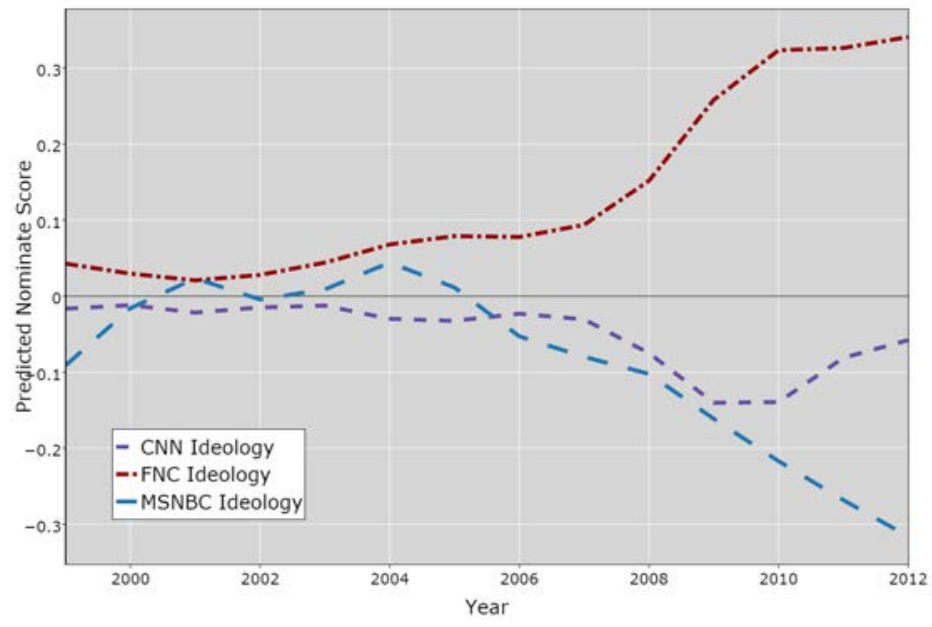

Figure 3: Estimated Ideology by Channel-Year: Each point corresponds to the estimated ideology of the news channels based on phrase usage as described in the text. As we use an elastic net variable selection scheme, standard errors are not available.

\begin{tabular}{rrrrrr}
\hline 2000 & Party & 2004 & Party & 2008 & Party \\
\hline \hline republican leadership & $\mathrm{D}$ & mai 5 & $\mathrm{R}$ & bush administr & $\mathrm{D}$ \\
clinton gore & $\mathrm{R}$ & ronald reagan & $\mathrm{R}$ & strong support & $\mathrm{D}$ \\
feder govern & $\mathrm{R}$ & social justic & $\mathrm{D}$ & african american & $\mathrm{D}$ \\
african american & $\mathrm{D}$ & war iraq & $\mathrm{D}$ & cost energi & $\mathrm{R}$ \\
civil right & $\mathrm{D}$ & african american & $\mathrm{D}$ & pass bill & $\mathrm{D}$ \\
gore administr & $\mathrm{R}$ & reagan said & $\mathrm{R}$ & will us & $\mathrm{R}$ \\
death tax & $\mathrm{R}$ & fail provid & $\mathrm{D}$ & new refineri & $\mathrm{R}$ \\
pass bill & $\mathrm{R}$ & illeg alien & $\mathrm{R}$ & civil right & $\mathrm{D}$ \\
support democrat & $\mathrm{D}$ & marriag licens & $\mathrm{R}$ & work famili & $\mathrm{D}$ \\
peopl color & $\mathrm{D}$ & limit govern & $\mathrm{R}$ & full time & $\mathrm{D}$ \\
\hline \hline
\end{tabular}

Table 1: Top 10 Partisan Phrases for Years 2000, 2004, and 2008. These are the ten phrases which have the largest absolute magnitude coefficient among those selected by the Elastic Net for the corresponding year. Word variants are stemmed to their roots. 


\section{Regression Analysis}

This sections presents the relationship between cable channel positions, watching FNC, and voting for Republican presidential candidates. These results underlie the model estimation and simulation in later sections. However, the results here do not depend on that model, and can be read as a stand-alone instrumental variables regression analysis.

First Stage: Viewership and Channel Position The first stage describes how cable news viewers' time watched vary with channel position. The idea is that lower channel positions induce more viewership for channels such as FNC because the more popular channels tend to be in lower positions, for historical reasons. ${ }^{11}$ Consider a viewer who just finished watching a television program, and begins to search for a new program. Their search will begin from the channel they were watching, which is likely to be in a low position. They are more likely to stop nearer to the original channel than further away. ${ }^{12}$

Table 2 presents first stage estimates of Nielsen-measured FNC viewership on the position of FNC. This set of viewership data spans all states and the years 2005 to 2008. The estimating equations for a news channel $c$ take the form:

$$
h_{z t}^{c}=\delta_{c t}+a_{z c t}+\alpha_{c} x_{z t}+\zeta_{c, F N C} p_{z t}^{F N C}+\zeta_{c, M S N B C} p_{z t}^{M S N B C}+\epsilon_{z c t}^{H}
$$

where $h_{z t}^{c}$ is the average minutes watched per week of all Nielsen households ${ }^{13}$ in zip code $z$ in year $t ; \delta_{c t}$ are channel fixed effects, which are allowed to vary by year, state-year, or county-year depending on the specification; $p_{z t}^{j}$ is the cable channel position of channel $j$ in zip code $z$ in year $t ; x_{z t}$ are average demographic characteristics of zip code $z$; and $a_{z c t}$ are dummy variables for cable availability of the cable news channels in zip code $z$ in year $t$. We weight the observations by the number of Nielsen respondents in the zip code-year. This weighting improves efficiency as the variance of the left hand side ratings estimate is decreasing in the

\footnotetext{
${ }^{11}$ In addition to the broadcast networks ABC, CBS, Fox, and NBC, the lower channel positions are generally occupied by the earliest cable entrants (eg ESPN, MTV, TNT, and USA), which also have high viewership.

${ }^{12}$ Bias to the top of a list or default option in search is documented in eye tracking studies for yellow pages (Lohse (1997)) and survey response (Galesic et al. (2008)). There is a theoretical literature in economics modelling such behavior (see Rubinstein and Salant (2006), Horan (2010), Masatlioglu and Nakajima (2013), and the literature on status-quo bias more generally.)

${ }^{13}$ We use time among all households, and not only wired cable subscribers, even though the instrument can only affect cable subscribers. The reason for this is that the second stage dataset - vote totals - does not allow us to discriminate between cable and satellite subscribers. The first stage is substantially stronger when estimated on cable subscribers alone, which can be seen in table 7 .
} 
zip code-year sample size. In particular, a handful of zip codes have sample sizes of one and ratings measurements that are six or more standard deviations from the mean whose relative importance is reduced when weighting by sample size.

Table 2 reports specifications with year fixed effects, state-year fixed effects, and countyyear fixed effects and different sets of conditioning variables. The primary covariate of interest in these regressions - FNC channel position - varies at the level of the cable system, which may span multiple zip codes. We therefore present cluster-robust standard errors in all specifications, using cable system as the cluster variable. Our preferred specification is column (4), which includes state-year fixed effects and an extensive set of demographic covariates that correlate with Republican voting and residential sorting, including measures of Republican voting and donations from 1996, effectively before FNC.

In Column (4), cable positions of both FNC and MSNBC significantly predict viewership of FNC, in the expected directions. A one standard deviation increase in FNC channel position predicts a decrease in average viewership of about two and one-half minutes per week. In Column (6), we use county-year fixed effects and the extensive demographic set. Here, the coefficient falls in magnitude by about $40 \%$, however it remains significantly different from zero. The more limited variation induced by the instrument within a county-year is one limitation of this specifcation. The cluster-robust F statistic for the ordinal FNC position is 39.02 in the specification with state-year fixed effects and extensive demographics. The effect of cable access to FNC, as used in DellaVigna and Kaplan (2007), is a large and statistically precise predictor of FNC viewership.

Columns (5) and (7) of the table add the minutes per week of FNC viewership among satellite subscribers in the same zip code. To the extent that satellite and cable subscribers in the same zip code have similar tastes for the news channels, conditioning on satellite viewership controls for unobserved variation in taste for FNC which, if it were correlated with channel position, would bias the estimates of the position effects. Comparing columns (4) with (5) and (6) with (7) reveals that the position coefficients are essentially unchanged with the addition of conditioning on same-zip code satellite minutes.

First stage results with MSNBC viewership on the left-hand side of equation (1) are very similar, though the direction of coefficients on FNC and MSNBC positions are reversed. The power of channel positions for predicting MSNBC viewership is also similar. For brevity, we relegate these results to Appendix F, Table A16. Appendix D, Tables A11 and A17 document that the same first-stage relationships are also evident in the independently sampled individuallevel viewership dataset. 
Table 2: First Stage Regressions: Nielsen Data

\begin{tabular}{lccccccc}
\hline & \multicolumn{7}{c}{ FNC Minutes Per Week } \\
& $(1)$ & $(2)$ & $(3)$ & $(4)$ & $(5)$ & $(6)$ & $(7)$ \\
\hline FNC Position & $-0.146^{* * *}$ & $-0.075^{*}$ & $-0.155^{* * *}$ & $-0.174^{* * *}$ & $-0.167^{* * *}$ & $-0.097^{* * *}$ & $-0.111^{* * *}$ \\
& $(0.043)$ & $(0.039)$ & $(0.029)$ & $(0.028)$ & $(0.025)$ & $(0.033)$ & $(0.030)$ \\
MSNBC Position & $0.078^{* *}$ & $0.073^{* *}$ & $0.074^{* * *}$ & $0.064^{* * *}$ & $0.070^{* * *}$ & 0.019 & 0.020 \\
& $(0.036)$ & $(0.032)$ & $(0.027)$ & $(0.025)$ & $(0.022)$ & $(0.034)$ & $(0.035)$ \\
Has MSNBC Only & 1.904 & 1.137 & -1.428 & -3.954 & -2.804 & -1.220 & -1.562 \\
& $(3.697)$ & $(3.713)$ & $(3.559)$ & $(4.255)$ & $(3.416)$ & $(6.180)$ & $(5.397)$ \\
Has FNC Only & $31.423^{* * *}$ & $26.526^{* * *}$ & $22.111^{* * *}$ & $23.460^{* * *}$ & $22.011^{* * *}$ & $15.141^{* * *}$ & $15.069^{* * *}$ \\
& $(2.677)$ & $(2.546)$ & $(2.033)$ & $(2.278)$ & $(1.864)$ & $(2.697)$ & $(2.314)$ \\
Has Both & $24.859^{* * *}$ & $23.118^{* * *}$ & $16.242^{* * *}$ & $18.338^{* * *}$ & $16.168^{* * *}$ & $15.159^{* * *}$ & $14.486^{* * *}$ \\
& $(2.919)$ & $(2.687)$ & $(2.128)$ & $(2.361)$ & $(1.991)$ & $(3.216)$ & $(2.842)$ \\
Sat. FNC Minutes & & & & & $0.197^{* * *}$ & & $0.173^{* * *}$ \\
& & & & & $(0.013)$ & $(0.015)$ \\
Fixed Effects: & Year & State-Year & State-Year & State-Year & State-Year & County-Year & County-Year \\
Cable Controls: & $\mathrm{Y}$ & $\mathrm{Y}$ & $\mathrm{Y}$ & $\mathrm{Y}$ & $\mathrm{Y}$ & $\mathrm{Y}$ & $\mathrm{Y}$ \\
Demographics: & None & None & Basic & Extended & Extended & Extended & Extended \\
Robust F-Stat & 11.39 & 3.72 & 29.34 & 39.02 & 44.7 & 8.86 & 13.43 \\
Number of Clusters & 5789 & 5789 & 5788 & 4830 & 4761 & 4839 & 4770 \\
$\mathrm{~N}$ & 71,150 & 71,150 & 71,102 & 59,541 & 52,053 & 59,684 & 52,165 \\
$\mathrm{R}^{2}$ & 0.030 & 0.074 & 0.191 & 0.213 & 0.377 & 0.428 & 0.544 \\
\hline
\end{tabular}

${ }^{*} \mathrm{p}<.1 ;{ }^{* *} \mathrm{p}<.05 ;{ }^{* * *} \mathrm{p}<.01$

Notes: Cluster-robust standard errors in parentheses (clustered by cable system). Instrument is the ordinal position of FNC on the local system. The omitted category for the availability dummies is systems where neither FNC nor MSNBC is available. In Columns (5) and (7), the specification conditions on the average FNC ratings among satellite subscribers in the same zip code. Cable system controls include the total number of channels on the system and the number of broadcast channels on the system, as well as an indicator for Nielsen collection mode (diary vs. settop). "Basic" demographics include the racial, gender, age, income, educational, and urban/rural makeup of the zip code. "Extended" demographics adds information on the percentage of homeowners; median housing values, sizes, ages, and property tax rates; the fraction of the population receiving food stamps; median social security income; the fraction of veterans; the fractions of married, unmarried, and same-sex couples; the share of federal campaign contributions that went to Republican candidates in 1996; the Republican presidential share of the county in 1996; and the religious composition of the county. Observations are weighted by the number of survey individuals in the zipcode according to Nielsen. 
Second Stage: Voting and Viewership We begin in Table 3 with the reduced form for the zip level data. The regressions take the form:

$$
y_{z}=\gamma_{g}+a_{z}+\beta x_{z}+\zeta_{F N C} p_{z}^{F N C}+\zeta_{M S N B C} p_{z}^{M S N B C}+\epsilon_{z}^{R}
$$

Where $y_{z}$ is Republican vote share in zip code $z, \gamma_{g}$ are either state or county fixed effects, $a_{z}$ are indicators for availability of the channels, $\beta$ are coefficients on zip code demographics and cable system characteristics $x_{z}$, and $p_{z}^{C}$ are the ordinal cable channel positions of channel $C$ in zip code $z$.

FNC position is significantly negatively correlated with zip code 2008 Republican vote share in all specifications which include demographic covariates, although the relationship is significant only at the $90 \%$ level in the specification with both county-year fixed effects and the extensive demographics.

The MSNBC position coefficient in the reduced form tables is generally positive but, unsurprisingly given MSNBC's substantially lower viewership, much less precise and less robust across specifications compared to the FNC reduced form. In addition, the ideological estimates in Figure 3 put MSNBC, even in 2008, at a relatively centrist position compared to FNC. Prior to 2006, MSNBC is generally to the right of CNN.

Table 3: Reduced Form Regressions: Precinct Voting Data

\begin{tabular}{lcccccc}
\hline & \multicolumn{5}{c}{2008 McCain Vote Percentage } \\
& $(1)$ & $(2)$ & $(3)$ & $(4)$ & $(5)$ & $(6)$ \\
\hline FNC Cable Position & -0.011 & 0.004 & $-0.024^{* *}$ & $-0.027^{* * *}$ & $-0.015^{* *}$ & $-0.015^{*}$ \\
& $(0.023)$ & $(0.020)$ & $(0.011)$ & $(0.008)$ & $(0.007)$ & $(0.008)$ \\
MSNBC Cable Position & $0.054^{* * *}$ & $0.041^{* * *}$ & 0.009 & 0.008 & 0.003 & 0.003 \\
& $(0.019)$ & $(0.016)$ & $(0.008)$ & $(0.005)$ & $(0.005)$ & $(0.006)$ \\
Fixed Effects: & None & State & State & State & County & County \\
Cable System Controls: & $\mathrm{Y}$ & $\mathrm{Y}$ & $\mathrm{Y}$ & $\mathrm{Y}$ & $\mathrm{Y}$ & $\mathrm{Y}$ \\
Demographics: & None & None & Basic & Extended & Basic & Extended \\
Number of Clusters & 6035 & 6035 & 6029 & 4814 & 6029 & 4814 \\
$\mathrm{~N}$ & 22,584 & 22,584 & 22,509 & 17,400 & 22,509 & 17,400 \\
$\mathrm{R}^{2}$ & 0.148 & 0.294 & 0.730 & 0.833 & 0.880 & 0.907 \\
\hline${ }^{*} \mathrm{p}<.1 ;{ }^{* *} \mathrm{p}<.05 ; * * *$ \\
Cluster-robust standard errors in parentheses (clustered by cable system). See first stage tables for \\
description of instruments and control variables.
\end{tabular}

Next, we present zip code-level second stage regression results in Table 4. The regressions 
take the form:

$$
y_{z}=\gamma_{g}+a_{z}+\beta x_{z}+\zeta_{M S N B C} p_{z}^{M S N B C}+\rho_{f} h_{z}^{f}+\epsilon_{z}^{V}
$$

Where $y_{z}$ is Republican vote share in zip code $z, \gamma_{g}$ are either state or county fixed effects, $a_{z}$ are indicators for availability of the channels, and $\beta$ are coefficients on zip code demographics and cable system characteristics $x_{z}$. We are interested in the coefficient $\rho_{f}$ on the zip code's predicted average hours watched per week of FNC, $h_{z}^{f}$, produced by the first stage from Table 2 .

We compute standard errors by a bootstrap, as deemed appropriate in two-sample IV settings by Inoue and Solon (2010). We use a cluster-robust block bootstrap at the level of cable systems to allow for correlation across zip codes and over time within cable systems. ${ }^{14}$ Our estimates imply that being induced to watch an additional hour per week of FNC by the channel position instrument would lead to an approximately 7.2 point increase in the probability of voting Republican in presidential elections for those induced into watching by the instrument. However, the magnitude of the variation induced by the instrument is typically much less than one hour: a one standard deviation increase in channel position induces a roughly 2.5-minute-per-week increase in FNC viewing. The implied change in probability of voting for the Republican candidate from a one standard deviation increase in channel position is thus -0.3 points. With county fixed effects, the precision of the estimates goes down as the confidence intervals widen; however, the point estimates are of a similar magnitude as when using state fixed effects. Appendix D, Table A12 reports the second-stage results for the individual-level data, which are also very comparable in magnitude though somewhat less precise than the zip-level version.

Within Table 4, the second-stage coefficient is essentially unaffected by the inclusion of the extensive demographic set. It declines slightly, but remains positive and significantly different from zero, when FNC hours among satellite subscribers in the same zip code are included as a covariate. Both of these facts lend some credence to the idea that channel position is not simply picking up local variation in unobserved political tastes. ${ }^{15}$

The OLS coefficient on FNC hours in Table 5 is significant and positive, as expected, but

\footnotetext{
${ }^{14}$ We resample with replacement from the set of cable systems in the data, with independent resamples drawn for the viewership and the voting data.

${ }^{15}$ In the specification with satellite hours, the coefficient on satellite hours is negative, a result that may seem counter-intuitive. The reason for this is that predicted hours are predicted total hours, across both cable and satellite subscribers. The negative coefficient on satellite hours implies that, holding total FNC hours watched constant, the effect on vote shares is smaller, the more of those hours that come from satellite.
} 
Table 4: Second Stage Regressions: Precinct Voting Data

\begin{tabular}{|c|c|c|c|c|c|c|}
\hline & \multicolumn{6}{|c|}{2008 McCain Vote Percentage } \\
\hline & $(1)$ & $(2)$ & $(3)$ & $(4)$ & $(5)$ & $(6)$ \\
\hline Pred. FNC Mins. & $\begin{array}{c}0.167^{* *} \\
(0.013,0.346)\end{array}$ & $\begin{array}{c}0.158^{* * *} \\
(0.056,0.277)\end{array}$ & $\begin{array}{c}0.120^{* *} \\
(0.005,0.248)\end{array}$ & $\begin{array}{c}0.180 \\
(-0.114,1.084)\end{array}$ & $\begin{array}{c}0.158 \\
(-0.126,0.938)\end{array}$ & $\begin{array}{c}0.098 \\
(-0.121,0.429)\end{array}$ \\
\hline Fixed Effects: & State & State & State & County & County & County \\
\hline Cable System Controls: & $\mathrm{Y}$ & $\mathrm{Y}$ & Y & $\mathrm{Y}$ & $\mathrm{Y}$ & $\mathrm{Y}$ \\
\hline $\mathrm{N}$ & 22,509 & 17,400 & 12,417 & 22,290 & 17,283 & 12,443 \\
\hline $\mathrm{R}^{2}$ & 0.730 & 0.833 & 0.841 & 0.879 & 0.907 & 0.919 \\
\hline
\end{tabular}

it is much smaller in magnitude than the corresponding IV coefficients. This is due to at least two factors: first, the zip code level viewership levels are estimates based on samples leading to attenuated OLS coefficients. Second, as the behavioral model makes clear, we are estimating a single coefficient in a world of heterogeneous treatment effects. The IV coefficient measures the local average treatment effect on zip codes whose viewership levels are affected by channel position. The OLS estimate averages across all zip codes in the sample, weighting most heavily those with unusually high or low Republican vote share. It is reasonable to suspect that the complier zip codes are more centrist relative to the outlier zip codes, and thus subject to larger persuasion effects: those whose choice among ideological news channels is most susceptible to influence by channel position are also likely to be those whose pre-existing ideological attachments are relatively weak.

In Appendix F, we include an analogous specification to Table 4 where MSNBC viewership is the endogenous variable, as well as a dual-instrument version where FNC and MSNBC viewership are both instrumented by FNC and MSNBC positions. The point estimate of the second-stage MSNBC hours coefficient is negative, though smaller in magnitude than the analogous FNC coefficient, in the single-instrument specification. However, the confidence intervals do not allow us to reject a zero effect of MSNBC in the analogue to our preferred FNC specification. We conclude that while there is some suggestive evidence of a MSNBC persuasive effect, it is weaker and less robust than the evidence for FNC. Accordingly, we fit the behavioral model in section 5 using only the information from the single-instrument second stage results for FNC. 
Table 5: OLS Regressions: Precinct Voting Data

\begin{tabular}{lcccccc}
\hline & \multicolumn{5}{c}{2008 McCain Vote Percentage } \\
& $(1)$ & $(2)$ & $(3)$ & $(4)$ & $(5)$ & $(6)$ \\
\hline FNC Minutes & $0.081^{* * *}$ & $0.073^{* * *}$ & $0.022^{* * *}$ & $0.017^{* * *}$ & $0.011^{* * *}$ & $0.011^{* * *}$ \\
& $(0.006)$ & $(0.005)$ & $(0.002)$ & $(0.002)$ & $(0.001)$ & $(0.001)$ \\
MSNBC Cable Position & 0.035 & 0.026 & $0.022^{* *}$ & $0.010^{*}$ & $-0.009^{*}$ & -0.006 \\
& $(0.023)$ & $(0.020)$ & $(0.010)$ & $(0.006)$ & $(0.005)$ & $(0.005)$ \\
Fixed Effects: & None & State & State & State & County & County \\
Cable System Controls: & $\mathrm{Y}$ & $\mathrm{Y}$ & $\mathrm{Y}$ & $\mathrm{Y}$ & $\mathrm{Y}$ & $\mathrm{Y}$ \\
Demographics: & None & None & Basic & Extended & Basic & Extended \\
Number of Clusters & 4913 & 4913 & 4913 & 4162 & 4913 & 4162 \\
$\mathrm{~N}$ & 16,948 & 16,948 & 16,946 & 14,281 & 16,946 & 14,281 \\
$\mathrm{R}^{2}$ & 0.155 & 0.288 & 0.766 & 0.856 & 0.914 & 0.929 \\
\hline${ }^{*} \mathrm{p}<.1 ;{ }^{* *} \mathrm{p}<.05 ;{ }^{* * *} \mathrm{p}<.01$ & \multicolumn{5}{c}{} \\
Cluster-robust standard errors in parentheses (clustered by cable system). See first stage tables for \\
description of instruments and control variables.
\end{tabular}

Instrument Validity Support In this section, we defend the quasi-experimental nature of the channel position. We ask: (1) In zip codes whose demographics predict that the Republican vote share should be high, is FNC systematically in lower channel positions? (2) In zip codes whose demographics predict that the viewership of FNC should be high, is FNC systematically in lower channel positions? (3) Is FNC in lower positions in zip codes which had higher measures of Republican-ness in 1996, before FNC? (4) Does the FNC position in the cable lineup predict viewership for satellite subscribers in the same zip code, who do not interface with the cable lineup? and (5) Do the coefficients on FNC position in both the first stage and the reduced form change appreciably when we add or remove covariates? ${ }^{16}$ The answers to questions (1)-(5) are all negative.

The first two columns of Table 6 show the relationship of FNC cable position with observable variation in local taste for FNC. The left hand side here is predicted minutes watched of FNC per week, using only demographic information as covariates; predicted minutes per week are then regressed on FNC cable position. The relationship is positive and significant. For assessing the identifying assumption, positive estimates are re-assuring as they indicate that FNC positions are higher in locations with observable demographics which would predict more FNC viewing.

\footnotetext{
${ }^{16}$ In Appendix G.3, we show additionally that FNC viewership does not correlate with FNC channel positions on nearby systems, nor future FNC channel positions on the same system. Furthermore, the 2008 McCain vote share does not correlate with FNC channel position on nearby systems.
} 
Table 6: FNC cable position coefficients on predicted viewing / voting, and 1996 Republican voting and contributions.

\begin{tabular}{|c|c|c|c|c|c|c|c|c|}
\hline & \multicolumn{2}{|c|}{ Predicted Viewing } & \multicolumn{2}{|c|}{ Predicted Voting } & \multicolumn{2}{|c|}{1996 Contributions } & \multicolumn{2}{|c|}{1996 Vote } \\
\hline & $(1)$ & $(2)$ & $(3)$ & $(4)$ & $(5)$ & $(6)$ & $(7)$ & $(8)$ \\
\hline FNC Position & $\begin{array}{c}0.078^{* *} \\
(0.030)\end{array}$ & $\begin{array}{c}0.100^{* * *} \\
(0.034)\end{array}$ & $\begin{array}{c}0.036^{* *} \\
(0.016)\end{array}$ & $\begin{array}{c}0.027 \\
(0.022)\end{array}$ & $\begin{array}{c}0.0004 \\
(0.0002)\end{array}$ & $\begin{array}{c}0.0002 \\
(0.0002)\end{array}$ & $\begin{array}{c}0.0002 \\
(0.0001)\end{array}$ & $\begin{array}{l}-0.0001 \\
(0.0001)\end{array}$ \\
\hline Fixed Effects: & State-Year & State-Year & State-Year & State-Year & State-Year & State-Year & State-Year & State-Year \\
\hline Demographics: & Basic & Extended & Basic & Extended & Basic & Extended & Basic & Extended \\
\hline Number of Clusters & 5788 & 4830 & 6029 & 4814 & 4844 & 4830 & 5779 & 4830 \\
\hline $\mathrm{N}$ & 71,129 & 59,551 & 22,509 & 17,400 & 59,843 & 59,551 & 70,971 & 59,551 \\
\hline $\mathrm{R}^{2}$ & 0.389 & 0.380 & 0.402 & 0.339 & 0.146 & 0.176 & 0.464 & 0.571 \\
\hline
\end{tabular}

${ }^{*} \mathrm{p}<.1 ;{ }^{* *} \mathrm{p}<.05 ;{ }^{* * *} \mathrm{p}<.01$

Cluster-robust standard errors in parentheses (clustered by cable system). Columns 1-4 regress predicted hours of FNC and predicted Republican vote share, respectively, on FNC cable position. The predicting regressions exclude FNC position but include the indicated set of demographic controls. Columns 5-8 regress indicators of pre-treatment political attitudes (1996 county-level Republican presidential vote share and 1996 zipcode-level Republican campaign contribution share) on FNC cable position.

The next two columns of Table 6 regress the predicted voting outcome from a regression of vote preference that excludes position, on the FNC cable position. This predictable component of variation in political preference has a correlation with FNC position that is again positive, though not always significantly different from zero. I.e., FNC's position in cable territories that are expected to be more Republican given observables is, if anything, slightly worse than average. These results together say that areas which are predicted, based on demographics, to be highly Republican or to have high FNC viewership do not have lower FNC channel positions.

Columns (5) through (8) check whether FNC position is correlated with political variables that predate FNC's arrival: the share of federal campaign contributions from the zip code that went to Republican candidates in 1996, and the (county-level) Republican presidential vote share in 1996. The idea is to test the conjecture that cable position proxies for pre-treatment variation in political tastes. Again, the majority of the correlations are positive (the opposite direction from the reduced form), and none differs significantly from zero.

We next introduce a placebo test using satellite viewership in the same zip code. Satellite subscribers in the same zip code provide a useful placebo group because they do not interface with the local cable lineup; they see a different lineup which is set by the satellite provider at the national level, yet they look similar on observable demographic dimensions. To carry out the satellite placebo test in the zip code level data, we create a data set which has two observations for each zip code and year: the mean viewership amongst cable subscribers and the mean viewership amongst satellite subscribers. We then run the first stage regression, but 
interacting the channel positions on their local cable system with an indicator for whether the observation represents viewership for cable or for satellite. If the channel positions on the local cable system are chosen in response to unobservable local characteristics, then these positions should also predict satellite subscribers' viewership.

Table 7 presents the results of the satellite placebo test. The Chow test p-value tests for equality between the FNC cable position coefficients. In all columns, we cannot reject that the FNC cable position interacted with satellite subscription is zero, while we reject zero strongly for FNC position interacted with cable subscription. Furthermore, we can always reject the hypothesis that these two coefficients are equal to each other.

Table 7: First Stage Regressions: Nielsen Data, Satellite and Cable Subscribers

\begin{tabular}{|c|c|c|c|c|c|c|}
\hline & \multicolumn{6}{|c|}{ FNC Minutes Per Week } \\
\hline & $(1)$ & $(2)$ & $(3)$ & $(4)$ & $(5)$ & $(6)$ \\
\hline FNC Position $\times$ cable & $\begin{array}{c}-0.155^{* * *} \\
(0.043)\end{array}$ & $\begin{array}{c}-0.237^{* * *} \\
(0.036)\end{array}$ & $\begin{array}{c}-0.264^{* * *} \\
(0.035)\end{array}$ & $\begin{array}{c}-0.151^{* * *} \\
(0.048)\end{array}$ & $\begin{array}{c}-0.178^{* * *} \\
(0.047)\end{array}$ & $\begin{array}{c}-0.219^{* * *} \\
(0.051)\end{array}$ \\
\hline FNC Position $\times$ sat & $\begin{array}{c}0.031 \\
(0.049)\end{array}$ & $\begin{array}{l}-0.044 \\
(0.039)\end{array}$ & $\begin{array}{l}-0.050 \\
(0.041)\end{array}$ & $\begin{array}{c}0.037 \\
(0.063)\end{array}$ & $\begin{array}{c}0.032 \\
(0.058)\end{array}$ & $\begin{array}{c}0.045 \\
(0.067)\end{array}$ \\
\hline MSNBC Position $\times$ cable & $\begin{array}{c}0.102^{* * *} \\
(0.036)\end{array}$ & $\begin{array}{c}0.099^{* * *} \\
(0.036)\end{array}$ & $\begin{array}{c}0.092^{* * *} \\
(0.032)\end{array}$ & $\begin{array}{c}0.035 \\
(0.049)\end{array}$ & $\begin{array}{l}0.026 \\
(0.046)\end{array}$ & $\begin{array}{c}0.046 \\
(0.048)\end{array}$ \\
\hline MSNBC Position $\times$ sat & $\begin{array}{l}-0.004 \\
(0.040)\end{array}$ & $\begin{array}{l}-0.019 \\
(0.033)\end{array}$ & $\begin{array}{l}-0.029 \\
(0.033)\end{array}$ & $\begin{array}{l}-0.029 \\
(0.072)\end{array}$ & $\begin{array}{l}-0.037 \\
(0.066)\end{array}$ & $\begin{array}{l}-0.033 \\
(0.074)\end{array}$ \\
\hline Fixed Effects: & State-Year & State-Year & State-Year & County-Year & County-Year & County-Year \\
\hline Cable Controls: & $\mathrm{Y}$ & $\mathrm{Y}$ & Y & $\mathrm{Y}$ & $\mathrm{Y}$ & $\mathrm{Y}$ \\
\hline Demographics: & None & Basic & Extensive & None & Basic & Extensive \\
\hline Chow Test p-value & 0 & 0 & 0 & 0.011 & 0.004 & 0.001 \\
\hline Number of Clusters & 5786 & 5785 & 4830 & 5786 & 5785 & 4830 \\
\hline $\mathrm{N}$ & 127,072 & 127,016 & 107,829 & 127,072 & 127,016 & 107,829 \\
\hline $\mathrm{R}^{2}$ & 0.032 & 0.070 & 0.077 & 0.232 & 0.255 & 0.278 \\
\hline
\end{tabular}

${ }^{*} \mathrm{p}<.1 ;{ }^{* *} \mathrm{p}<.05 ;{ }^{* * *} \mathrm{p}<.01$

Cluster-robust standard errors in parentheses (clustered by cable system). Positions are the ordinal position of FNC/MSNBC on the local cable system. The omitted category for the availability dummies is systems where neither FNC nor MSNBC is available. Cable system controls include the total number of channels on the system and the number of broadcast channels on the system. All controls (including fixed effects) are interacted with a dummy for the observation corresponding to satellite viewership. Observations are weighted by the number of survey individuals in the zipcode according to Nielsen.

Finally, in Table 8, we show that the coefficients on FNC position in both the first stage viewership regression and the reduced form do not change substantially as we add or remove subsets of variables that are highly predictive of both voting Republican and watching FNC. For example, consider the zip code fraction of campaign contributions going to Republicans in 
Table 8: Comparison of covariate groups' influence on viewing equation, voting equation, and the first stage coefficient estimate: Nielsen Data.

\begin{tabular}{|c|c|c|c|c|}
\hline & $\mathrm{R}^{2}$ Change (Viewing) & $\mathrm{R}^{2}$ Change (Voting) & First Stage & Reduced Form \\
\hline Race & 0.0001 & 0.075 & $\begin{array}{c}-0.172^{* * *} \\
(0.034)\end{array}$ & $\begin{array}{c}-0.019^{* *} \\
(0.009)\end{array}$ \\
\hline Density / Urban & 0.00004 & 0.001 & $\begin{array}{c}-0.170^{* * *} \\
(0.034)\end{array}$ & $\begin{array}{c}-0.026^{* * *} \\
(0.008)\end{array}$ \\
\hline Age & 0.0004 & 0.003 & $\begin{array}{c}-0.139^{* * *} \\
(0.035)\end{array}$ & $\begin{array}{c}-0.025^{* * *} \\
(0.008)\end{array}$ \\
\hline Education & 0.0001 & 0.007 & $\begin{array}{c}-0.178^{* * *} \\
(0.034)\end{array}$ & $\begin{array}{c}-0.030^{* * *} \\
(0.008)\end{array}$ \\
\hline Marital Status & 0.0001 & 0.012 & $\begin{array}{c}-0.170^{* * *} \\
(0.034)\end{array}$ & $\begin{array}{c}-0.034^{* * *} \\
(0.009)\end{array}$ \\
\hline 1996 Voting / Contribs. & 0.010 & 0.056 & $\begin{array}{c}-0.163^{* * *} \\
(0.033)\end{array}$ & $\begin{array}{c}-0.023^{* *} \\
(0.009)\end{array}$ \\
\hline Religion & 0.00001 & 0.005 & $\begin{array}{c}-0.175^{* * *} \\
(0.034)\end{array}$ & $\begin{array}{c}-0.022^{* *} \\
(0.008)\end{array}$ \\
\hline (No Demographics) & 0.013 & 0.540 & $\begin{array}{c}-0.075^{*} \\
(0.039)\end{array}$ & $\begin{array}{c}0.004 \\
(0.020)\end{array}$ \\
\hline Number of Clusters & 4830 & 4814 & 4830 & 4814 \\
\hline $\mathrm{N}$ & 59,541 & 17,400 & 59,541 & 17,400 \\
\hline
\end{tabular}

${ }^{*} \mathrm{p}<.1 ;{ }^{* *} \mathrm{p}<.05 ;{ }^{* * *} \mathrm{p}<.01$

Cluster-robust standard errors in parentheses (clustered by cable system). The first two columns are the decrease in $R^{2}$ resulting from excluding all variables in the listed group from the viewership and the voting regressions, respectively, relative to the value for the model with the complete (extended) set of controls. The third column shows the estimated first stage coefficient on FNC position when the corresponding group of demographic variables is excluded from the equation. The final column is the same exercise, for the reduced form equation. All regressions include the "Extended" demographic set, with the exception of the indicated group of variables, plus state-year fixed effects. 
1996, before the arrival of FNC. This variable is an extremely strong predictor of Republican voting, with t-statistics exceeding 8. It is also a significant predictor of FNC viewership in 2008. However, including this variable on the right-hand side does not appreciably change the coefficients on FNC position in either the first stage or the reduced form.

\section{Model}

We now specify a behavioral model of viewership and voting. The purpose of the model is two-fold: first, we can run counterfactual predictions, such as predicting the effect of removing FNC or quantifying the role of cable news in polarization. Second, the model helps to interpret the meaning of the IV results. Specifically, the heterogeneity in the model draws attention to the role of the IV as measuring local average treatment effects among agents who are heterogeneous in both their ideological malleability and in their viewership responsiveness to channel position. These benefits come at the cost of functional forms assumptions on exactly how consumers allocate their time watching cable news and how they change their ideology after watching slanted news.

The model has two stages. In the first stage, consumer-voters choose a television package, and how much time to spend watching the cable news channels. In the second stage, consumervoters vote in the Presidential election. Between the first and second stage, consumer-voters' ideologies evolve as a function of the ideologies of and time spent watching the news channels.

Voter Ideology and Presidential Vote Decision Consumer-voters have a latent unidimensional political ideology which determines their vote choice in presidential elections. We denote the left-right ideology of consumer-voter $i$ in year $t$ by $r_{i t}$.

We specify voters' initial ideologies as a function of their county of residence and demographic attributes. Specifically, we estimate a logit model of vote choice with county dummies as explanatory variables, which matches county level vote shares from 1996 . The county-level intercepts from this model then determine the simulated consumers' initial ideologies, along with demographic effects and an iid logit error term:

$$
r_{i j 0}=\delta_{j}+\beta_{V}^{\prime} d_{i}+\epsilon_{i j}
$$

Where $\delta_{j}$ is the estimated county intercept for county $j$, consumer $i$ 's county of residence, $d_{i}$ is a vector of demographic characteristics associated with consumer $i$, and $\beta_{V}$ is a parameter 
vector to be estimated. From this starting point, the consumer's ideology evolves in response to both random shocks and the influence of the news channels he watches, according to a process described in detail later in this section.

Each voter votes for the party whose candidate's announced position is closest to her own. Each presidential election has a cutpoint parameter $P_{t}$, for $t \in\{2000,2004,2008\}$. All voters to the left of the cutpoint (with $r_{i t}<P_{t}$ ) vote for the Democratic candidate, and those to the right vote for the Republican. We do not model the turnout decision. ${ }^{17}$

Viewership and Subscription The viewership time allocation and subscription portion of the model follows Crawford and Yurukoglu (2012). Given access to the news channels $C_{j t}$ in package $j$ in year $t$, consumer-voter $i$ allocates their time amongst watching those channels and other activities to maximize:

$$
v_{i j}=\sum_{c \in C_{j t}} \gamma_{i c t} \log \left(1+T_{i j c}\right)
$$

where $\gamma_{i c t}$ is consumer-voter $i$ 's preference parameter for news channel $c$ in year $t$, subject to a budget constraint that the total time available to allocate is 168 hours per week. We normalize the outside option (doing anything other than watching cable news) such that $\gamma_{i 0 t}=$ 1 for all $i, t$, and parameterize the remaining vector of $\gamma_{i c t}$ as

$$
\begin{aligned}
\gamma_{i t} & =\chi_{i t} \circ \nu_{i t} \\
\chi_{i c t} & \sim \operatorname{Bernoulli}\left(\alpha_{0 c t}+\Pi_{0 c} d_{i}+\zeta_{0} p o s_{i c t}-\eta\left(\left(a+b r_{c t}\right)-r_{i t}\right)^{2}\right) \\
\nu_{i c t} & \sim \operatorname{Exp}\left(\alpha_{c t}+\Pi_{c} d_{i}+\zeta p o s_{i c t}\right)
\end{aligned}
$$

$\chi_{i c t}$ determines whether consumer-voter $i$ has a non-zero preference for channel $c$. It is a random function of demographics $d_{i}$ according to parameters $\Pi_{0}$, a channel-year specific fixed effect $\alpha_{0 c t}$, the position of the channel in the lineup according to $\zeta_{0}$, and the distance of consumer-voter $i$ 's one dimensional political ideology $r_{i t}$ from the channel's text based estimated ideology $r_{c t}$ according to $\eta$. This last term represents taste for like-minded news as in Gentzkow and Shapiro (2010). The parameters $a$ and $b$ scale the text based ideology measures to allow for consumers to perceive slant as a linear function of the text based slant measure. If $\eta$ is positive, then increasing the ideological distance between consumer-voter $i$ and channel $c$ reduces the probability $i$ watches $c$.

\footnotetext{
${ }^{17}$ In Table A27 of the Appendix, we are not able to pin down a precise effect of cable news on turnout.
} 
If the consumer-voter has a non-zero preference for a channel, the intensity of her preference is drawn from an exponential distribution whose parameter depends on $\alpha_{c t}$, a channel-year specific fixed effect, demographics $d_{i}$ according to parameters $\Pi$, and the channel position according to $\zeta$. The exponential mixed with a mass at zero is inspired by the individual viewership data, which features a mass at zero and monotonically decreasing density.

The constrained maximization problem defined by (5) has an analytic solution described in Appendix H. The indirect utility from solving this problem enters into the consumervoter's decision of whether to subscribe to cable, satellite, or no television package at all. The conditional indirect utility from subscribing to package $j$ is

$$
u_{i j}=v_{i j}^{*}+\tilde{\delta}_{j}+\tilde{\epsilon}_{i j}
$$

where $\tilde{\delta}_{j}$ is the mean utility of package $j, \tilde{\epsilon}_{i j}$ is an idiosyncratic logit error term and $j$ corresponds to cable or satellite. We also allow consumers to subscribe to no package at all which yields corresponding $u_{i 0}=\log (1+B)+\tilde{\epsilon}_{i 0}$.

Ideological Influence After watching cable news, consumer-voter $i$ 's one-dimensional political ideology evolves as a function of how much time $i$ spends watching the news channels and the ideology of the news channels. ${ }^{18}$ We assume that $i$ is attracted towards the ideologies of the news channels she watches, the more so the more time $i$ spends watching. Specifically

$$
r_{i t}=\frac{r_{i, t-1}+\rho \sum_{c} T_{i c, t-1}\left(a+b r_{c, t-1}\right)}{1+\rho \sum_{c} T_{i c, t-1}}+\xi_{i t}
$$

where $r_{i, t-1}$ is $i$ 's ideology in the previous year, $r_{i t}$ is $i$ 's new ideology, and $\rho$ is a parameter to be estimated which controls the magnitude of news channels' influence on viewers' ideology. The $\xi_{i t}$ 's are mean-zero, normally distributed random shocks. ${ }^{19}$ This formulation implies that in the absence of watching cable news, viewers' ideologies evolve according to a random walk with zero drift.

\footnotetext{
${ }^{18}$ The channel's ideology measure is the same function of the text based slant measure that enters the viewership decision problem.

${ }^{19}$ We calibrate the variance of the ideology shocks to match the yearly rate of party switching found in the American National Election Study's (ANES) 2008-2009 Panel Study. This study tracked and repeatedly interviewed the same group of respondents over the course of a presidential campaign, allowing an estimate of the within-individual propensity to change support from the Republican to the Democratic presidential candidate over time. Specifically, we calibrated the standard deviation to 0.4654 . This magnitude implies that, when such a shock is added to standard logistic distribution, the mass which changes sign matches the observed fraction of switchers in ANES.
} 
One interpretation of $\rho$ is as a (per-hour) rate at which viewers receive ideological signals while watching cable news. If voters treat signals from slanted outlets as true draws on the state of the world, and further, if they do not account for the correlation between repeated signals from the same source as in the model of DeMarzo et al. (2003), ${ }^{20}$ then equation (8) arises as the inverse-variance-weighted average of signals observed by viewer $i$ in period $t .^{21}$

The functional form here implies that a consumer-voter's attraction is governed by the same parameter $(\rho)$, whether coming from the left or the right. This rules out that a voter might watch a slanted channel, become disgusted, and move in the opposite direction of the channel as in Arceneaux et al. (2012). Furthermore, consumer-voters are naive about the influence effect when choosing time watched.

\section{Estimation and Results}

We estimate the parameters of the model by indirect inference (Smith (1990); Gourieroux et al. (1993)). This implies choosing the model's parameters to generate predictions for an auxiliary model which match the auxiliary model estimated from the data. In essence, we are choosing model parameters so that they generate regression results as close as possible to those in Section 4. The auxiliary model consists of thirteen linear regressions that fall into four categories, plus a set of unconditional moments: (1) regressions of individual-level and zipcode-level viewership of each cable news channel on demographics and channel positions, (six regressions), (2) a linear probability model of watching any positive amount of each cable news channel at the individual level on demographics and channel positions (three regressions), (3) regressions of individual level intent to vote Republican and zipcode level Republican vote share on demographics and predicted time spent watching FNC from (1) (two regressions), and (4) OLS regressions of intent to vote Republican and zipcode level Republican vote share on hours of FNC, MSNBC, or CNN watched (two regressions). ${ }^{22}$ (1) and (3) correspond to the two-stage least squares estimate of the effects of watching FNC on voting Republican, with the addition of analogous first-stage regressions for the other two channels. We introduce (2) to

\footnotetext{
${ }^{20}$ Gentzkow and Shapiro (2006) explore media consumption and endogenous slant with fully Bayesian consumers.

${ }^{21}$ For this interpretation to hold over a series of periods, we require that at the beginning of each period the consumer gets an ideology shock which returns the variance of his ideology to 1.

${ }^{22}$ The individual-level OLS regression uses, rather than hours watched, an indicator for whether FNC, MSNBC, or CNN is an individual's "most-watched" news source as the right-hand-side variable. The reason for this substitution is, as described in Section 3, that we lack an individual-level data set with information on both hours watched and voting preferences. The NAES survey asked respondents only to list which of the news channels, if any, they watched the most.
} 
identify the Bernoulli and exponential components of our utility specification. (4) corresponds to the OLS regression of intent to vote Republican on viewership presented in Table 5. All regressions include state-year fixed effects. Finally, we also match (5) the actual vote shares in each presidential election, the year by year average hours watched for each channel, and the year by year fraction of non-zero viewership for each channel. We choose the model's parameters so that estimating (1)-(5) on data simulated from the model produce coefficient estimates with minimum distance to those in the data. We weight the distance metric in proportion to the inverse of the variance in the estimated relationships in the real data.

Discussion of Variation in Data and Model Parameters An intuitive description of what in the data helps drive estimates of the model's parameters is relatively straightforward. $\rho$, the parameter which determines the degree of influence, is sensitive to the coefficients on projected time in the second stage regression. $\eta$, the parameter governing the degree of tastes for like-minded news, is sensitive to coefficients in OLS regression relative to the coefficients on viewership in the second stage regressions. The OLS coefficient estimates on FNC viewership conflates tastes for like-minded news with any influence effect. We isolate the influence effect by using channel positions as instrumental variables, and choose the level of tastes for like minded news to explain the OLS coefficient conditional on the influence effect.

$\zeta$, the parameters determining the strength of channel positions in the time allocation problem, are sensitive to the first stage coefficients on channel positions. A similar straightforward relationship applies to the demographic factors influencing time watched and the coefficients on demographics in the first stage regressions.

$P_{t}$, the parameters characterizing the three presidential elections in our sample period, are sensitive to the unconditional aggregate vote share moments. These parameters allow the model to capture national trends in party preference. $\beta_{V}$ are sensitive to the OLS and second stage IV coefficients on demographics. They allow consumers with different demographics to have different mean preferences over party.

Separate identification of $a$ and $b$, from $\rho$ and $\eta$ is possible because there are three channels and thus seven moments to work with- the IV coefficient and three from each of the OLS regressions. The asymmetries in the channels' estimated effects relative to their text-based ideological positioning provide variation to distinguish the scaling parameters from $\rho$ and $\eta$. The FNC OLS coefficient is more positive than the MSNBC coefficient is negative. Increasing $\eta$ intensifies the magnitude of both OLS coefficients in similar proportions. Increasing $b$ at a fixed $\eta$ increases the magnitude of the FNC coefficient at a faster rate than the MSNBC 
coefficient, because the text-based FNC ideology is more conservative than the text-based MSNBC ideology is liberal.

Model Estimates Table 9 shows the main parameter estimates from the model. ${ }^{23}$ We estimate positive values for both $\rho$, the influence parameter, and $\eta$, the taste for like-minded news, implying a positive feedback process where voters watch slanted news, are influenced to move closer to the news' channel's ideology, and subsequently have even stronger preference for that channel, due to the decreased ideological distance.

\begin{tabular}{lrr}
\hline \hline Parameter & Estimate & Bootstrapped Standard Error \\
\hline Slant Preference $(\eta)$ & 0.02473 & 0.00628 \\
Ideological Influence $(\rho)$ & 0.05244 & 0.01439 \\
Position Effect - Ratings & -0.00020 & 0.00008 \\
Position Effect - Viewership & -0.00039 & 0.00092 \\
\hline 2000 R/D Threshold & -0.31354 & 0.02623 \\
2004 R/D Threshold & 0.06380 & 0.01265 \\
2008 R/D Threshold & 0.12089 & 0.01914 \\
\hline Channel Ideology Intercept $(a)$ & 0.32259 & 0.08810 \\
Channel Ideology Slope $(b)$ & 17.27089 & 0.05509 \\
\hline \hline
\end{tabular}

Table 9: Key parameter estimates with standard errors clustered by cable system and computed by block bootstrap.

The magnitude of the estimate of the taste for like minded news parameter $\eta$ implies that an ideological distance of one unit between viewer and channel reduces that viewer's probability of watching by about $2.5 \%$. For reference, at our estimated scaling parameters, the ideological distance between FNC and MSNBC in 2008 is 4.3 units. Given the quadratic-loss specification of ideological tastes, this distance implies that an average demographic voter located at the ideological position of FNC in 2008 is about $45 \%$ more likely to watch FNC than she is to watch MSNBC.

The magnitude of $\rho$ implies that a voter watching an hour per week of a news channel for a year would be influenced to a new ideological position just over $5 \%$ of the distance to the channel's ideology. Estimates of the channel position parameters, consistent with the data, imply that increasing channel position decreases both the probability of watching any of a channel, as well as the number of hours watched conditional on watching any. The effect on

\footnotetext{
${ }^{23}$ The full set of parameters additionally contains channel-year fixed effects and demographic terms, separately for the amount watched and the probability of watching any. These are omitted here for brevity. The estimated model's fit on regression coefficients is available in Appendix I.
} 
the probability of watching any - row 4 in the table - implies increasing channel position by 20 positions decreases the probability of a typical voter watching a channel by about $1 \%$.

The channel position effect on the number of hours watched is harder to interpret directly, as the hours-watched model is nonlinear and hence effects of changing these quantities depend on the values of all the other covariates. Tables 10 and 11 therefore show some interpretable quantities generated by the model for viewers with various demographic and ideological profiles.

\begin{tabular}{cccccccrr}
\hline \hline & & & & & & \multicolumn{2}{c}{ Channel position semi-elasticity } \\
\cline { 6 - 9 } Age & Income $(\$ 000 \mathrm{~s})$ & Ethnicity & College & Gender & Ideology & CNN & FNC & MSNBC \\
\hline 65 & 25 & White & No & Man & Centrist & 8.3 & 10.7 & 5.1 \\
65 & 25 & White & No & Man & Median Republican & 7.4 & 10.9 & 0.0 \\
65 & 25 & White & No & Man & Median Democrat & 8.5 & 5.4 & 11.2 \\
\hline 30 & 85 & Black & Yes & Man & Centrist & 10.1 & 0.0 & 0.0 \\
30 & 85 & Black & Yes & Man & Median Republican & 10.2 & 0.0 & 0.0 \\
30 & 85 & Black & Yes & Man & Median Democrat & 12.1 & 0.0 & 0.0 \\
\hline 65 & 85 & Hispanic & No & Man & Centrist & 11.4 & 0.0 & 0.0 \\
65 & 85 & Hispanic & No & Man & Median Republican & 8.3 & 0.0 & 0.0 \\
65 & 85 & Hispanic & No & Man & Median Democrat & 9.0 & 0.0 & 5.4 \\
\hline 30 & 25 & White & Yes & Woman & Centrist & 6.2 & 0.0 & 3.8 \\
30 & 25 & White & Yes & Woman & Median Republican & 4.9 & 0.0 & 0.0 \\
30 & 25 & White & Yes & Woman & Median Democrat & 6.9 & 0.0 & 5.9 \\
\hline 65 & 25 & Black & No & Woman & Centrist & 9.6 & 15.0 & 10.4 \\
65 & 25 & Black & No & Woman & Median Republican & 11.0 & 15.1 & 9.1 \\
65 & 25 & Black & No & Woman & Median Democrat & 10.1 & 13.8 & 10.7 \\
\hline 30 & 85 & Hispanic & Yes & Woman & Centrist & 7.1 & 3.1 & 0.0 \\
30 & 85 & Hispanic & Yes & Woman & Median Republican & 4.6 & 6.7 & 0.0 \\
30 & 85 & Hispanic & Yes & Woman & Median Democrat & 5.5 & 6.0 & 6.6 \\
\hline \hline
\end{tabular}

Table 10: The semi-elasticity is the change in mean ratings (in minutes watched per week) following a one-standarddeviation decrease in channel position, for selected demographic and ideological profiles.

Table 10 shows computed elasticities of viewers' expected minutes watched with respect to channel position. We compute the change in ratings (measured in minutes per week) resulting from a one-standard-deviation decrease in channel position. All are weakly positive, as expected, although some are exactly zero because the average viewer of the given demographic and ideological profile does not watch any of the channel, regardless of position.

Table 11 shows a different look at the relationship of viewer preference for channels to demographics and channel position. For the same ideological and demographic profiles as in the previous table, Table 11 lists that type of viewer's average hours watched over each of the three cable channels, on a hypothetical system where all three are available and positioned at their median position in the data in 2008. The last column shows the modal "most-watched" channel among viewers of that type. Demographic effects play a large role in determining the average hours watched, particularly for FNC and MSNBC. Within demographic profiles, ideology drives differences in preferences: all Republican types watch more FNC than they do 


\begin{tabular}{|c|c|c|c|c|c|c|c|c|c|}
\hline & & & & & & \multicolumn{3}{|c|}{ Mean minutes watched } & Modal \\
\hline Age & Income $(\$ 000 \mathrm{~s})$ & Ethnicity & College & Gender & Ideology & $\mathrm{CNN}$ & FNC & MSNBC & Fav. Chan. \\
\hline 65 & 25 & White & No & Man & Centrist & 130.84 & 172.86 & 46.32 & CNN \\
\hline 65 & 25 & White & No & Man & Median Republican & 110.37 & 249.00 & 0.00 & FNC \\
\hline 65 & 25 & White & No & Man & Median Democrat & 137.79 & 61.51 & 71.54 & $\mathrm{CNN}$ \\
\hline 30 & 85 & Black & Yes & Man & Centrist & 132.47 & 0.37 & 0.37 & CNN \\
\hline 30 & 85 & Black & Yes & Man & Median Republican & 116.65 & 0.42 & 0.38 & $\mathrm{CNN}$ \\
\hline 30 & 85 & Black & Yes & Man & Median Democrat & 140.12 & 0.32 & 0.35 & $\mathrm{CNN}$ \\
\hline 65 & 85 & Hispanic & No & Man & Centrist & 139.92 & 0.31 & 0.00 & CNN \\
\hline 65 & 85 & Hispanic & No & Man & Median Republican & 121.20 & 0.41 & 0.00 & $\mathrm{CNN}$ \\
\hline 65 & 85 & Hispanic & No & Man & Median Democrat & 146.87 & 0.22 & 27.69 & CNN \\
\hline 30 & 25 & White & Yes & Woman & Centrist & 88.24 & 0.00 & 39.58 & CNN \\
\hline 30 & 25 & White & Yes & Woman & Median Republican & 62.61 & 0.00 & 0.00 & $\mathrm{CNN}$ \\
\hline 30 & 25 & White & Yes & Woman & Median Democrat & 94.45 & 0.00 & 75.20 & $\mathrm{CNN}$ \\
\hline 65 & 25 & Black & No & Woman & Centrist & 152.04 & 137.52 & 153.49 & FNC \\
\hline 65 & 25 & Black & No & Woman & Median Republican & 132.91 & 138.72 & 111.94 & FNC \\
\hline 65 & 25 & Black & No & Woman & Median Democrat & 159.88 & 124.34 & 169.89 & $\mathrm{CNN}$ \\
\hline 30 & 85 & Hispanic & Yes & Woman & Centrist & 86.36 & 87.79 & 0.00 & $\mathrm{CNN}$ \\
\hline 30 & 85 & Hispanic & Yes & Woman & Median Republican & 65.15 & 125.73 & 0.00 & $\mathrm{FNC}$ \\
\hline 30 & 85 & Hispanic & Yes & Woman & Median Democrat & 93.91 & 28.36 & 21.05 & $\mathrm{CNN}$ \\
\hline
\end{tabular}

Table 11: Preference orderings of channels, in terms of average minutes per week watched, for selected demographic and ideological profiles. The final column is the channel which is most commonly the most watched for that profile.

MSNBC, and most Democratic types watch more MSNBC than they do FNC.

In both our raw data and in the simulations, cable news programs are consumed by agents who do not necessarily share the same ideology as the channel. This result is consistent with the analysis in Gentzkow and Shapiro (2011) who find that much of FNC's audience is composed of people who do not self-identify as conservative, and related, that self-identified conservatives watch other cable news besides FNC. The model estimates match these facts. Furthermore, such a lack of ideological segregation is a necessary precursor in this model for cable news consumption to change voter intentions.

We find that the perception of slant for the channels is a multiple of about 17 times the text based slant measure. The text based slant measures place FNC and MSNBC in 2008 closer to the center than the median Republican or median Democratic congressman, respectively. The scaled ideology estimates place FNC to the right of the median Republican voter in 2008. MSNBC's position falls to the left of the median Democratic voter in 2008, although only slightly.

Table 12 shows the change in the probability of voting Republican with respect to watching one hour per week of each of the cable channels, again for viewers with different initial ideological types. For initially centrist voters, watching CNN has an influence on the probability of voting Republican that ranges from slightly positive to slightly negative depending on the election. The effect of MSNBC is small but positive (meaning watching MSNBC increases the 


\begin{tabular}{cc|rrr}
\hline \hline Election & Voter Ideology & 1 Hour CNN & 1 Hour FNC & 1 Hour MSNBC \\
\hline \multirow{2}{*}{2000} & Centrist & 0.019 & 0.053 & 0.012 \\
& Median Republican & -0.025 & -0.001 & -0.031 \\
& Median Democrat & 0.053 & 0.083 & 0.047 \\
\hline \multirow{2}{*}{2004} & Centrist & -0.013 & 0.061 & 0.039 \\
& Median Republican & -0.049 & 0.009 & -0.008 \\
& Median Democrat & 0.029 & 0.090 & 0.071 \\
\hline \multirow{2}{*}{2008} & Centrist & -0.050 & 0.122 & -0.070 \\
& Median Republican & -0.080 & 0.052 & -0.098 \\
& Median Democrat & 0.001 & 0.148 & -0.013 \\
\hline \hline
\end{tabular}

Table 12: Effects of watching an additional 1 hour per week on the probability of voting Republican.

\begin{tabular}{c|rr|rr}
\hline \hline Election & \multicolumn{2}{|c}{ All voters } & \multicolumn{2}{c}{ Only attached voters } \\
& FNC (D to R) & MSNBC (R to D) & FNC (D to R) & MSNBC (R to D) \\
\hline 2000 & $58 \%$ & $16 \%$ & $53 \%$ & $12 \%$ \\
2004 & $27 \%$ & $0 \%$ & $6 \%$ & $0 \%$ \\
2008 & $28 \%$ & $8 \%$ & $11 \%$ & $1 \%$ \\
\hline \hline
\end{tabular}

Table 13: Persuasion rates of Fox News and MSNBC. "All voters" counts as a Democrat any voter initially to the left of the election cutoff, and counts as a Republican any voter initially to the right. "Only attached voters" includes only voters in the leftmost $33 \%$ and rightmost $33 \%$ of the voter ideology distribution. Percentages are conditional on watching the channel.

likelihood of Republican voting) in 2000 and 2004, but becomes substantially negative (at 6.6 percentage points) in 2008 after MSNBC's format switch. The effect of Fox on centrist viewers is consistently positive, ranging from 5.3 points in 2000 to 12.6 points in 2008 .

The largest elasticity magnitudes are on individuals from the opposite ideology of the channel. Were a viewer initially at the ideology of the median Democratic voter in 2008 to watch an hour of Fox per week, her likelihood of voting Republican would increase by just over 15 percentage points. Another pattern that emerges from the table is that Fox is substantially better at influencing Democrats than MSNBC is at influencing Republicans. This last feature is consistent with the regression result that the IV effect of Fox is greater and more consistent than the corresponding effect for MSNBC.

Finally, Table 13 shows an estimate of DellaVigna and Kaplan (2007)'s concept of persuasion rates: the success rate of the channels at converting votes from one party to the other. ${ }^{24}$

\footnotetext{
${ }^{24}$ DellaVigna and Kaplan (2007) use a measure of FNC cable availability in 2000 to generate variation in selfreported viewership. In their case, the viewership measure is an indicator for whether the respondent reports watching thirty minutes or more in a given week. Here, we use a continuous measure, condition on demographics,
} 
The numerator here is the number of, for example, FNC viewers who are initially Democrats but by the end of an election cycle change to supporting the Republican party. The denominator is the number of FNC viewers who are initially Democrats. ${ }^{25}$ Again, Fox is consistently more effective at converting viewers than is MSNBC.

\section{Polarization and Media Power}

In this section, we perform several exercises to quantify the effects of cable news on election outcomes. First, we simulate the evolution of ideology for a group of voters over time to ask whether cable news can contribute to polarization. Second, we estimate the effect of the entry of FNC on the 2000 presidential election, as well as the effects of the post-2004 MSNBC format switch on the 2008 presidential election. Finally, we measure the "media power" (Prat, 2014) of the individual channels as well as a hypothetical combination of the three under unified ownership.

Polarization A positive $\rho$ and a positive $\eta$ together create the potential for a polarizing feedback loop, as watching a channel attracts a viewer towards that channel's ideology, which makes watching the channel more attractive, and so on. Figure 4 shows the results of a simulation of viewing and voting behavior to assess the degree of polarization that cable news viewing can generate.

A sample of 10,000 viewers in an average cable system ${ }^{26}$ in a county with average demographic characteristics are assigned ideologies from the initial ideology distribution, conditional on their simulated demographics. We run these simulated individuals through the model over ten years.

The resulting distribution of ideologies becomes visibly more polarized as the process continues, with new right and left modes emerging from the initially approximately unimodal distribution. In addition to plotting the distribution, we show the value of the axiomatic measure of polarization of Esteban and Ray (1994) and Duclos et al. (2004) in each year. ${ }^{27}$ This

and account for satellite viewership.

${ }^{25}$ As our model has no inherent notion of partisanship, only an ideological cutpoint between the parties, in Table 13 we consider two definitions of what constitutes a Democratic or Republican partisan.

${ }^{26}$ For purposes of this simulation, all viewers are given access to all three cable channels, at the channels' mean positions in 2008. We hold channel positioning, channel fixed-effects, and each channel's ideological slant constant at their 2008 values.

${ }^{27}$ There are four axioms which imply this measure. For example, the first axiom is "If a distribution is composed of a single basic density, then a squeeze of that density cannot increase polarization." We refer the reader to the 
value increases as time goes on, by a total of about $2.5 \%$ by the end of the 10 -year period. The locations of the local maxima in the distribution correspond to FNC' ideological location and an intermediate location between that of MSNBC and CNN.

This increase in polarization requires a taste for like-minded news. Figure 4(b) shows the evolution of the ideology distribution when the taste for like-minded news is set to zero. Here, the distribution remains roughly unimodal throughout. Furthermore, the tails of the distribution thin out, as viewers from across the political spectrum are exposed to and persuaded by news from the other side. Additionally, the distribution shifts on the whole to the right, as FNC's relatively more extreme location allows it to out-persuade its relatively moderate competition. Normally, this greater potential for influence is counterbalanced by the fact that the more extreme location dissuades many left-leaning viewers from watching. But with the taste for slant disabled, viewers from across the political spectrum are exposed to Fox.

As a benchmark, we computed the polarization measure after an extreme "hollowing out" of the ideology distribution. ${ }^{28}$ The polarization measure in this scenario more than doubles to 0.591. We conclude that while cable news can generate modest increases in polarization, the audiences are neither large nor selected enough to generate a dramatic polarization.

Fox Entry in 2000, and MSNBC Format Switch Next, we estimate the effect of two counterfactual scenarios aimed at measuring the aggregate influence of the cable news channels on election outcomes. First, we estimate the effect of the entry of FNC on the 2000 presidential election. We compare a base case where Fox was available to cable subscribers in the 1997-2000 period according to the observed rollout pattern to a scenario where Fox was available exclusively to satellite subscribers and not on any local cable system.

The first column of Table 14 shows the effects of eliminating Fox from cable lineups prior to the 2000 election, as well as the effect on subsequent election cycles. The population-weighted average Republican vote share falls by .46 percentage points under the no-Fox scenario relative to the baseline. This prediction is in line with the estimate of 0.26 to 0.36 of DellaVigna and Kaplan (2007), when updated to use more accurate data.

In subsequent cycles, the implied FNC effect increases due to two forces. First and most importantly, overall FNC viewership approximately doubles during the period from 2000 to 2008, meaning nearly twice as many viewers are exposed to FNC in later cycles. Second,

original articles for full definitions and examples. We compute the measure with the parameter $\alpha$ set to 1 .

${ }^{28}$ Specifically, we transformed the initial distribution of ideology by assigning all Democratic simulated voters to the right of the median Democrat the median Democratic ideology, and assigning all Republican simulated voters to the left of the median Republican the median Republican ideology. 

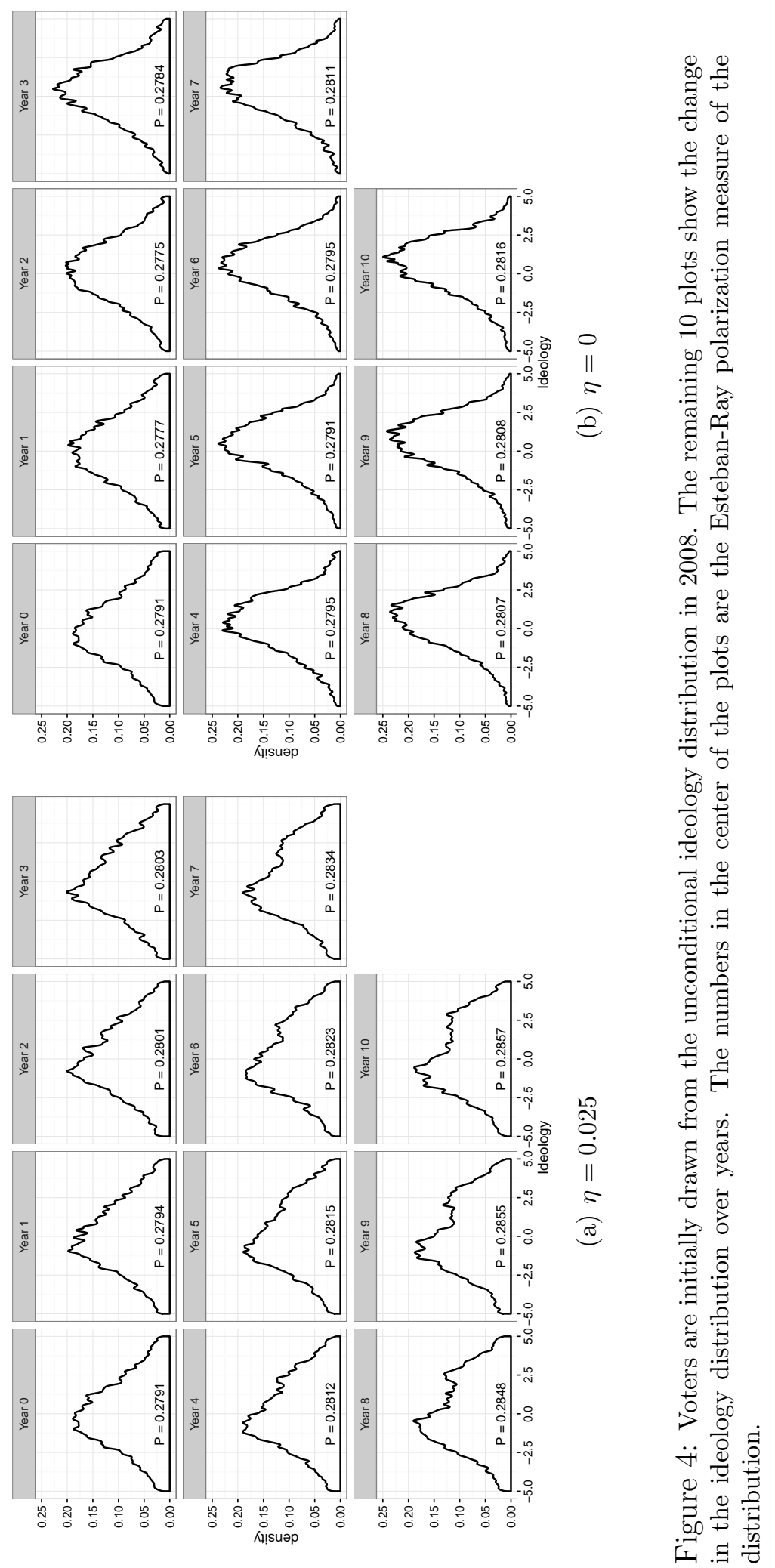


\begin{tabular}{lrr}
\hline \hline & \multicolumn{2}{c}{ R Vote Share Change } \\
Election & No Fox News & MSNBC Tracks CNN \\
\hline 2000 & -0.0046 & 0.0006 \\
2004 & -0.0359 & -0.0124 \\
2008 & -0.0634 & -0.0009 \\
\hline \hline
\end{tabular}

Table 14: Effects of two counterfactual scenarios. In the first, Fox News is eliminated from cable lineups. Column 2 shows the change in the Republican vote share of the presidential popular vote in the no-Fox scenario relative to the baseline. In the second, MSNBC's ideological positioning matches that of CNN throughout the 2000-2008 period. Column 3 shows the change in the Republican vote share of the presidential popular vote in the MSNBC-matchingCNN scenario relative to the baseline.

according to our ideological estimates, FNC moves well to the right over this period, increasing its persuasive effect enough to outweigh any loss in viewership due to the ideological drift.

The second column of Table 14 estimates the effects of MSNBC's switch to liberal slant. We simulated a condition where MSNBC's ideology matched that of CNN. The estimated effect in the 2008 election cycle is to decrease the Republican share by just 0.09 percentage points, an effect two orders of magnitude smaller than the estimated effect of eliminating FNC in 2008. This minimal effect derives from two sources. One, MSNBC's viewership is substantially smaller than that of FNC. Second, MSNBC's estimted ideological position in the 2008 cycle is not all that far to the left of CNN, whereas FNC is well to the right.

Media Power and Optimal Positioning Prat's (2014) notion of media power refers to the minimal quality candidate for whom a media owner could engineer an election victory through persuasive efforts. While our election model has no quality dimension, we can ask a similar question: how many presidential votes could the cable news channels swing from one party to the other, by changing the ideological orientation of their content? Table 15 shows the results of an exercise where we allow each channel to choose its ideological location in each year in order to maximize the vote share of the Republican candidate, and then do the same for the Democratic candidate, holding the positions of the other channels fixed. The table shows the difference in Republican aggregate vote share between these two scenarios. In the last column of the table, we show the potential influence of a combined cable news monopolist controlling all three channels.

In this time period, CNN has the highest power to swing election outcomes, due to its relatively large viewership, favorable channel positioning, and broad demographic appeal. The potential to change election outcomes are large - the achievable vote share swing of a cable 


\begin{tabular}{lrrrr}
\hline \hline & \multicolumn{4}{c}{ Potential Vote Share Swing } \\
Election & CNN & FNC & MSNBC & Monopolist \\
\hline 2000 & 0.0316 & 0.0126 & 0.0082 & 0.0465 \\
2004 & 0.1456 & 0.0955 & 0.0409 & 0.2123 \\
2008 & 0.1862 & 0.1568 & 0.0563 & 0.2893 \\
\hline \hline
\end{tabular}

Table 15: The maximum potential vote share swing that the channel could engineer, by election. The "monopolist" column is the is the maximum vote share

news monopolist exceeds $25 \%$ by 2008 - and increasing over time. The time trend is a result of the accumulation of influence over time, as the cumulative reach of the channels grow with each passing year.

The preceding is a "worst-case" scenario, in the sense that it assumes cable news operators seek only to maximize the vote share of a favored party. In reality, the cable channels are businesses whose revenue derives from advertising and affiliate fees from cable providers, ${ }^{29}$ which are generally increasing in audience size. The profit motive presumably provides some disincentive from choosing extreme ideological locations that would reduce ratings by turning off too many moderate viewers.

We examined the extent to which this tradeoff constrains the channels' persuasive power, by comparing the power-maximizing ideological position to the ratings-maximizing ideological position. Figure 7 compares each of the three channels' actual, ratings-maximizing, and influence-maximizing ${ }^{30}$ ideological positioning in the $2000-2008$ period.

The optimal ideological location from a ratings perspective is quite centrist, and similar for all three of the channels. Comparison of the channel's actual location with the vote-share maximizing choice, however, reveals an asymmetry: the two relatively liberal channels, and $\mathrm{CNN}$ in particular, are far from the location that would maximize the vote share of Democratic candidates. FNC, on the other hand, is close to, and by 2008 actually exceeds, the position that maximizes Republican vote share. Were Fox to move even further to the right, the loss of liberal viewers turned off by Fox's extreme location would outweigh the gain in persuasive potential among liberal viewers who continued to watch, reducing FNC's overall influence on election outcomes.

Relatedly, the power figures presented in Table 15 do not represent symmetric swings around the actual vote share totals: FNC is already close to achieving the maximal Republican

\footnotetext{
${ }^{29}$ According to SNL, the FNC received $64 \%$ of its revenue from affiliate fees in 2015.

${ }^{30}$ For MSNBC and CNN, we plot the choice that maximizes Democratic vote share; for FNC we plot the choice that maximizes Republican vote share.
} 

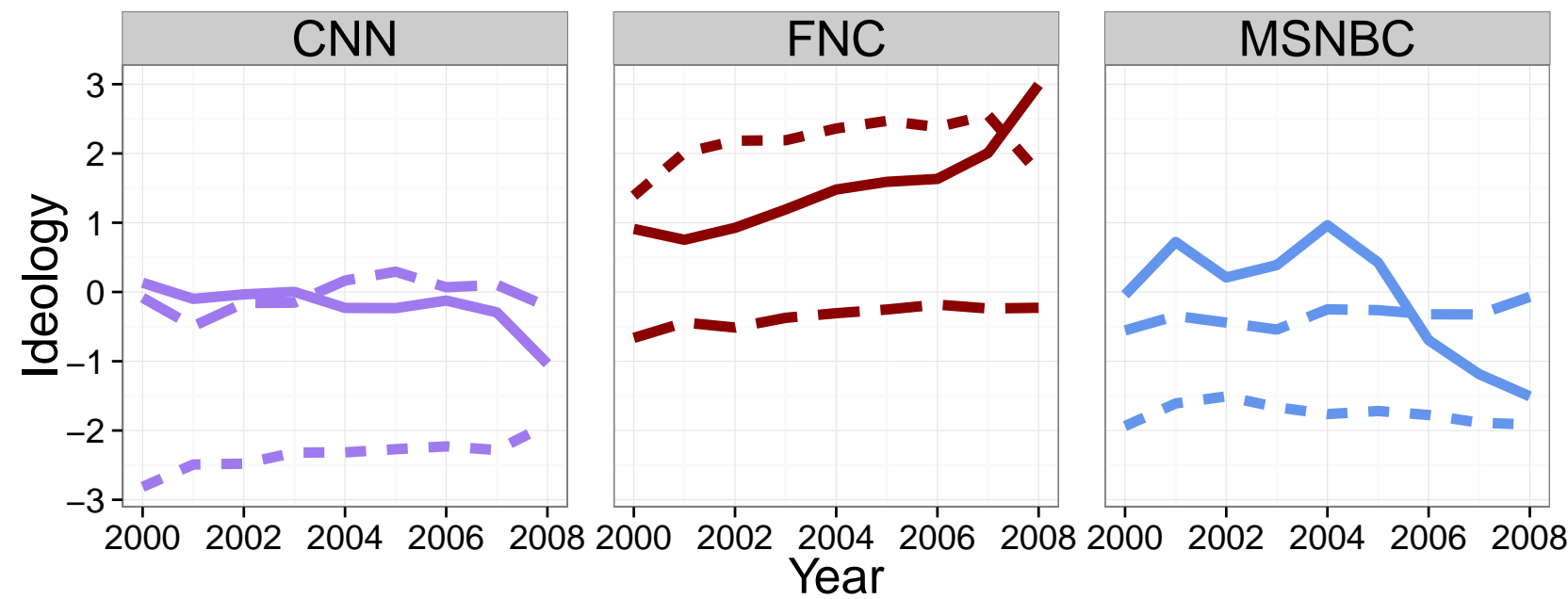

Type $=$ actual $=$ power $=$ ratings

Figure 5: Channels' ideological positioning from 2000-2008. The three lines are the observed position from the text-based measure, the position that would maximize the channel's ratings, and the position that maximizes the vote share for a favored party. For FNC, we show the position that maximizes Republican vote share; for the other two channels we show the position that maximizes Democratic vote share.

vote share it can attain on its own, and its power consists almost entirely of the damage it could do to Republican candidates by moving to the left.

Several caveats to this exercise are in order. First, these are partial-equilibrium results holding the locations of the other channels fixed at their actual locations. Although an interesting question in its own right, modeling the strategic interaction between channels in this complex dynamic game is beyond the scope of this paper. Second, although ratings are related to profitability, they are not the same thing. Advertising rates vary with the demographics of the audience, and it is possible that a smaller audience is more valuable than a larger one if its composition is skewed in ways - towards higher income households, for example - that are attractive to advertisers. And cable providers' willingness to pay affiliate fees is likely to be higher for differentiated news channels than for homogeneous ones. Hence, though FNC's strategy appears to cost it some viewers relative to a more centrist positioning, we cannot conclude from this observation that the FNC ownership must therefore be willing to sacrifice profits for Republican votes. 


\section{Conclusion}

This paper provides estimates of both the influence of slanted news on voting behavior and the taste for like-minded news in the context of cable television news in the U.S. The key ingredient in the analysis is the use of channel positions as instrumental variables to estimate a model of viewership, voting, and ideology evolution. We show instrumental variables estimates that watching FNC increases the probability of voting Republican in presidential elections. We probe the instrumental variables assumption by correlating channel positions with observables: demographics which predict FNC viewership, demographics which predict partisan vote shares, pre-FNC partisan vote shares, pre-FNC partisan donations, and local satellite viewership of FNC.

We estimate a model of consumer-viewer-voters who choose cable subscriptions, allocate time to watching news channels, and vote in elections. The tastes for news channels are partly determined by the closeness of the news channels' estimated ideology to the individuals. Individual ideology evolves towards the estimated ideologies of the news channels that a consumer watches. We use the estimated model to characterize the degree of polarization that one can attribute to slanted cable news consumption, to measure effects of cable news on elections, and to assess the positioning strategies of the cable news channels. Our estimates imply large effects of FNC on presidential elections. Furthermore, we estimate that cable news can increase polarization, and that this increase depends on both a persuasive effect of cable news and the existence of tastes for like-minded news. Finally, we find that an influence-maximizing owner of the cable news channels could have large effects on vote shares, but would have to sacrifice some levels of viewership to maximize influence.

Future research could go in a number of directions. The use of channel positions as instrumental variable could be useful in other studies of how media consumption affects behavior. One could also use channel position variation to study the cable news channels in more detail by examining specific programs, e.g. "The O'Reilly Factor," and specific issues like abortion, gay marriage, or government spending. In a different direction, studying the causes and consequences of the divergence in estimated ideologies seems fruitful. ${ }^{31}$ It would also be useful to test, refine, or expand the specific model we employ for belief updating after media consumption. For example, one could allow for a joint distribution of influence parameters and tastes for like-minded news in the population.

\footnotetext{
${ }^{31}$ This includes improving these text based procedures to allow for sentiment analysis or other partisan indicators.
} 


\section{References}

Ansolabehere, Stephen, Maxwell Palmer, and Amanda Lee, "Precinct-Level Election Data," 2014.

Arceneaux, Kevin, Martin Johnson, and Chad Murphy, "Polarized political communication, oppositional media hostility, and selective exposure," The Journal of Politics, 2012, 74 (01), 174-186.

Chiang, Chun-Fang and Brian Knight, "Media bias and influence: Evidence from newspaper endorsements," The Review of Economic Studies, 2011, 78 (3), 795.

Colman, Price, "TCI will carry Fox news channel," Broadcasting \& Cable, July 1996.

Crawford, Gregory S and Ali Yurukoglu, "The welfare effects of bundling in multichannel television markets," The American Economic Review, 2012, 102 (2), 643-685.

DellaVigna, Stefano and Ethan Kaplan, "The Fox News effect: Media bias and voting," The Quarterly Journal of Economics, 2007, 122 (3), 1187-1234.

DeMarzo, Peter M, Dimitri Vayanos, and Jeffrey Zwiebel, "Persuasion bias, social influence, and unidimensional opinions," The Quarterly Journal of Economics, 2003, 118 (3), 909-968.

Dempsey, John, "Spurned cable webs revile TCI," Variety, August 1996.

Duclos, Jean-Yves, Joan Esteban, and Debraj Ray, "Polarization: concepts, measurement, estimation," Econometrica, 2004, 72 (6), 1737-1772.

Enikolopov, Ruben, Maria Petrova, and Ekaterina Zhuravskaya, "Media and political persuasion: Evidence from Russia," The American Economic Review, 2011, 101 (7), 32533285 .

Esteban, Joan-Maria and Debraj Ray, "On the measurement of polarization," Econometrica: Journal of the Econometric Society, 1994, pp. 819-851.

Galesic, Mirta, Roger Tourangeau, Mick P Couper, and Frederick G Conrad, "EyeTracking data new insights on response order effects and other cognitive shortcuts in survey responding," Public Opinion Quarterly, 2008, 72 (5), 892-913. 
Gentzkow, Matthew, "Television and voter turnout," The Quarterly Journal of Economics, 2006, 121 (3), 931-972.

_ , "Polarization in 2016," Toulouse Network for Information Technology, 2016.

_ and Jesse M. Shapiro, "Media Bias and Reputation," Journal of Political Economy, 2006, 114 (2), 280-316.

_ and _, "Competition and Truth in the Market for News," The Journal of Economic Perspectives, 2008, pp. 133-154.

_ and _ , "What drives media slant? Evidence from US daily newspapers," Econometrica, 2010, 78 (1), 35-71.

_ and _ , "Ideological segregation online and offline," The Quarterly Journal of Economics, 2011, 126 (4), 1799-1839.

Gerber, Alan S., Dean Karlan, and Daniel Bergan, "Does the Media Matter? A Field Experiment Measuring the Effect of Newspapers on Voting Behavior and Political Opinions," American Economic Journal: Applied Economics, 2009, 1 (2), 35-52.

Gourieroux, Christian, Alain Monfort, and Eric Renault, "Indirect inference," Journal of Applied Econometrics, 1993, 8 (S1), S85-S118.

Groseclose, Tim and Jeffrey Milyo, "A measure of media bias," The Quarterly Journal of Economics, 2005, pp. 1191-1237.

Horan, Sean, "Sequential search and choice from lists," Unpublished paper., 2010.

Inoue, Atsushi and Gary Solon, "Two-sample instrumental variables estimators," The Review of Economics and Statistics, 2010, 92 (3), 557-561.

Lim, Claire S.H., James M. Snyder Jr., and David Stromberg, "The Judge, the Politician, and the Press: Newspaper Coverage and Criminal Sentencing Across Electoral Systems," Working paper., 2014.

Lohse, Gerald L, "Consumer eye movement patterns on yellow pages advertising," Journal of Advertising, 1997, 26 (1), 61-73. 
Masatlioglu, Yusufcan and Daisuke Nakajima, "Choice by iterative search," Theoretical Economics, 2013, 8 (3), 701-728.

McCarty, Nolan M, Keith T Poole, and Howard Rosenthal, "Income redistribution and the realignment of American politics," 1997.

Mullainathan, Sendhil and Andrei Shleifer, "The market for news," American Economic Review, 2005, pp. 1031-1053.

Prat, Andrea, "Media Power," 2014. CEPR Discussion Paper 10094.

Rubinstein, Ariel and Yuval Salant, "A model of choice from lists," Theoretical Economics, 2006, 1 (1), 3-17.

Sanneh, Kelefa, "Twenty-Four Hour Party People: MSNBC tries to figure out what liberals really want.," The New Yorker, September 2013.

Smith, Anthony Alan, "Three essays on the solution and estimation of dynamic macroeconomic models." PhD dissertation, Duke University 1990.

Zou, Hui and Trevor Hastie, "Regularization and variable selection via the elastic net," Journal of the Royal Statistical Society: Series B (Statistical Methodology), 2005, 67 (2), 301-320. 


\section{A Data Construction}

\section{A.1 Nielsen FOCUS Lineups}

The Nielsen FOCUS data set were provided in two formats. For the largest 55 DMA's, we were given yearly spreadsheets for each DMA. For the DMA's ranked 56 to 210, we were given a CSV file with all systems and years. We stacked all the 1-55 DMA spreadsheets with the 56-210 CSV file. An observation in the main combined file is a cable system-yearchannel. A separate file links cable system-years to zip codes. We dropped any cable system labeled "-ADS" or "APTS". These system correspond to alternative delivery systems for single apartment buildings. We synchronized cable channel names across years and system by manual inspection.

The three main challenges with these data are that some zip codes have more than one cable system which serve it, and some cable systems have multiple "devices" whose lineups sometimes, but not always, differ, and some cable system devices have multiple channels listed in a channel position. To deal with the first issue, we first kept the cable system which reports the highest number of total subscribers (across all zip codes). To break ties, we then considered which cable system had the highest number of county subscribers, the most homes passed, and the highest number of channels, and at random, in that order. 124252 ties are broken by total subscribers, and a total of 222 further ties broken by the other criteria. In the case where a device listed two channels in the same position, we kept the channel if it was a news channel, and at random if no news channel was involved. If a channel showed up in two different positions, we used the minimum channel position.

We first dropped any device labeled "COMMUNITY SPECIFIC" or "UNIQUE SITUATION." These were always in systems which had other devices that were labelled "DIGITAL" or "REGULAR." In cases where two devices did not have any overlapping channel numbers, we combined the two devices into one. For systems with multiple devices, we kept the device with the most number of channels. This is often innocuous as the devices would be nested and have the same channel positions for most of the basic channels. If multiple devices had the same number of channels, we kept the device that was labelled "DIGITAL," if possible. If not, we kept the device labelled "REGULAR." These conditions broke all ties.

We dropped any system which did not report carrying any of the top 60 cable channels by Mediamark viewership after the cleaning. These are likely due to error in the cleaning process and correspond to 587 zip code-years out of 522,139 zip code-years (0.11\%).

The number of channels variable corresponds to the total number of non-empty channel 
positions in the cleaned cable lineup. We dropped any pay-per-view channels, channels labeled "BLACKOUT," program guide channels, split-channels (e.g. "Nick at Nite" which is the evening version of Nickelodeon), and HD channels. The number of broadcast channels variable corresponds to the total number of channels that have an associated over-the-air channel number.

\section{A.2 Nielsen Viewership Data}

We use zip code-level viewership data from Nielsen Local Television View (NLTV) for the years 2005 through 2008.

Sample selection We downloaded reports from the NLTV interface for zip code level ratings aggregated for each year separately in any zip code where the estimated sample size in the report interface was positive. We used the 5am-5am daypart, and all persons 18 and over. Each zip code year had 9 observations: three for each of CNN, Fox News Channel, and MSNBC. Within each channel, we had a rating for all television households, a rating for households who subscribed to cable television, and a rating for households who subcribed to Alternative Delivery Systems (ADS) which are defined as "Satellite (C-band), DBS (KU-band), SMATV (master antenna), MDS (includes multi-channel, multi-point and multi-point distribution service) and Broadband Only." (http://en-us.nielsen.com/sitelets/cls/documents/nltv/NLTVCharacteristicDefinitions-Diary.pdf). DirecTV and Dish Network are DBS providers.

Matching to lineup and availability data We match this data set to the Nielsen FOCUS lineups by the zip code and year.

\section{A.3 MRI-Simmons Viewership Data}

We use individual-level viewership data from two sources: Mediamark Research's Survey of the American Consumer and Experian Simmons' National Consumer Study. We use Mediamark data from 2000 to 2007, and Experian Simmons data for 2008. In this section, we detail the steps we took in cleaning and combining these data sets.

Sample selection We included in our sample any respondent who responded to all relevant demographic characteristics: race, income, education, age, and gender. We also required the respondent to have a valid zip code. 
Demographics We make some simplifications to the demographic questions, as follows. First, racial categories are simplified to three dummy variables, for white, black, and hispanic respectively. The excluded category is all other racial categories. Education variables are reduced to a single dummy variable for having completed at least a bachelor's degree.

Household income comes in binned indicator form in the raw data. For example, there is an indicator for household income of " $\$ 15,000$ to less than $\$ 25,000$." We convert these indicators to a continuous variable by computing the expected value of a log-normally-distributed random variable, conditional on the variable falling within the bin boundaries. ${ }^{32}$ The parameters of this distribution are calibrated to match the shares of the national population falling into each of the income bins collected by the US Census Bureau. All respondents in the same income bin are, therefore, assigned the same level of income.

Viewership of Cable Channels Both surveys ask about the number of hours viewed in a given week for a variety of television channels. This study uses responses to CNN, the Fox News Channel, and MSNBC. Mediamark asks whether the respondent watched any amount, as well as a multiple choice question for each channel with the following options: 1 hour, 2 hours, 3 hours, 4 hours, 5 hours, 6-9 hours, 10 hours, 11-15 hours, 16-20 hours, and 21+ hours. Experian Simmons also asks whether the respondent watched any amount, and a multiple choice question for each channel with the following options: Less than 1 hour, 1 hour to less than 3, 3 hours to less than 5, 5 hours to less than 7, 7 hours to less than 10, and 10 hours or more. We assigned the midpoint of each interval as the hours watched for that respondent when possible. ${ }^{33}$

Cable or Satellite Subscription We also use whether the respondent subscribes to Cable, DirecTV, Dish Network, or none of the above. For the 5,386 respondents (2.5\%) who indicate that they subscribe to both cable and one of the satellite providers, we assume they only subscribe to the satellite provider.

Matching to lineup and availability data We match both data sets to the Nielsen FOCUS lineups by the respondent's zip code and year.

\footnotetext{
${ }^{32}$ For the top-coded categories, we compute the expected value conditional on being above the top-coding threshold.

${ }^{33}$ For the highest bin, we used 25 hours for Mediamark and 12.84 hours for Simmons.
} 


\section{A.4 Construction of 2008 zip-level vote}

Precinct-level voting data for the 2008 presidential election come from the Harvard Election Data Archive (HEDA, Ansolabehere and Rodden, 2011). We matched each precinct to a ZIP code (the level at which our cable position data is defined) using a spatial matching procedure. For each precinct in the HEDA shapefile, we computed the coordinates of the precinct's centroid. We then overlaid the precinct centroids onto the polygon files defining zip code tabulation area boundaries provided by the US Census Bureau's TIGER/Line series, generating a corresponding ZIP code for each precinct.

There are a minority of cases for which the precinct centroid does not fall within the boundaries of any ZIP code. This can happen, for instance, if the precinct centroid falls in a lake or other body of water, which are excluded from the ZIP polygon boundaries. In these cases, we match to ZIPs by computing the centroids for each ZIP, and finding the nearest neighbor ZIP centroid (by geographic distance) for each precinct centroid.

Once a ZIP code match for every precinct has been constructed in this fashion, we aggregate voting totals across precincts up to the ZIP level. This ZIP level dataset is then used in our reduced-form regression of 2008 Republican presidential vote share on position.

\section{A.5 Construction of CCES and NAES datasets}

For the 2000, 2004 and 2008 election cycles, we use individual-level political preference data from the National Annenberg Election Survey (NAES). The NAES is a nationally representative telephone survey, conducted as a rolling cross-section between the December of the preceding year and the January following the election year. Survey waves were timed roughly to correspond with major campaign events such as the televised debates. Those interviewed after the election date were asked for whom they actually had cast a ballot; those interviewed before were asked for whom they intended to cast a ballot. The bulk of the interviews occur in the three months prior to the election; $10-15 \%$ occur after the election.

Sample selection We included in our sample any respondent in the rolling cross-section who indicated a preference for one of the two major-party presidential candidates, either in the form of intention to vote or of actual vote, pooling together all survey waves. NAES also asked pre-election voters to state how certain they were of their choice, on a scale ranging from "Definitely will vote for candidate" to "Good chance will change mind." We pool all of these responses together as votes for the stated candidate. Voters who did not answer the 
presidential preference question, or said they "Don't know" or are "Uncertain" of their choice are excluded from the sample.

Demographics We make some simplifications to the demographic questions in NAES, as follows. First, racial categories are simplified to three dummy variables, for white, black, and hispanic respectively. The excluded category is all other racial categories. Education variables are reduced to a single dummy variable for having completed at least a bachelor's degree, which includes the NAES" "Four-year college degree" and "Graduate or professional degree" categories.

Household income comes in binned indicator form in the raw NAES data. For example, there is an indicator for household income of " $\$ 15,000$ to less than $\$ 25,000$." We convert these indicators to a continuous variable by computing the expected value of a lognormallydistributed random variable, conditional on the variable falling within the bin boundaries. ${ }^{34}$ The parameters of this distribution are calibrated to match the shares of the national population falling into each of the income bins collected by the US Census Bureau. All respondents in the same income bin are, therefore, assigned the same level of income.

Most-watched cable channel The 2004 and 2008 editions of the NAES ask respondents to state the TV news source which they watch most. In 2004 this question is phrased in terms of channels (i.e. respondents can select CNN, MSNBC, FNC, or one of the networks) whereas in 2008 it is phrased in terms of programs (i.e, respondents can select The O'Reilly Factor, Anderson Cooper 360, and so forth.) We convert the 2008 response to channel level by aggregating across all responses that indicate a show affiliated with a particular channel, as well as responses that state the channel name but not a specific program. We then create three mutually exclusive dummy variables for selecting each of the three channels. It is possible (and, in fact, likely) that a respondent may have a 0 for all three of these variables, indicating either that the respondent does not consume any TV news or that she prefers a non-cable source.

Matching to lineup and availability data NAES data is matched to the Nielsen FOCUS lineups by the respondent's zip code and year. Because Nielsen's lineups data are released at the end of December each year, we apply the following rule for temporal matching: any respondent interviewed in the first six months of a year is matched to his zip code's lineup

\footnotetext{
${ }^{34}$ For the top-coded categories, we compute the expected value conditional on being above the top-coding threshold.
} 
from the previous December 31. Any respondent interviewed in the last six months is matched to his zip code's lineup from the following December 31.

CCES For 2008, we supplement the NAES data with additional respondents from the Cooperative Congressional Election Study (CCES), an online cross-section survey which began operation in 2006. Our construction of the CCES data exactly parallels the discussion of NAES data above. The only differences are that the CCES does not include the most-watched news source question, and that the income bins differ from those used by NAES. The conversion of income to a continuous variable discussed above allows the CCES data to be appended cleanly to the NAES sample. 


\section{B Summary Statistics for Voting and Viewership Datasets}

Tables A1 through A4 present summary statistics for the primary datasets employed in the 2SLS analysis and behavioral model: voting and viewership data, at the zip code and individual levels. 
Table A1: Summary Statistics for 2008 Zip Code Level Voting

\begin{tabular}{|c|c|c|c|c|c|}
\hline Statistic & $\mathrm{N}$ & Mean & St.Dev. & Min & Max \\
\hline Year & 22984.00 & 2008.00 & 0.00 & 2008.00 & 2008.00 \\
\hline Republican Two Party Vote Share & 22984.00 & 52.24 & 17.49 & 0.35 & 94.05 \\
\hline Has FNC & 22584.00 & 0.94 & 0.24 & 0.00 & 1.00 \\
\hline Has MSNBC & 22584.00 & 0.85 & 0.36 & 0.00 & 1.00 \\
\hline FNC Position & 22584.00 & 39.08 & 16.93 & 0.00 & 140.00 \\
\hline CNN Position & 22584.00 & 30.28 & 13.69 & 0.00 & 123.00 \\
\hline MSNBC Position & 22584.00 & 38.99 & 24.57 & 0.00 & 164.00 \\
\hline Number Channels & 22584.00 & 161.58 & 51.48 & 8.00 & 249.00 \\
\hline Number Broadcast Channels & 22584.00 & 13.55 & 8.40 & 2.00 & 45.00 \\
\hline Nielsen Diary Market & 22984.00 & 0.48 & 0.50 & 0.00 & 1.00 \\
\hline FNC Minutes & 17742.00 & 49.39 & 97.04 & 0.00 & 4233.60 \\
\hline CNN Minutes & 17374.00 & 31.60 & 62.55 & 0.00 & 2046.24 \\
\hline MSNBC Minutes & 17374.00 & 16.30 & 46.13 & 0.00 & 1673.28 \\
\hline FNC Minutes (Cable) & 15616.00 & 58.94 & 137.80 & 0.00 & 4233.60 \\
\hline CNN Minutes (Cable) & 15277.00 & 41.86 & 103.93 & 0.00 & 3487.68 \\
\hline MSNBC Minutes (Cable) & 15277.00 & 22.20 & 72.49 & 0.00 & 3276.00 \\
\hline FNC Minutes (Satellite) & 14947.00 & 56.03 & 143.19 & 0.00 & 4163.04 \\
\hline CNN Minutes (Satellite) & 14598.00 & 34.22 & 96.40 & 0.00 & 4082.40 \\
\hline MSNBC Minutes (Satellite) & 14598.00 & 14.00 & 59.80 & 0.00 & 1703.52 \\
\hline Population & 22984.00 & 12828.07 & 14841.96 & 0.00 & 113916.00 \\
\hline Pct Black & 22979.00 & 0.09 & 0.16 & 0.00 & 0.98 \\
\hline Pct Asian & 22979.00 & 0.02 & 0.05 & 0.00 & 0.72 \\
\hline Pct Other & 22979.00 & 0.07 & 0.09 & 0.00 & 1.00 \\
\hline Pct Hispanic & 22979.00 & 0.09 & 0.15 & 0.00 & 1.00 \\
\hline Pct Male & 22979.00 & 0.50 & 0.03 & 0.10 & 1.00 \\
\hline Pct Age $10-20$ & 22979.00 & 0.15 & 0.04 & 0.00 & 0.88 \\
\hline Pct Age $20-30$ & 22979.00 & 0.12 & 0.06 & 0.00 & 0.89 \\
\hline Pct Age $30-40$ & 22979.00 & 0.12 & 0.03 & 0.00 & 0.42 \\
\hline Pct Age $40-50$ & 22979.00 & 0.14 & 0.02 & 0.00 & 0.33 \\
\hline Pct Age 50-60 & 22979.00 & 0.15 & 0.03 & 0.00 & 0.50 \\
\hline Pct Age $60-70$ & 22979.00 & 0.11 & 0.03 & 0.00 & 0.50 \\
\hline Pct Age $70-80$ & 22979.00 & 0.06 & 0.03 & 0.00 & 0.34 \\
\hline Pct Age $80+$ & 22979.00 & 0.04 & 0.02 & 0.00 & 0.61 \\
\hline Median HH Income & 22909.00 & 53204.33 & 22090.18 & 2499.00 & 250001.00 \\
\hline Pct HS Graduate & 22964.00 & 0.34 & 0.11 & 0.00 & 1.00 \\
\hline Pct Some College & 22964.00 & 0.29 & 0.07 & 0.00 & 1.00 \\
\hline Pct Bachelors Degree & 22964.00 & 0.15 & 0.09 & 0.00 & 1.00 \\
\hline Pct Post Graduate Degree & 22964.00 & 0.08 & 0.08 & 0.00 & 1.00 \\
\hline Pct Own Home & 22953.00 & 0.73 & 0.16 & 0.00 & 1.00 \\
\hline Median Home Value & 22815.00 & 187870.02 & 155380.38 & 9999.00 & 1000001.00 \\
\hline Aggregate Tax Rate & 22590.00 & 0.01 & 0.01 & 0.00 & 0.04 \\
\hline Median Number of Rooms & 22911.00 & 5.70 & 0.80 & 1.30 & 9.00 \\
\hline Pct Homes Built After 2005 & 22937.00 & 0.03 & 0.05 & 0.00 & 1.00 \\
\hline Pct Food Stamps & 22931.00 & 0.11 & 0.08 & 0.00 & 1.00 \\
\hline Median Social Security Income & 22843.00 & 16085.78 & 2479.94 & 275.00 & 46761.00 \\
\hline Pct Veteran & 22931.00 & 0.69 & 0.11 & 0.00 & 1.00 \\
\hline Pct Married & 22971.00 & 0.55 & 0.11 & 0.00 & 1.00 \\
\hline Pct Same Sex HH & 22953.00 & 0.00 & 0.00 & 0.00 & 0.12 \\
\hline Pct Unmarried HH & 22953.00 & 0.06 & 0.02 & 0.00 & 0.50 \\
\hline Pct Family HH & 22966.00 & 0.11 & 0.05 & 0.00 & 1.00 \\
\hline Fraction of 1996 Contributions to Republican & 17944.00 & 0.70 & 0.30 & 0.00 & 1.00 \\
\hline Pct Evangelical (County) & 22979.00 & 169.76 & 146.91 & 0.00 & 1113.76 \\
\hline Pct Catholic (County) & 22979.00 & 189.47 & 154.32 & 0.00 & 946.82 \\
\hline Pct Jewish (County) & 22979.00 & 11.81 & 26.76 & 0.00 & 313.86 \\
\hline Pct Mormon (County) & 22979.00 & 13.66 & 65.55 & 0.00 & 915.70 \\
\hline Pct Southern Baptist Convention (County) & 22979.00 & 84.30 & 126.84 & 0.00 & 961.39 \\
\hline Pct Suburban & 22955.00 & 0.10 & 0.24 & 0.00 & 1.00 \\
\hline Pct Urban & 22955.00 & 0.38 & 0.46 & 0.00 & 1.00 \\
\hline 1996 County Republican Vote Share & 22924.00 & 0.47 & 0.11 & 0.11 & 0.88 \\
\hline
\end{tabular}


Table A2: Summary Statistics for NAES/CCES Voting Survey

\begin{tabular}{|c|c|c|c|c|c|}
\hline Statistic & $\mathrm{N}$ & Mean & St. Dev. & Min & $\operatorname{Max}$ \\
\hline Year & 135574 & 2003.79 & 3.20 & 2000 & 2008 \\
\hline Has FNC & 135574 & 0.88 & 0.32 & 0 & 1 \\
\hline Has MSNBC & 135574 & 0.87 & 0.34 & 0 & 1 \\
\hline FNC Position & 135574 & 37.84 & 18.99 & 0 & 125 \\
\hline CNN Position & 135574 & 29.75 & 12.95 & 0 & 123 \\
\hline MSNBC Position & 135574 & 39.54 & 21.61 & 0 & 164 \\
\hline Number Channels & 135574 & 141.02 & 51.55 & 1 & 249 \\
\hline Number Broadcast Channels & 135574 & 14.03 & 7.48 & 2 & 45 \\
\hline Intent to vote Republican & 135574 & 0.50 & 0.50 & 0 & 1 \\
\hline Age & 134608 & 48.21 & 16.42 & 18 & 99 \\
\hline White & 135574 & 0.84 & 0.37 & 0 & 1 \\
\hline Black & 135574 & 0.08 & 0.27 & 0 & 1 \\
\hline Hispanic & 135574 & 0.07 & 0.25 & 0 & 1 \\
\hline Bachelors & 135574 & 0.36 & 0.48 & 0 & 1 \\
\hline HH Income & 123679 & 0.66 & 0.52 & 0.07 & 2.17 \\
\hline Male & 135574 & 0.45 & 0.50 & 0 & 1 \\
\hline Most Watched FNC & 48695 & 0.30 & 0.46 & 0 & 1 \\
\hline Most Watched CNN & 48695 & 0.38 & 0.49 & 0 & 1 \\
\hline Most Watched MSNBC & 48695 & 0.10 & 0.30 & 0 & 1 \\
\hline Population & 135386 & 28864.83 & 18292.89 & 1 & 113916 \\
\hline Pct Black & 135386 & 0.11 & 0.17 & 0.00 & 1.00 \\
\hline Pct Asian & 135386 & 0.04 & 0.06 & 0.00 & 0.72 \\
\hline Pct Other & 135386 & 0.09 & 0.09 & 0.00 & 0.98 \\
\hline Pct Hispanic & 135386 & 0.13 & 0.17 & 0.00 & 0.99 \\
\hline Pct Male & 135386 & 0.49 & 0.02 & 0.28 & 1.00 \\
\hline Pct Age 10-20 & 135386 & 0.14 & 0.03 & 0.00 & 0.95 \\
\hline Pct Age 20-30 & 135386 & 0.14 & 0.06 & 0.00 & 0.93 \\
\hline Pct Age $30-40$ & 135386 & 0.13 & 0.03 & 0.00 & 0.35 \\
\hline Pct Age $40-50$ & 135386 & 0.14 & 0.02 & 0.00 & 0.30 \\
\hline Pct Age 50-60 & 135386 & 0.14 & 0.02 & 0.00 & 0.29 \\
\hline Pct Age $60-70$ & 135386 & 0.10 & 0.03 & 0.00 & 1.00 \\
\hline Pct Age $70-80$ & 135386 & 0.06 & 0.02 & 0.00 & 0.34 \\
\hline Pct Age $80+$ & 135386 & 0.04 & 0.02 & 0.00 & 0.33 \\
\hline Median HH Income & 135359 & 56307.44 & 21572.15 & 2499 & 240441 \\
\hline Pct HS Graduate & 135382 & 0.29 & 0.10 & 0.00 & 1.00 \\
\hline Pct Some College & 135382 & 0.29 & 0.06 & 0.00 & 1.00 \\
\hline Pct Bachelors Degree & 135382 & 0.18 & 0.09 & 0.00 & 1.00 \\
\hline Pct Post Graduate Degree & 135382 & 0.11 & 0.08 & 0.00 & 1.00 \\
\hline Pct Own Home & 135377 & 0.67 & 0.16 & 0.00 & 1.00 \\
\hline Median Home Value & 135273 & 230027.60 & 166599.70 & 9999 & 1000001 \\
\hline Aggregate Tax Rate & 135159 & 0.01 & 0.01 & 0.0001 & 0.04 \\
\hline Median Number of Rooms & 135357 & 5.60 & 0.82 & 1.40 & 9.00 \\
\hline Pct Homes Built After 2005 & 135363 & 0.01 & 0.01 & 0.001 & 0.88 \\
\hline Pct Food Stamps & 135363 & 0.11 & 0.07 & 0.00 & 0.72 \\
\hline Median Social Security Income & 135324 & 16279.69 & 2071.40 & 610 & 31735 \\
\hline Pct Veteran & 135363 & 0.66 & 0.11 & 0.00 & 1.00 \\
\hline Pct Married & 135383 & 0.52 & 0.10 & 0.00 & 1.00 \\
\hline Pct Same Sex HH & 135377 & 0.005 & 0.004 & 0.00 & 0.12 \\
\hline Pct Unmarried HH & 135377 & 0.07 & 0.02 & 0.00 & 0.20 \\
\hline Pct Family HH & 135383 & 0.10 & 0.04 & 0.00 & 1.00 \\
\hline Fraction of 1996 Contributions to Republican & 128791 & 0.69 & 0.23 & 0.00 & 1.00 \\
\hline Pct Evangelical (County) & 135341 & 147.62 & 127.82 & 0.00 & 1113.76 \\
\hline Pct Catholic (County) & 135341 & 207.80 & 148.39 & 0.00 & 946.82 \\
\hline Pct Jewish (County) & 135341 & 18.76 & 32.10 & 0.00 & 313.86 \\
\hline Pct Mormon (County) & 135341 & 15.56 & 66.89 & 0.00 & 915.70 \\
\hline Pct Southern Baptist Convention (County) & 135341 & 72.79 & 108.71 & 0.00 & 961.39 \\
\hline Pct Suburban & 135377 & 0.11 & 0.25 & 0.00 & 1.00 \\
\hline Pct Urban & 135377 & 0.68 & 0.43 & 0.00 & 1.00 \\
\hline 1996 County Republican Vote Share & $1350 \rho \mathrm{A}$ & 0.46 & 0.11 & 0.11 & 0.88 \\
\hline
\end{tabular}

An observation is an individual. Zip Code demographic data comes from the US Census Bureau. Religious adherence data is from 2010 U.S. Religion Census: Religious Congregations and Membership Study (RCMS). 
Table A3: Summary Statistics for Nielsen Viewership Sample

\begin{tabular}{|c|c|c|c|c|c|}
\hline Statistic & $\mathrm{N}$ & Mean & St. Dev. & Min & $\operatorname{Max}$ \\
\hline Year & 71177 & 2006.50 & 1.12 & 2005 & 2008 \\
\hline Has FNC & 71177 & 0.94 & 0.23 & 0 & 1 \\
\hline Has MSNBC & 71177 & 0.86 & 0.35 & 0 & 1 \\
\hline FNC Position & 71177 & 39.89 & 16.69 & 0 & 140 \\
\hline CNN Position & 71177 & 29.94 & 13.23 & 0 & 123 \\
\hline MSNBC Position & 71177 & 38.84 & 21.65 & 0 & 164 \\
\hline Number Channels & 71177 & 157.03 & 46.62 & 7 & 249 \\
\hline Number Broadcast Channels & 71177 & 12.50 & 7.76 & 2 & 45 \\
\hline Nielsen Sample Size & 71177 & 57.05 & 73.58 & 0.50 & 1028.00 \\
\hline Nielsen Cable Sample Size & 71071 & 34.69 & 53.75 & 0.00 & 948.00 \\
\hline Nielsen Satellite Sample Size & 71072 & 15.30 & 19.11 & 0.00 & 371.00 \\
\hline Nielsen Diary Market & 71177 & 0.51 & 0.50 & 0 & 1 \\
\hline FNC Minutes & 71150 & 43.27 & 84.14 & 0.00 & 4233.60 \\
\hline CNN Minutes & 69731 & 24.23 & 50.92 & 0.00 & 2388.96 \\
\hline MSNBC Minutes & 69731 & 10.06 & 34.51 & 0.00 & 2076.48 \\
\hline FNC Minutes (Cable) & 64894 & 51.03 & 124.35 & 0.00 & 7388.64 \\
\hline CNN Minutes (Cable) & 63602 & 32.48 & 85.81 & 0.00 & 4122.72 \\
\hline MSNBC Minutes (Cable) & 63602 & 13.01 & 48.14 & 0.00 & 3276.00 \\
\hline FNC Minutes (Satellite) & 62178 & 48.81 & 133.41 & 0.00 & 7953.12 \\
\hline CNN Minutes (Satellite) & 60840 & 24.13 & 72.40 & 0.00 & 4082.40 \\
\hline MSNBC Minutes (Satellite) & 60840 & 8.66 & 43.94 & 0.00 & 3185.28 \\
\hline Population & 71137 & 15485.43 & 15591.85 & 6 & 113916 \\
\hline Pct Black & 71137 & 0.10 & 0.17 & 0.00 & 0.98 \\
\hline Pct Asian & 71137 & 0.03 & 0.06 & 0.00 & 0.72 \\
\hline Pct Other & 71137 & 0.07 & 0.09 & 0.00 & 0.98 \\
\hline Pct Hispanic & 71137 & 0.10 & 0.16 & 0.00 & 0.99 \\
\hline Pct Male & 71137 & 0.50 & 0.03 & 0.34 & 0.84 \\
\hline Pct Age $10-20$ & 71137 & 0.15 & 0.03 & 0.00 & 0.60 \\
\hline Pct Age $20-30$ & 71137 & 0.12 & 0.05 & 0.00 & 0.66 \\
\hline Pct Age 30-40 & 71137 & 0.12 & 0.03 & 0.004 & 0.30 \\
\hline Pct Age 40-50 & 71137 & 0.14 & 0.02 & 0.00 & 0.29 \\
\hline Pct Age $50-60$ & 71137 & 0.15 & 0.03 & 0.001 & 0.32 \\
\hline Pct Age $60-70$ & 71137 & 0.11 & 0.03 & 0.00 & 0.50 \\
\hline Pct Age $70-80$ & 71137 & 0.06 & 0.02 & 0.00 & 0.34 \\
\hline Pct Age $80+$ & 71137 & 0.04 & 0.02 & 0.00 & 0.31 \\
\hline Median HH Income & 71129 & 52689.98 & 20622.01 & 2499 & 228726 \\
\hline Pct HS Graduate & 71136 & 0.33 & 0.10 & 0.00 & 1.00 \\
\hline Pct Some College & 71136 & 0.29 & 0.07 & 0.00 & 1.00 \\
\hline Pct Bachelors Degree & 71136 & 0.15 & 0.09 & 0.00 & 0.61 \\
\hline Pct Post Graduate Degree & 71136 & 0.09 & 0.07 & 0.00 & 0.92 \\
\hline Pct Own Home & 71136 & 0.72 & 0.15 & 0.003 & 1.00 \\
\hline Median Home Value & 71002 & 187049.60 & 145519.30 & 9999 & 1000001 \\
\hline Aggregate Tax Rate & 70780 & 0.01 & 0.01 & 0.0001 & 0.04 \\
\hline Median Number of Rooms & 71132 & 5.66 & 0.77 & 1.50 & 9.00 \\
\hline Pct Homes Built After 2005 & 71135 & 0.02 & 0.02 & 0.001 & 0.62 \\
\hline Pct Food Stamps & 71135 & 0.11 & 0.08 & 0.00 & 0.78 \\
\hline Median Social Security Income & 71057 & 16050.84 & 2249.87 & 610 & 30336 \\
\hline Pct Veteran & 71135 & 0.68 & 0.10 & 0.00 & 1.00 \\
\hline Pct Married & 71136 & 0.55 & 0.10 & 0.00 & 1.00 \\
\hline Pct Same Sex HH & 71136 & 0.004 & 0.003 & 0.00 & 0.11 \\
\hline Pct Unmarried HH & 71136 & 0.06 & 0.02 & 0.00 & 0.20 \\
\hline Pct Family HH & 71136 & 0.11 & 0.04 & 0.00 & 0.55 \\
\hline Fraction of 1996 Contributions to Republican & 59864 & 0.71 & 0.28 & 0.00 & 1.00 \\
\hline Pct Evangelical (County) & 71167 & 170.35 & 144.60 & 0.00 & 978.98 \\
\hline Pct Catholic (County) & 71167 & 185.96 & 150.07 & 0.00 & 946.82 \\
\hline Pct Jewish (County) & 71167 & 11.50 & 24.97 & 0.00 & 313.86 \\
\hline Pct Mormon (County) & 71167 & 13.40 & 60.77 & 0.00 & 915.70 \\
\hline Pct Southern Baptist Convention (County) & 71167 & 85.79 & 126.23 & 0.00 & 852.45 \\
\hline Pct Suburban & 71136 & 0.12 & 0.25 & 0.00 & 1.00 \\
\hline Pct Urban & 71136 & 0.43 & 0.47 & 0.00 & 1.00 \\
\hline 1996 County Republican Vote Share & 71019 & 0.47 & 0.11 & 0.11 & 0.85 \\
\hline
\end{tabular}

An observation is a zip code-year. Demographic data comes from the US Census Bureau. Religious adherence data is from 2010 U.S. Religion Census: Religious Congregations and Membership Study (RCMS). 
Table A4: Summary Statistics for Mediamark/Simmons Viewership Survey

\begin{tabular}{|c|c|c|c|c|c|}
\hline Statistic & $\mathrm{N}$ & Mean & St. Dev. & Min & Max \\
\hline Year & 207950 & 2003.72 & 2.47 & 2000 & 2008 \\
\hline Has FNC & 207950 & 0.94 & 0.24 & 0 & 1 \\
\hline Has MSNBC & 207950 & 0.93 & 0.25 & 0 & 1 \\
\hline FNC Position & 207950 & 40.79 & 17.29 & 0 & 140 \\
\hline CNN Position & 207950 & 31.34 & 13.32 & 0 & 109 \\
\hline MSNBC Position & 207950 & 42.48 & 18.56 & 0 & 164 \\
\hline Number Channels & 207950 & 153.14 & 42.38 & 14 & 249 \\
\hline Number Broadcast Channels & 207950 & 16.61 & 7.32 & 2 & 45 \\
\hline Age & 207950 & 46.31 & 15.75 & 21 & 70 \\
\hline White & 207950 & 0.81 & 0.39 & 0 & 1 \\
\hline Black & 207950 & 0.10 & 0.31 & 0 & 1 \\
\hline Hispanic & 207950 & 0.11 & 0.31 & 0 & 1 \\
\hline Bachelors & 207950 & 0.32 & 0.47 & 0 & 1 \\
\hline HH Income & 207860 & 0.74 & 0.63 & 0.04 & 6.33 \\
\hline Male & 207950 & 0.51 & 0.50 & 0 & 1 \\
\hline FNC Minutes & 207950 & 61.52 & 162.22 & 0.00 & 1500.00 \\
\hline CNN Minutes & 207950 & 71.21 & 163.34 & 0.00 & 1500.00 \\
\hline MSNBC Minutes & 207950 & 30.59 & 97.87 & 0.00 & 1500.00 \\
\hline Cable Subscriber & 207950 & 0.65 & 0.48 & 0 & 1 \\
\hline Satellite Subscriber & 207950 & 0.18 & 0.38 & 0 & 1 \\
\hline Population & 207630 & 31101.55 & 18279.02 & 0 & 113916 \\
\hline Pct Black & 207628 & 0.12 & 0.18 & 0.00 & 1.00 \\
\hline Pct Asian & 207628 & 0.06 & 0.08 & 0.00 & 0.72 \\
\hline Pct Other & 207628 & 0.09 & 0.09 & 0.00 & 1.00 \\
\hline Pct Hispanic & 207628 & 0.15 & 0.18 & 0.00 & 0.98 \\
\hline Pct Male & 207628 & 0.49 & 0.02 & 0.37 & 1.00 \\
\hline Pct Age 10-20 & 207628 & 0.15 & 0.03 & 0.00 & 0.47 \\
\hline Pct Age $20-30$ & 207628 & 0.13 & 0.05 & 0.00 & 0.66 \\
\hline Pct Age $30-40$ & 207628 & 0.13 & 0.03 & 0.00 & 0.35 \\
\hline Pct Age $40-50$ & 207628 & 0.15 & 0.02 & 0.00 & 0.24 \\
\hline Pct Age $50-60$ & 207628 & 0.14 & 0.02 & 0.00 & 0.26 \\
\hline Pct Age $60-70$ & 207628 & 0.10 & 0.03 & 0.001 & 1.00 \\
\hline Pct Age $70-80$ & 207628 & 0.05 & 0.02 & 0.00 & 0.34 \\
\hline Pct Age $80+$ & 207628 & 0.04 & 0.02 & 0.00 & 0.35 \\
\hline Median HH Income & 207614 & 65344.72 & 25327.25 & 9100 & 228726 \\
\hline Pct HS Graduate & 207614 & 0.26 & 0.10 & 0.00 & 0.90 \\
\hline Pct Some College & 207614 & 0.28 & 0.06 & 0.00 & 0.60 \\
\hline Pct Bachelors Degree & 207614 & 0.21 & 0.09 & 0.00 & 0.54 \\
\hline Pct Post Graduate Degree & 207614 & 0.13 & 0.09 & 0.00 & 0.63 \\
\hline Pct Own Home & 207627 & 0.69 & 0.17 & 0.00 & 0.99 \\
\hline Median Home Value & 207562 & 288273.00 & 193230.30 & 9999 & 1000001 \\
\hline Aggregate Tax Rate & 207426 & 0.01 & 0.01 & 0.0002 & 0.03 \\
\hline Median Number of Rooms & 207612 & 5.75 & 0.97 & 1.50 & 9.00 \\
\hline Pct Homes Built After 2005 & 207620 & 0.01 & 0.01 & 0.001 & 0.75 \\
\hline Pct Food Stamps & 207614 & 0.09 & 0.07 & 0.00 & 0.78 \\
\hline Median Social Security Income & 207552 & 16695.29 & 2219.52 & 7122 & 37418 \\
\hline Pct Veteran & 207614 & 0.68 & 0.11 & 0.00 & 1.00 \\
\hline Pct Married & 207614 & 0.53 & 0.10 & 0.00 & 0.88 \\
\hline Pct Same Sex HH & 207627 & 0.01 & 0.004 & 0.00 & 0.11 \\
\hline Pct Unmarried HH & 207627 & 0.06 & 0.02 & 0.00 & 0.20 \\
\hline Pct Family HH & 207614 & 0.09 & 0.04 & 0.00 & 0.33 \\
\hline Fraction of 1996 Contributions to Republican & 198700 & 0.68 & 0.23 & 0.00 & 1.00 \\
\hline Pct Evangelical (County) & 207745 & 118.08 & 108.77 & 0.00 & 809.59 \\
\hline Pct Catholic (County) & 207745 & 249.19 & 146.38 & 0.00 & 946.82 \\
\hline Pct Jewish (County) & 207745 & 28.12 & 37.96 & 0.00 & 313.86 \\
\hline Pct Mormon (County) & 207745 & 13.06 & 57.96 & 0.00 & 915.70 \\
\hline Pct Southern Baptist Convention (County) & 207745 & 54.61 & 90.84 & 0.00 & 736.46 \\
\hline Pct Suburban & 207627 & 0.05 & 0.18 & 0.00 & 1.00 \\
\hline Pct Urban & 207627 & 0.82 & 0.34 & 0.00 & 1.00 \\
\hline 1996 County Republican Vote Share & 207053 & 0.45 & 0.12 & 0.11 & 0.82 \\
\hline
\end{tabular}

An observation is an individual. Zip Code demographic data comes from the US Census Bureau. Religious adherence data is from 2010 U.S. Religion Census: Religious Congregations and Membership Study (RCMS). 


\section{Update of DellaVigna and Kaplan (2007)}

DellaVigna and Kaplan (2007) (henceforth DVK) compare changes in presidential vote shares in towns which had access to the Fox News Channel by the year 2000 compared to towns that did not conditional on a rich set of co-variates. In this section, we update the estimates from DVK using Nielsen data on availability of Fox News.

\section{C.1 Data Sources}

The data source in DVK is the Warren's Cable and Television Factbook (henceforth Factbook). The Factbook updates only a minority of cable systems every year. The extent of non-updating has been documented by Crawford and Yurukoglu (2012). We reproduce the relevant years from their Appendix table below in Table A5. Updating is especially poor around DVK sample year. Between 1999 and 2000, only 22\% of observations were updated. Between 1998 and 1999, only $37 \%$ of observations were updated. Since Fox News was expanding across the country rapidly during these years, this infrequent updating is consequential: many towns in the Factbook were listed as not having cable access to Fox News, when in fact they did but the Factbook simply wasn’t updated yet. Nearly all systems in the Nielsen FOCUS data are updated every year.

To audit the Factbook data against the Nielsen FOCUS data, we consulted a third data source: cable conversion charts that appeared in weekly TV Week additions of local newspapers. These tables listed channel numbers for local cable systems. Figure C.1 provides an example capture from the microfilms of such a chart. To conduct the audit, we sorted the set of communities where FOCUS and Factbook disagreed on Fox News availability in 2000 by population size. We tried to find cable conversion charts for the largest two hundred communities. We were able to readily find conversion charts which reference the community name in the system name and provide information on Fox News Channel for 45 communities. ${ }^{35}$ For these 45 communities, the Nielsen FOCUS data was correct on 42 (93.33\%) whereas the Factbook was correct on 3. Second, we investigated the systems with a particular large discrepancy: those where Nielsen FOCUS indicated had Fox News availability in 1998 while the Factbook

\footnotetext{
${ }^{35}$ The exact requirement is that the newspaper explicitly names the community in question. For example, we did not match Greenwich, CT to Cablevision Southern Connecticut as the newspaper did not explicitly mention that Greenwich was covered by this system. Furthermore, some conversion grids did not list all channels. For example, the Boston Globe only provided numbers for 31 basic cable channels, omitting Fox News, even though it had listings for 50 systems. The microfilm scans and spreadsheet with details on the audit are available on request from the authors.
} 
Table A5: Data Quality of Factbook

\begin{tabular}{rrrr}
\hline Year & Variable & Number of Bundles & Fraction of Bundles \\
\hline \hline 1998 & Total bundles & 15,743 & $100.0 \%$ \\
& Full information & 10,872 & $69.0 \%$ \\
& Updated & 4,714 & $30.0 \%$ \\
& Full information and updated & 3,461 & $22.0 \%$ \\
\hline \multirow{2}{*}{1999} & Total bundles & 15,497 & $100.0 \%$ \\
& Full information & 10,444 & $67.0 \%$ \\
& Updated & 5,663 & $37.0 \%$ \\
& Full information and updated & 3,595 & $23.0 \%$ \\
\hline \multirow{2}{*}{2000} & Total bundles & 15,453 & $100.0 \%$ \\
& Full information & 10,312 & $67.0 \%$ \\
& Updated & 3,358 & $22.0 \%$ \\
& Full information and updated & 2,478 & $16.0 \%$ \\
\hline \multirow{2}{*}{001} & Total bundles & 15,391 & $100.0 \%$ \\
& Full information & 9,793 & $64.0 \%$ \\
& Updated & 4,173 & $27.0 \%$ \\
& Full information and updated & 2,663 & $17.0 \%$ \\
\hline \multirow{2}{*}{002} & Total bundles & 15,287 & $100.0 \%$ \\
& Full information & 7,776 & $51.0 \%$ \\
& Updated & 5,086 & $33.0 \%$ \\
& Full information and updated & 1,484 & $10.0 \%$ \\
\hline Total bundles & 166,619 & $100.0 \%$ \\
$1997-2007$ & Full information & 91,100 & $55.0 \%$ \\
& Updated & 62,299 & $37.0 \%$ \\
& Full information and updated & 31,493 & $19.0 \%$ \\
\hline
\end{tabular}

Notes: This table is a reproduction from Crawford and Yurukoglu (2012) indicating the degree of non-updating in Factbook data. 
indicated no availability by 2000. 353 of these systems were operated by Tele-Communcations Inc. (TCI) in 1998. Press reports from the time period indicate that Fox News would be available to over $90 \%$ of TCI customers by 1998 (Colman (1996)).

Finally, the number of subscribers for Fox News implied by the Factbook data conflict with the amount of viewership Fox News had in 2000, including the viewership data used in DVK. According to DVK, "About half of the Fox News audience, therefore, watches Fox News in ways other than via cable, possibly via satellite. This finding could also be due to measurement error in our measure of availability via cable." According to their data, 17\% of households were watching Fox News in 2000. Therefore, $8.5 \%$ of all households must have been simultaneously satellite subscribers and watching Fox News. However, the market share of satellite in the year 2000 was $11.4 \%^{36}$ Therefore, a vast majority of satellite subscribers must have been watching Fox News in 2000 to be consistent with the Factbook availability measures. Our Mediamark data indicate that the fraction of satellite subscribers watching Fox News in 2000 is only $19 \%$. $^{37}$

To correct this issue, we matched the voting and demographic data in DVK to Nielsen FOCUS. The identification numbers in the Factbook and Nielsen FOCUS do not match. We employed a matching procedure based on community names and firm names, using manual inspection when matches weren't obvious. We were able to reliably match 8,013 observations out of 9,256 to Nielsen FOCUS. Tables A6 and A7 compare the availability of Fox News according to the two data sources.

\begin{tabular}{lrccc}
\hline \hline & \multicolumn{4}{c}{ Factbook Fox News } \\
& & 0 & 1 & Total \\
Nielsen Fox News & 0 & 3,527 & 51 & 3,578 \\
(Year 2000) & 1 & 3,076 & 1,520 & 4,435 \\
& Total & 6,478 & 1,535 & 8,013 \\
\hline \hline
\end{tabular}

Table A6: Year 2000: Nielsen Fox News Availability and Factbook non-updated Fox News Availability.

About 40 percent of the control group in DVK is mis-classified as not having cable access to Fox News. About 25 percent already had access in 1998 and hadn't been updated for at

\footnotetext{
${ }^{36}$ The cable market share was $70.2 \%$ implying a $81.6 \%$ total market share. Thus, about $14 \%$ of cable or satellite subscribers were satellite subscribers.

${ }^{37}$ Their viewership data and our Mediamark data agree on the aggregate $17 \%$ number. Our Mediamark data indicate the conditional probability of watching Fox News conditional on satellite is only marginally higher at $19 \%$.
} 


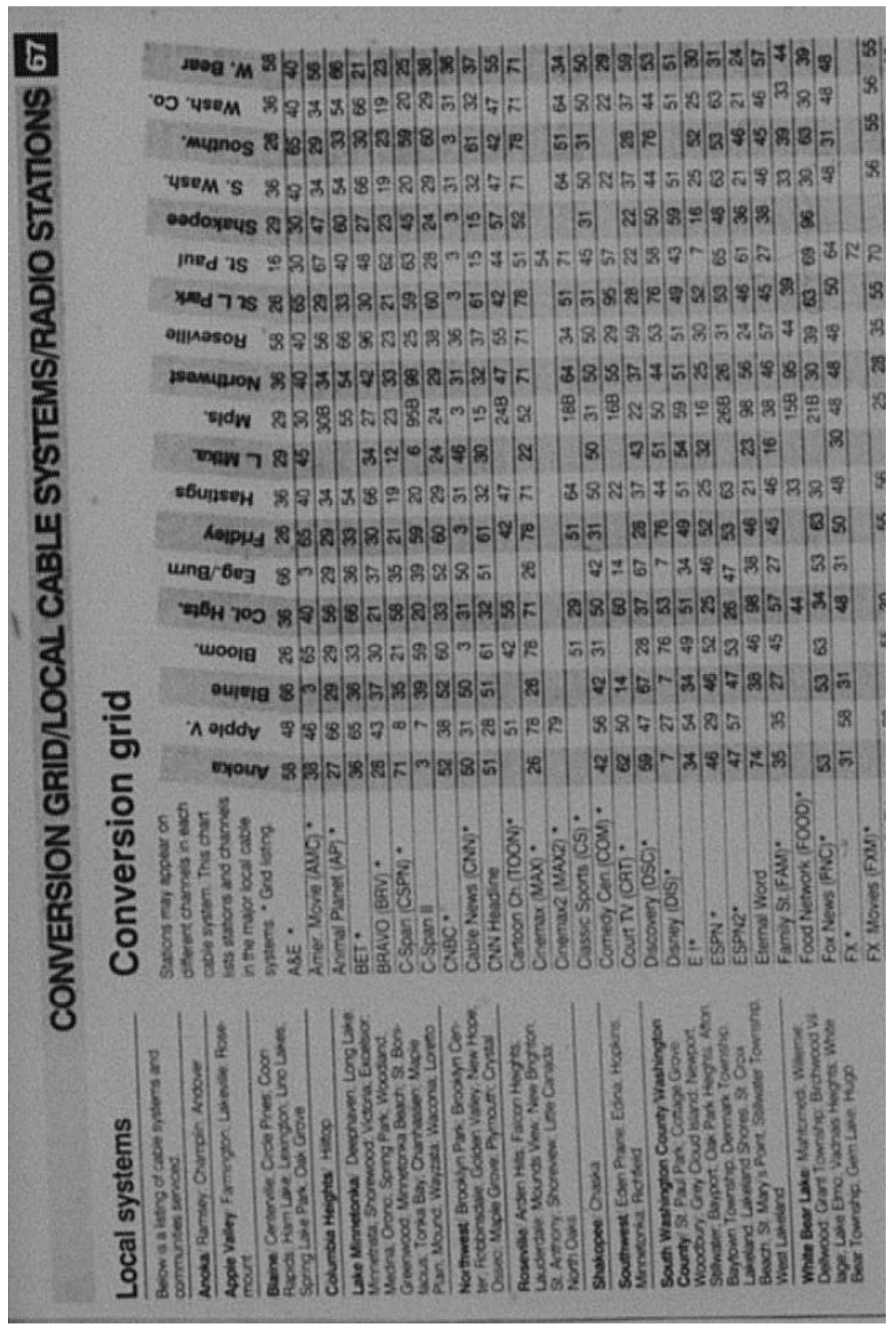

Figure A1: Cable conversion chart from Minneapolis Star-Tribune in October 2000. The rows correspond to cable channels. The columns correspond to local cable systems. According to the Factbook data used in DVK, Minneapolis did not have access to the Fox News Channel by November 2000. The Nielsen FOCUS data indicate that Minneapolis did have access to Fox News Channel in 1999, and also correctly indicates the channel number of $21 \mathrm{~B}$. 


\begin{tabular}{lrccc}
\hline \hline & \multicolumn{4}{c}{ Factbook Fox News } \\
& & 0 & 1 & Total \\
Nielsen Fox News & 0 & 4,687 & 355 & 5,042 \\
(Year 1998) & 1 & 1,791 & 1,180 & 2,971 \\
& Total & 6,478 & 1,535 & 8,013 \\
\hline \hline
\end{tabular}

Table A7: Nielsen Fox News Availability in 1998 and Factbook non-updated Fox News Availability in 2000 .

least two years in the Factbook.

\section{C.2 Estimates with Nielsen Data}

We now re-run the two benchmark specifications from DVK: the county level fixed effects regression and the US House district level fixed effects regression. These correspond to equation (2) in DVK. Table A8 compares the resulting estimates.

The estimate in the county level fixed effects regression drops from a statistically significant at 1\% 0.00694 (Column 7) to a significant at 10\% 0.00256 (Column 9). The difference cannot be attributed to not matching all of DVK's observations. Their estimated effect is stronger when using their Fox variable, but only on the subset of matching observations (Column 8). The estimate in the Congressional district fixed effects regression remains stable with the Nielsen data. The change in results could possibly reflect that availability in the Factbook indicates a longer period of availability and the effects of exposure accumulate over time, however the Nielsen availability data only goes back to 1998 so we can not empirically test this explanation.

We now update the placebo result regarding Fox News availability in 2000. Table A9 compares the placebo regression estimates using the original data and the Nielsen data. Using the more correct data in the district fixed effect specification, the placebo regression's estimate for the effect of Fox News availability in 2000 on the change in vote shares from 1992 to 1996 is 0.0028 , nearly the same as the estimate for the change in 1996 to 2000, compared to 0.00386 using the Factbook data. The coefficient's precision can not rule out a zero effect. The confidence interval for the Fox News availability in 2000 has shifted from $(-0.0085,0.0038)$ to $(-0.0014,0.0070)$.

For the district fixed effects specification, when examining the correlation of Fox News availability in 2000 with the level of Republican vote share in 1996, the point estimate changes from -0.0343 to 0.150 , though in both cases the estimates are noisy with standard errors of 


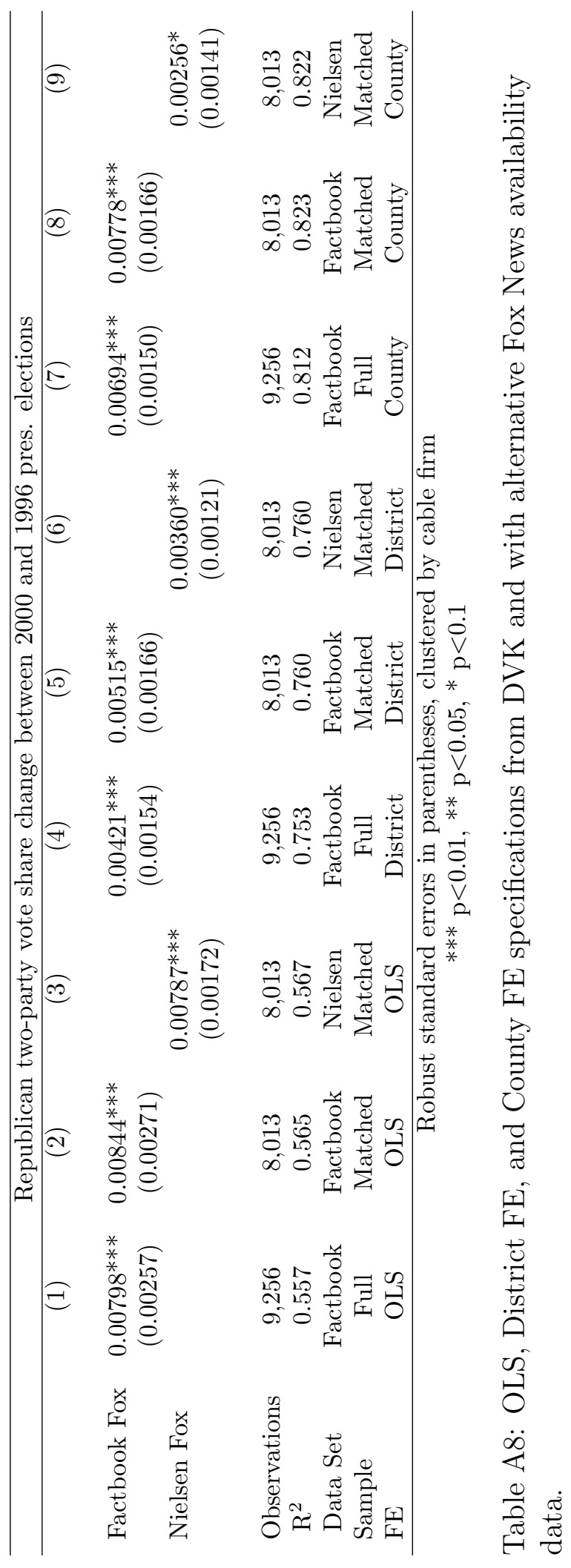


0.095 and 0.124 , respectively. The coefficient in the county fixed effects specification becomes slightly more negative, which is reassuring, though again the estimate is noisy.

To summarize, using the more correct Nielsen FOCUS data revises down the DVK estimates from a range of 0.4-0.7 to 0.3-0.4. The $99 \%$ confidence intervals in the placebo regression of the change in Republican vote share from 1992 to 1996 (before Fox News) on Fox News availability in 2000 include the point estimate for the effect of Fox News availability in 2000 on the change in Republican vote share from 1996 to 2000, in both the district and county fixed effects specifications. The evidence on balance could be interpreted that in studying the effects of Fox News, researchers should utilize the more accurate Nielsen data, and pay special attention to the source of variation identifying the estimates and weigh the costs and benefits of using availability in 2000 or channel positions as sources of variation in viewership of Fox News. Both sources of variation are attractive on different dimensions. 


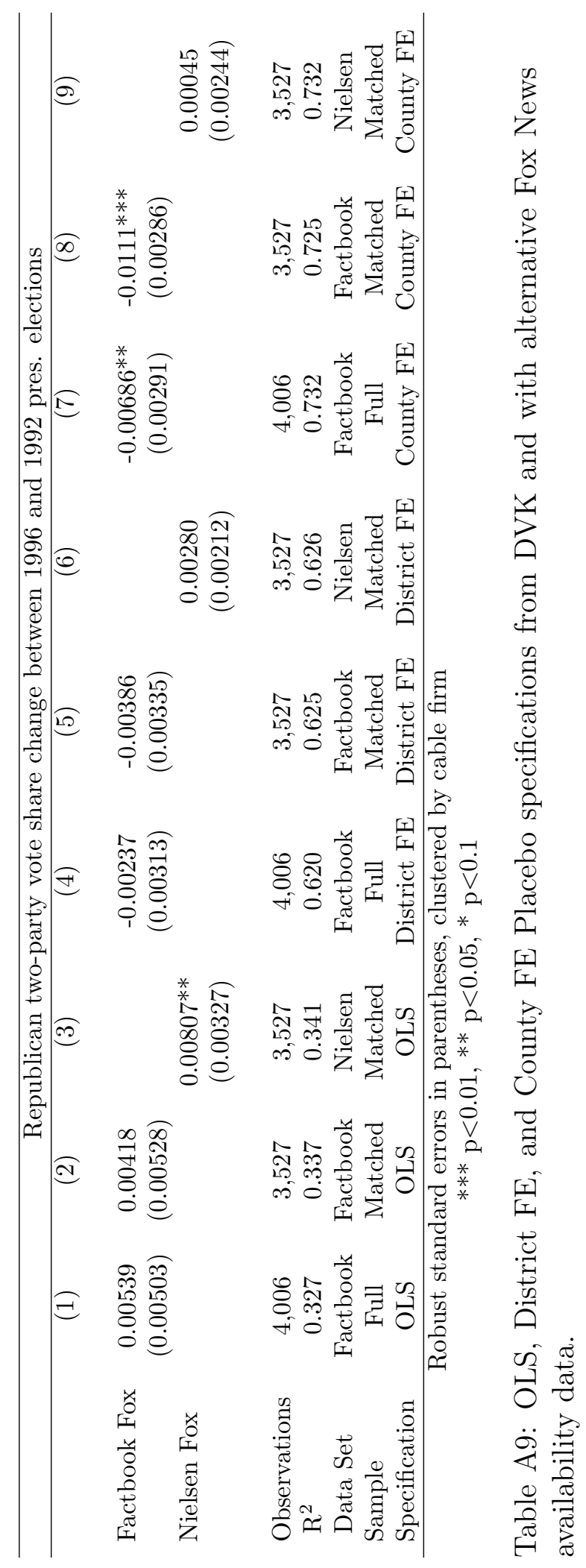




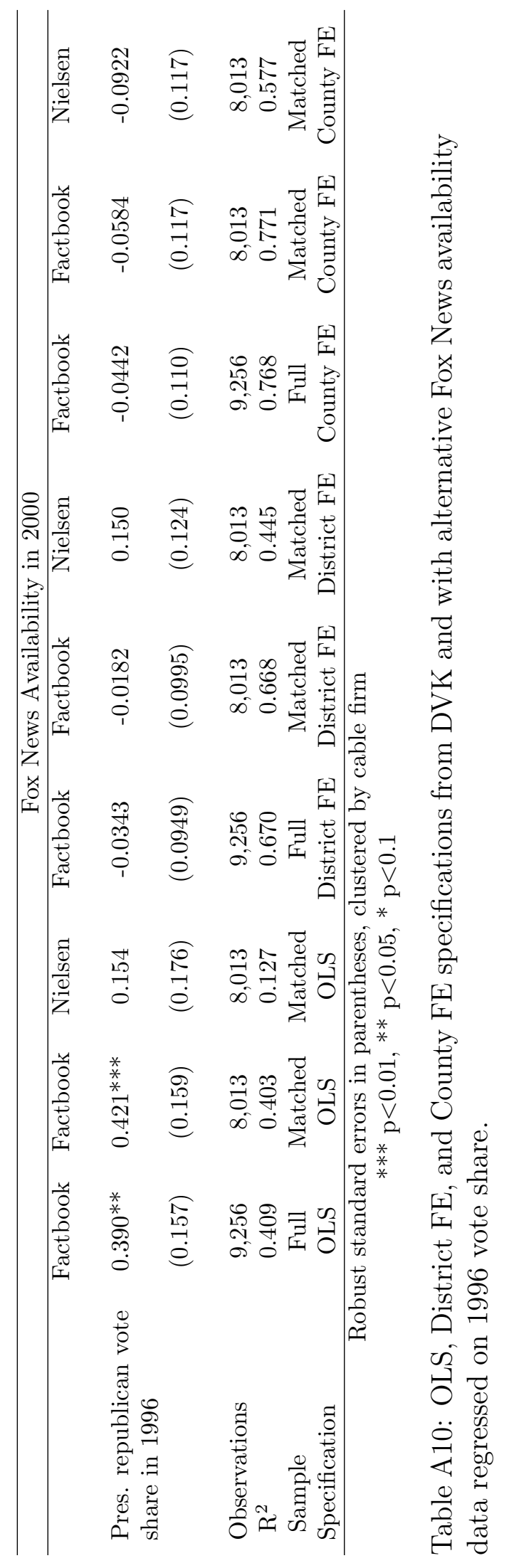




\section{IV-2SLS Results with Individual Level Data}

\section{D.1 First Stage}

Table A11 presents the analogous results using the individual-level data from MediaMark. In this version, we are able to include demographic characteristics measured at the individual level in addition to the full set of extensive zip level demographic measures. Estimating equations here take the form:

$$
h_{i z t}^{c}=\delta_{c t}+a_{z c t}+\alpha_{c}^{1} x_{z t}+\alpha_{c}^{2} x_{i t}+\zeta_{c, F N C} p_{z t}^{F N C}+\zeta_{c, M S N B C} p_{z t}^{M S N B C}+\epsilon_{i c t}^{H}
$$

Again, the FNC channel position correlates negatively with viewership, with very similar magnitude as in the independently sampled zip code level data. Unfortunately, because the individual level data span only about one-half as many clusters (cable systems) as the zip-code level data, the cluster-robust F statistics fall below ten in most cases, and the first stage coefficient on the instrument falls to zero when county-year fixed effects are included. The sample in Table A11 includes all respondents, including satellite subscribers and those who subscribe to neither wired cable nor satellite television. We use the pooled-sample first stage because the second stage data set lacks information on individuals' subscription choices. Section 4 presents a first stage estimated among cable subscribers alone; among cable subscribers, the individual-level position effect is precise and consistently negative.

In the individual level data, we can directly identify whether a respondent is a cable subscriber, a satellite subscriber, or neither. ${ }^{38}$ We therefore run the first stage individual-level regression restricted to only cable and satellite subscribers, and interact channel positions with an indicator for whether the viewer subscribes to satellite.

\section{D.2 Second Stage}

The individual-level regressions are directly analogous, with the exception that the outcome $y_{i z t}$ is now an indicator for whether individual $i$ states their intention to vote for the Republican presidential candidate in the election of year $t$ :

\footnotetext{
${ }^{38}$ Satellite subscribers make up about $18 \%$ of MediaMark respondents, and roughly $16 \%$ of MediaMark respondents report subscribing to neither cable nor satellite television service.
} 
Table A11: First Stage Regressions: Mediamark / Simmons Data

\begin{tabular}{|c|c|c|c|c|c|c|}
\hline & \multicolumn{6}{|c|}{ FNC Minutes per Week } \\
\hline & $(1)$ & $(2)$ & (3) & (4) & $(5)$ & (6) \\
\hline FNC Cable Position & $\begin{array}{l}-0.0833 \\
(0.0572)\end{array}$ & $\begin{array}{c}-0.0977^{*} \\
(0.0542)\end{array}$ & $\begin{array}{c}-0.1008^{* *} \\
(0.0504)\end{array}$ & $\begin{array}{c}-0.1068^{* *} \\
(0.0447)\end{array}$ & $\begin{array}{c}0.0124 \\
(0.0485)\end{array}$ & $\begin{array}{c}0.0302 \\
(0.0464)\end{array}$ \\
\hline MSNBC Cable Position & $\begin{array}{c}0.0522 \\
(0.0549)\end{array}$ & $\begin{array}{c}0.0480 \\
(0.0552)\end{array}$ & $\begin{array}{c}0.0270 \\
(0.0504)\end{array}$ & $\begin{array}{c}0.0628 \\
(0.0441)\end{array}$ & $\begin{array}{l}-0.0323 \\
(0.0511)\end{array}$ & $\begin{array}{l}-0.0115 \\
(0.0472)\end{array}$ \\
\hline HH Income & & & $\begin{array}{c}43.5512^{* * *} \\
(2.9913)\end{array}$ & $\begin{array}{c}39.6030^{* * * *} \\
(2.9649)\end{array}$ & $\begin{array}{c}40.4058^{* * *} \\
(3.0338)\end{array}$ & $\begin{array}{c}36.6810^{* * *} \\
(3.0511)\end{array}$ \\
\hline HH Income ${ }^{2}$ & & & $\begin{array}{c}-18.6924^{* * *} \\
(1.6098)\end{array}$ & $\begin{array}{c}-16.8152^{* * *} \\
(1.5933)\end{array}$ & $\begin{array}{c}-17.1702^{* * *} \\
(1.6538)\end{array}$ & $\begin{array}{c}-15.5555^{* * * *} \\
(1.6464)\end{array}$ \\
\hline HH Income ${ }^{3}$ & & & $\begin{array}{c}1.9785^{* * *} \\
(0.1945)\end{array}$ & $\begin{array}{c}1.7680^{* * *} \\
(0.1915)\end{array}$ & $\begin{array}{c}1.8209^{* * *} \\
(0.2004)\end{array}$ & $\begin{array}{c}1.6416^{* * *} \\
(0.1974)\end{array}$ \\
\hline Age Quintile 2 & & & $\begin{array}{c}10.9538^{* * *} \\
(0.9631)\end{array}$ & $\begin{array}{c}10.4238^{* * *} \\
(1.0032)\end{array}$ & $\begin{array}{c}10.6015^{* * *} \\
(0.9852)\end{array}$ & $\begin{array}{c}10.4606^{* * *} \\
(1.0104)\end{array}$ \\
\hline Age Quintile 3 & & & $\begin{array}{c}21.8585^{* * *} \\
(1.0367)\end{array}$ & $\begin{array}{c}21.0334^{* * *} \\
(1.0775)\end{array}$ & $\begin{array}{c}21.2143^{* * *} \\
(1.0734)\end{array}$ & $\begin{array}{c}20.8256^{* * *} \\
(1.1106)\end{array}$ \\
\hline Age Quintile 4 & & & $\begin{array}{c}31.5240^{* * *} \\
(1.1648)\end{array}$ & $\begin{array}{c}30.6014^{* * *} \\
(1.2012)\end{array}$ & $\begin{array}{c}30.9846^{* * *} \\
(1.2028)\end{array}$ & $\begin{array}{c}30.4839^{* * *} \\
(1.2334)\end{array}$ \\
\hline Age Quintile 5 & & & $\begin{array}{c}64.2801^{* * *} \\
(1.4777)\end{array}$ & $\begin{array}{c}62.4959^{* * *} \\
(1.4761)\end{array}$ & $\begin{array}{c}62.8403^{* * *} \\
(1.5076)\end{array}$ & $\begin{array}{c}61.4261^{* * *} \\
(1.5137)\end{array}$ \\
\hline White & & & $\begin{array}{c}11.2290^{* * *} \\
(1.1463)\end{array}$ & $\begin{array}{c}9.8168^{* * *} \\
(1.2379)\end{array}$ & $\begin{array}{c}11.1014^{* * *} \\
(1.1839)\end{array}$ & $\begin{array}{c}10.7936^{* * *} \\
(1.2764)\end{array}$ \\
\hline Black & & & $\begin{array}{c}8.9943^{* * *} \\
(1.8396)\end{array}$ & $\begin{array}{c}10.7470^{* * *} \\
(1.7492)\end{array}$ & $\begin{array}{c}11.9928^{* * *} \\
(1.7361)\end{array}$ & $\begin{array}{c}13.1555^{* * *} \\
(1.7497)\end{array}$ \\
\hline Hispanic & & & $\begin{array}{c}-11.3233^{* * *} \\
(1.4999)\end{array}$ & $\begin{array}{c}-8.5084^{* * *} \\
(1.3540)\end{array}$ & $\begin{array}{c}-9.9711^{* * *} \\
(1.3829)\end{array}$ & $\begin{array}{c}-8.4407^{* * *} \\
(1.3748)\end{array}$ \\
\hline College Degree & & & $\begin{array}{c}-7.6653^{* * *} \\
(0.9601)\end{array}$ & $\begin{array}{c}-6.1894^{* * *} \\
(0.9833)\end{array}$ & $\begin{array}{c}-6.6920^{* * *} \\
(0.9519)\end{array}$ & $\begin{array}{c}-6.3910^{* * *} \\
(0.9897)\end{array}$ \\
\hline Man & & & $\begin{array}{c}10.5359^{* * *} \\
(0.8083)\end{array}$ & $\begin{array}{c}10.5422^{* * *} \\
(0.8265)\end{array}$ & $\begin{array}{c}10.6558^{* * *} \\
(0.8155)\end{array}$ & $\begin{array}{c}10.7509^{* * *} \\
(0.8317)\end{array}$ \\
\hline Fixed Effects: & Year & State-Year & State-Year & State-Year & County-Year & County-Year \\
\hline Cable Controls: & $\mathrm{Y}$ & $\mathrm{Y}$ & $\mathrm{Y}$ & Y & $\mathrm{Y}$ & $\mathrm{Y}$ \\
\hline Demographics: & None & None & Individual & Extensive & Individual & Extensive \\
\hline Robust F-Stat & 2.1 & 3.2 & 4 & 5.7 & 0.1 & 0.4 \\
\hline Number of Clusters & 2589 & 2589 & 2589 & 2379 & 2589 & 2381 \\
\hline $\mathrm{N}$ & 207,950 & 207,950 & 207,860 & 197,551 & 207,860 & 198,300 \\
\hline $\mathrm{R}^{2}$ & 0.0099 & 0.0158 & 0.0395 & 0.0419 & 0.0737 & 0.0745 \\
\hline
\end{tabular}

${ }^{*} \mathrm{p}<.1 ;{ }^{* *} \mathrm{p}<.05 ;{ }^{* * *} \mathrm{p}<.01$

Cluster-robust standard errors in parentheses (clustered by cable system). Instrument is the ordinal position of FNC on the local system. The omitted category for the availability dummies is systems where neither FNC nor MSNBC is available. Cable system controls include the total number of channels on the system and the number of broadcast channels on the system. "Individual" demographics are measured at the level of the individual respondent. "Extensive" demographics include all of the same individual-level measures plus all of the zip-code-level demographics included in the zip-code-level analysis. 


$$
y_{i z t}=\gamma_{t}+a_{i t}+\beta^{1} x_{i t}+\beta^{2} x_{z t}+\rho_{f} h_{i t}^{f}+\epsilon_{i t}^{V}
$$

Predicted hours in the individual-level regression is produced by the first-stage estimates in Table A11.

Table A12: Second Stage Regressions: NAES / CCES Data

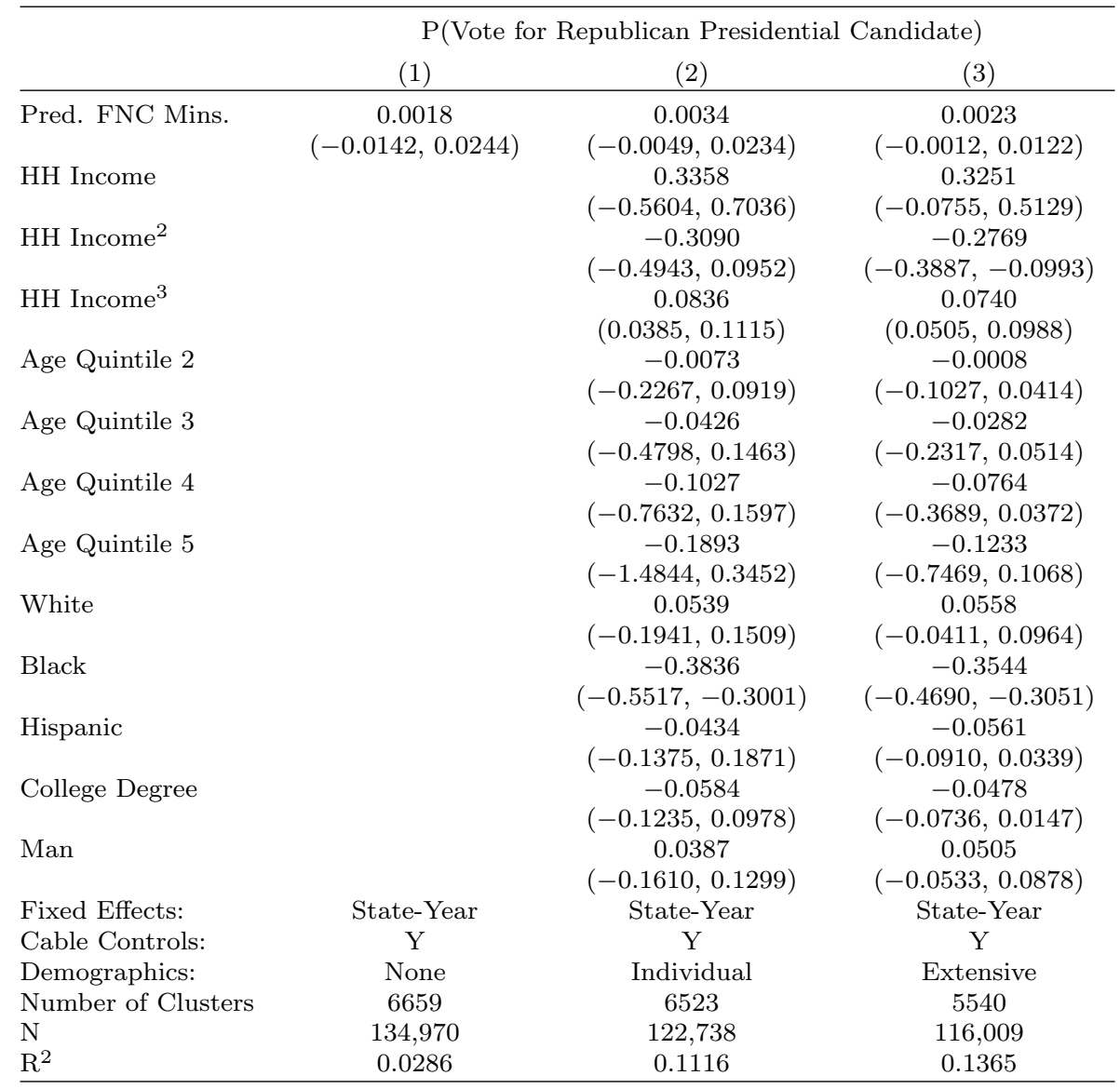

The first stage is estimated on all MediaMark/Simmons respondents. See first stage tables for description of instruments and control variables. Confidence intervals are generated from 500 independent STID-block-bootstraps of the first and second stage datasets. Reported lower and upper bounds give the central 95 percent interval of the relevant bootstrapped statistic. "Individual" demographics are measured at the level of the individual respondent. "Extensive" demographics include all of the same individual-level measures plus all of the zip-code-level demographics included in the zip-code-level analysis.

Comparing the two versions, the point estimate of the second-stage coefficient on FNC 
viewing is higher in the individual-level regression. It is also much less precise, however; the individual-level confidence interval entirely covers the zip code-level confidence interval. This difference is reflective of both the greater power of the instrument in the zip code-level first stage and the much greater predictability of zip code-level Republican vote shares as opposed to individual vote intentions: $R^{2}$ values in the zip code-level reduced form regression approach 0.85 , as compared to 0.15 in the corresponding individual-level regression.

There are two factors which temper the threat of misleading inference due to weak instruments in the second stage. First, we are using a single instrument in the just-identified case. Second, recalling the two-sample nature of the individual data, the intent-to-vote data span many more clusters than the viewership data.

\section{D.3 Reduced Form}

With the individual level data, these correlations are only significant in the specifications with state-year fixed effects; due to the relatively small number of clusters in this sample there is insufficient within-county variation to estimate the position effects precisely.

\section{D.4 Demographic Placebos}


Table A13: Reduced Form Regressions: NAES / CCES Data

\begin{tabular}{|c|c|c|c|c|c|c|}
\hline & \multicolumn{6}{|c|}{ P(Vote for Republican Presidential Candidate) } \\
\hline & $(1)$ & $(2)$ & $(3)$ & $(4)$ & $(5)$ & $(6)$ \\
\hline FNC Cable Position & $\begin{array}{c}-0.0003 \\
(0.0003)\end{array}$ & $\begin{array}{l}-0.0002 \\
(0.0002)\end{array}$ & $\begin{array}{c}-0.0003^{*} \\
(0.0002)\end{array}$ & $\begin{array}{c}-0.0002^{*} \\
(0.0001)\end{array}$ & $\begin{array}{l}-0.0004 \\
(0.0002)\end{array}$ & $\begin{array}{l}-0.0002 \\
(0.0002)\end{array}$ \\
\hline MSNBC Cable Position & $\begin{array}{l}0.001^{* * *} \\
(0.0003)\end{array}$ & $\begin{array}{c}0.0002 \\
(0.0002)\end{array}$ & $\begin{array}{c}0.0001 \\
(0.0002)\end{array}$ & $\begin{array}{c}0.0001 \\
(0.0001)\end{array}$ & $\begin{array}{c}-0.0003^{*} \\
(0.0002)\end{array}$ & $\begin{array}{c}-0.0005^{* * *} \\
(0.0002)\end{array}$ \\
\hline HH Income & & & $\begin{array}{c}0.481^{* * *} \\
(0.026)\end{array}$ & $\begin{array}{c}0.414^{* * *} \\
(0.027)\end{array}$ & $\begin{array}{c}0.452^{* * *} \\
(0.027)\end{array}$ & $\begin{array}{c}0.398^{* * *} \\
(0.028)\end{array}$ \\
\hline HH Income ${ }^{2}$ & & & $\begin{array}{c}-0.370^{* * *} \\
(0.030)\end{array}$ & $\begin{array}{c}-0.313^{* * *} \\
(0.030)\end{array}$ & $\begin{array}{c}-0.341^{* * *} \\
(0.031)\end{array}$ & $\begin{array}{c}-0.298^{* * *} \\
(0.032)\end{array}$ \\
\hline HH Income ${ }^{3}$ & & & $\begin{array}{c}0.090^{* * *} \\
(0.009)\end{array}$ & $\begin{array}{c}0.077^{* * *} \\
(0.009)\end{array}$ & $\begin{array}{c}0.083^{* * *} \\
(0.009)\end{array}$ & $\begin{array}{c}0.073^{* * *} \\
(0.010)\end{array}$ \\
\hline Age Quintile 2 & & & $\begin{array}{c}0.030^{* * *} \\
(0.005)\end{array}$ & $\begin{array}{c}0.023^{* * *} \\
(0.005)\end{array}$ & $\begin{array}{c}0.028^{* * *} \\
(0.005)\end{array}$ & $\begin{array}{c}0.025^{* * *} \\
(0.006)\end{array}$ \\
\hline Age Quintile 3 & & & $\begin{array}{c}0.031^{* * *} \\
(0.005)\end{array}$ & $\begin{array}{c}0.020^{* * *} \\
(0.005)\end{array}$ & $\begin{array}{c}0.028^{* * *} \\
(0.005)\end{array}$ & $\begin{array}{c}0.022^{* * *} \\
(0.005)\end{array}$ \\
\hline Age Quintile 4 & & & $\begin{array}{c}0.003 \\
(0.005)\end{array}$ & $\begin{array}{l}-0.007 \\
(0.005)\end{array}$ & $\begin{array}{c}0.001 \\
(0.006)\end{array}$ & $\begin{array}{c}-0.003 \\
(0.006)\end{array}$ \\
\hline Age Quintile 5 & & & $\begin{array}{c}0.027^{* * *} \\
(0.005)\end{array}$ & $\begin{array}{c}0.019^{* * *} \\
(0.005)\end{array}$ & $\begin{array}{c}0.028^{* * *} \\
(0.005)\end{array}$ & $\begin{array}{c}0.023^{* * *} \\
(0.005)\end{array}$ \\
\hline White & & & $\begin{array}{c}0.092^{* * *} \\
(0.006)\end{array}$ & $\begin{array}{c}0.079^{* * *} \\
(0.006)\end{array}$ & $\begin{array}{c}0.083^{* * *} \\
(0.006)\end{array}$ & $\begin{array}{c}0.079^{* * *} \\
(0.006)\end{array}$ \\
\hline Black & & & $\begin{array}{c}-0.353^{* * *} \\
(0.009)\end{array}$ & $\begin{array}{c}-0.329^{* * *} \\
(0.010)\end{array}$ & $\begin{array}{c}-0.338^{* * *} \\
(0.010)\end{array}$ & $\begin{array}{c}-0.322^{* * *} \\
(0.010)\end{array}$ \\
\hline Hispanic & & & $\begin{array}{c}-0.082^{* * *} \\
(0.008)\end{array}$ & $\begin{array}{c}-0.076^{* * *} \\
(0.008)\end{array}$ & $\begin{array}{c}-0.075^{* * *} \\
(0.009)\end{array}$ & $\begin{array}{c}-0.076^{* * *} \\
(0.008)\end{array}$ \\
\hline College Degree & & & $\begin{array}{c}-0.084^{* * *} \\
(0.004)\end{array}$ & $\begin{array}{c}-0.062^{* * *} \\
(0.004)\end{array}$ & $\begin{array}{c}-0.070^{* * *} \\
(0.004)\end{array}$ & $\begin{array}{c}-0.062^{* * *} \\
(0.004)\end{array}$ \\
\hline Man & & & $\begin{array}{c}0.074^{* * *} \\
(0.003)\end{array}$ & $\begin{array}{c}0.075^{* * *} \\
(0.003)\end{array}$ & $\begin{array}{c}0.075^{* * *} \\
(0.003)\end{array}$ & $\begin{array}{c}0.075^{* * *} \\
(0.003)\end{array}$ \\
\hline Fixed Effects: & Year & State-Year & State-Year & State-Year & County-Year & County-Year \\
\hline Cable Controls: & Y & $\mathrm{Y}$ & $\mathrm{Y}$ & $\mathrm{Y}$ & Y & Y \\
\hline Demographics: & None & None & Individual & Extensive & Individual & Extensive \\
\hline Number of Clusters & 6739 & 6739 & 6605 & 5582 & 6605 & 5582 \\
\hline $\mathrm{N}$ & 135,574 & 135,574 & 123,297 & 116,465 & 123,297 & 116,465 \\
\hline $\mathrm{R}^{2}$ & 0.012 & 0.029 & 0.112 & 0.137 & 0.188 & 0.197 \\
\hline
\end{tabular}

${ }^{*} \mathrm{p}<.1 ;{ }^{* *} \mathrm{p}<.05 ;{ }^{* * *} \mathrm{p}<.01$

Cluster-robust standard errors in parentheses (clustered by cable system). "Individual" demographics are measured at the level of the individual respondent. "Extensive" demographics include all of the same individual-level measures plus all of the zip-code-level demographics included in the zip-code-level analysis. 
Table A14: Comparison of covariate groups' influence on viewing equation, voting equation, and the first stage coefficient estimate: Mediamark / Simmons Data

\begin{tabular}{|c|c|c|c|c|}
\hline & $\mathrm{R}^{2}$ Change (Viewing) & $\mathrm{R}^{2}$ Change (Voting) & First Stage & Reduced Form \\
\hline Zip Race & 0.000038 & 0.000507 & $\begin{array}{c}-0.110166^{* *} \\
(0.044847)\end{array}$ & $\begin{array}{c}-0.000249^{*} \\
(0.000135)\end{array}$ \\
\hline Zip Age & 0.000204 & 0.000584 & $\begin{array}{c}-0.104163^{* *} \\
(0.044891)\end{array}$ & $\begin{array}{c}-0.000251^{*} \\
(0.000133)\end{array}$ \\
\hline Zip Education & 0.000284 & 0.001017 & $\begin{array}{c}-0.106287^{* *} \\
(0.045566)\end{array}$ & $\begin{array}{c}-0.000256^{*} \\
(0.000133)\end{array}$ \\
\hline Zip Marital Status & 0.000227 & 0.001200 & $\begin{array}{c}-0.101806^{* *} \\
(0.045826)\end{array}$ & $\begin{array}{c}-0.000318^{* *} \\
(0.000136)\end{array}$ \\
\hline Zip 1996 Voting / Contribs. & 0.000032 & 0.003585 & $\begin{array}{c}-0.104493^{* *} \\
(0.043564)\end{array}$ & $\begin{array}{c}-0.000318^{* *} \\
(0.000139)\end{array}$ \\
\hline County Religion & 0.000068 & 0.000087 & $\begin{array}{c}-0.113065^{* *} \\
(0.044444)\end{array}$ & $\begin{array}{l}-0.000241^{*} \\
(0.000134)\end{array}$ \\
\hline (No Demographics) & 0.026092 & 0.107699 & $\begin{array}{c}-0.097660^{*} \\
(0.054180)\end{array}$ & $\begin{array}{l}-0.000181 \\
(0.000248)\end{array}$ \\
\hline (Complete set) & 0.000000 & 0.000000 & $\begin{array}{c}-0.106764^{* *} \\
(0.044709)\end{array}$ & $\begin{array}{l}-0.000248^{*} \\
(0.000133)\end{array}$ \\
\hline Number of Clusters & 2379 & 5582 & 2379 & 5582 \\
\hline $\mathrm{N}$ & 197,551 & 116,465 & 197,551 & 116,465 \\
\hline
\end{tabular}

${ }^{*} \mathrm{p}<.1 ;{ }^{* *} \mathrm{p}<.05 ;{ }^{* * *} \mathrm{p}<.01$

Cluster-robust standard errors in parentheses (clustered by cable system). The first two columns are the decrease in $R^{2}$ resulting from excluding all variables in the listed group from the viewership and the voting regressions, respectively, relative to the version of the model with the complete set of demographic controls included. The third column shows the estimated first stage coefficient on FNC position when the corresponding group of demographic variables is excluded from the equation. The final column is the same exercise, for the reduced form equation. All regressions include the "Extensive" demographic set, with the exception of the indicated group of variables, plus state-year fixed effects. 


\section{E Construction of Channel Ideology Estimates}

Our estimates of each channel's political ideology are generated by an adaptation of the method employed in Gentzkow and Shapiro (2010) to measure ideology of print newspapers. The method compares the use frequency of phrases in transcripts of the cable channel's shows to the use frequency of the same phrases in floor speeches by members of Congress recorded in the Congressional Record.

Text sources and transcript selection We downloaded all transcripts from any show appearing on CNN, Fox News, and MSNBC during 2000-2013 that were available in the LexisNexis database. Most of the highest-rated prime-time shows on all of the channels were available in Lexis, with one exception: Glenn Beck's Fox News show, which aired from 20092011. ${ }^{39}$ We supplemented the Lexis transcripts by downloading transcripts of Glenn Beck's Fox News show from historical versions of the Fox News website archived by the Internet Archive (archive.org). Table A15 lists the shows for which we were able to collect transcripts, by channel. For each show, we downloaded all available transcripts of episodes of that show.

We also downloaded the 1998-2012 Congressional Record (CR) in its entirety from the US Government Publishing Office's website (http://gpo.gov). From the raw HTML files we extracted every speech that could be attributed to an individual member of Congress.

Pre-processing of text Both transcript and Congressional record text was pre-processed by removing a list of 184 common "stop words" such as "we," "have," "for," and the like. The list of stop words matches that used by Gentzkow and Shapiro (2010). We then applied the Porter stemming algorithm to reduce variants of words to their common roots. ${ }^{40}$ For example, the words "beaches" and "beach" would both be stemmed to "beach." Finally, a script counted the frequency of occurrence of every two word phrase that appears at least five times in total in the Congressional record in that year in the speech of every speaker. ${ }^{41} \mathrm{~A}$ two-word phrase is two stemmed words appearing next to each other (excluding stop words) in the same sentence.

\footnotetext{
${ }^{39}$ The version of Mr. Beck's show on CNN, which aired from 2006-2008, had transcripts available in the database.

${ }^{40}$ We used an implementation of the Porter stemmer written in the Haskell language by Dmitry Antonyuk and Mark Wotton: https://hackage.haskell.org/package/porter

${ }^{41} \mathrm{~A}$ "speaker" in the TV transcripts is a show; in the Congressional record it is a member of Congress, either a senator or representative.
} 


CNN Anderson Cooper 360, Campbell Brown, CNN Live To-
day, CNN News Room, CNN Tonight, Connie Chung
Tonight, Crossfire, Erin Burnett OutFront, Glenn Beck,
Greenfield at Large, John King, USA, Larry King Live,
Moneyline / Lou Dobbs Tonight, News Night with Aaron
Brown, Parker / Spitzer, Paula Zahn Now, Piers Mor-
gan, The Point with Greta van Susteren, The Situation
Room with Wolf Blitzer, Wolf Blitzer Reports
Fox News Edge, Fox News Sunday, Glenn Beck, Han-
nity, The O'Reilly Factor, On the Record with Greta van
Susteren, Special Report with Bret Baier, Special Report
with Brit Hume, The Edge with Paula Zahn, The Kelly
File, Your World with Neil Cavuto
All in with Chris Hayes, Ashleigh Banfield on Location,
Buchanan Er Press, Countdown with Keith Olbermann,
Donahue, Hardball with Chris Matthews, Live with Dan
Abrams, Morning Joe, Politics Nation, Rave for the
White House 1600 Pennsylvania Ave., Rita Cosby Live
and Direct, Scarborough Country, The Ed Show, Last
Word with Lawrence O'Donnell, The News with Brian
Williams, The Rachel Maddow Show, The Savage Na-
tion, Tucker

Table A15: Cable shows for which transcripts were available, by channel. 
Choice of phrase set There are millions of two-word phrases which result from the phrasecounting algorithm described above. Most of these are of no value for distinguishing the partisanship of a a speaker. As a result, it is necessary to reduce the set of phrases considered to a manageable size, and to limit the number of "noise" phrases. We construct, for each phrase appearing in the Congressional Record, the Gentzkow-Shapiro partisanship statistic. We use the top 1000 "most partisan" phrases in each year according to this criterion, subject to the condition that the phrase must appear at least 20 times in total in the cable news transcripts in that year. We impose this criterion to weed out the (many) purely procedural phrases that appear in the Congressional Record, many of which appear highly partisan because they are spoken primarily by committee chairs, the House Speaker, and other members of the Congressional leadership, who by definition are all members of the majority party in the chamber. ${ }^{42}$ The result is a set of 1000 phrases for each year.

Elastic-net regression For each speaker in both the CR and the transcripts, we compute the frequency of each phrase as the count of occurrences divided by the total number of two-word phrases (among all phrases, not just the set of 1000 selected in the previous set). We standardize all frequencies by subtracting the mean frequency (across all speakers) and dividing by the cross-speaker standard deviation of frequency of the phrase in that year. This scaling prevents phrases that are more common overall from being weighted more heavily in the elastic net objective.

The standardized phrase frequencies of the set of 1000 phrases in each year for Congressional speakers are then input to an elastic-net regression (Zou and Hastie, 2005) where the dependent variable is the common-space DW-nominate first dimension score (McCarty et al., 1997) of the legislator. We restrict the sample for this regression to the set of legislators who use the phrases in the set of 1000 at least 100 times in total, which drops a few very infrequent speakers from the sample. We select the lasso parameter $\lambda$ in each year by cross-validation, and set the parameter $\alpha$ to 0.01 . Finally, the estimated coefficients from the fitted models are used to compute a predicted ideology for each show-year.

Aggregation to channel-year level We aggregate the show-year-level predicted ideologies to the channel-year level by a simple weighted average: shows in prime time get weight of two, and non-prime-time shows get weight of one. This weighting scheme approximately

\footnotetext{
${ }^{42}$ Some examples of such phrases are "move (the) question," "cloture motion," "unanimous consent," and "absence (of a) quorum."
} 
reflects the cable news audience distribution across the two time slots. Finally, we apply a moving-average smoothing filter to transform the resulting channel-year ideology estimates. This filter has a window of three years; we assign weight of $1 / 2$ to the current year's estimate, and $1 / 4$ each to the previous and next year's estimate. 


\section{F Additional Regression Tables}

\section{F.1 MSNBC Analysis}

This section contains analogous 2SLS results to those in section 4, where MSNBC viewership is treated as the endogenous variable, either instead of or in addition to Fox News viewership. Tables A16 and A17 show the first stage regression of MSNBC hours watched on cable channel positions in the zip code level and individual level datasets, respectively.

Tables A18 and A19 show single-instrument second-stage results with MSNBC viewership instrumented by MSNBC position.

Tables A20 and A21 show dual-instrument second-stage results with both FNC and MSNBC viewership instrumented by FNC and MSNBC positions.

Table A22 presents the analog to Table 7 for MSNBC. Here, the MSNBC cable effect is also strongly negative. The effect on satellite subscribers is around one-tenth the size of the effect on cable subscribers. We also present in Table A23 the analog of Table 6 but probing MSNBC position instead of Fox News position. While most of the coefficients are re-assuring, MSNBC position is significantly positively correlated with the predictable-by-demographics Republican vote share. Taken alone, this would suggest some degree of endogenous positioning of MSNBC, but an alternative explanation tempers this interpretation. The Fox News position displays a coefficient of the same magnitude in Table 6. This suggests an alternative interpretation that both news channel positions tend to be lower overall in less Republican areas, which would bias the Fox News effect in the opposite direction of what we find.

\section{F.2 Separate Specifications Year by Year}

In Tables A24, A25, and A26, we run the reduced form and first stage separately by year, as well as a pooled specification where all demographics interact with year dummy variables. There is no zip-level reduced form year-by-year because those data only cover the 2008 election. In the individual level reduced form (Table A24), the Fox News cable position coefficient is negative in every specification, but only significant in the pooled specification and marginally significant in 2004. Fox News position is negative and significant in every specification of the

year-by-year zip-level first stage (Table A25). In the individual level year-by-year first stage (Table A26), the coefficient tends to be negative and noisy, though still negative and significant in the pooled specification. 
Table A16: First Stage Regressions: Nielsen Data

\begin{tabular}{lccccccc}
\hline & \multicolumn{7}{c}{ MSNBC Minutes Per Week } \\
& $(1)$ & $(2)$ & $(3)$ & $(4)$ & $(5)$ & $(6)$ & $(7)$ \\
\hline MSNBC Cable Position & $-0.099^{* * *}$ & $-0.088^{* * *}$ & $-0.087^{* * *}$ & $-0.082^{* * *}$ & $-0.082^{* * *}$ & $-0.035^{* *}$ & $-0.036^{* *}$ \\
& $(0.014)$ & $(0.022)$ & $(0.016)$ & $(0.014)$ & $(0.013)$ & $(0.018)$ & $(0.015)$ \\
FNC Cable Position & $0.037^{* * *}$ & $0.049^{* * *}$ & $0.040^{* * *}$ & $0.039^{* * *}$ & $0.036^{* * *}$ & 0.011 & 0.012 \\
& $(0.013)$ & $(0.015)$ & $(0.011)$ & $(0.010)$ & $(0.009)$ & $(0.012)$ & $(0.011)$ \\
Has MSNBC Only & $8.086^{* * *}$ & $7.758^{* * *}$ & $7.733^{* * *}$ & $8.086^{* * *}$ & $7.607^{* * *}$ & $5.730^{* * *}$ & $4.887^{* * *}$ \\
& $(1.414)$ & $(1.387)$ & $(1.246)$ & $(1.593)$ & $(1.311)$ & $(2.060)$ & $(1.761)$ \\
Has FNC Only & $-3.588^{* * *}$ & $-3.231^{* * *}$ & $-3.693^{* * *}$ & $-3.721^{* * *}$ & $-3.369^{* * *}$ & $-2.535^{* * *}$ & $-2.287^{* * *}$ \\
& $(0.625)$ & $(0.648)$ & $(0.556)$ & $(0.630)$ & $(0.541)$ & $(0.747)$ & $(0.661)$ \\
Has Both & $6.157^{* * *}$ & $5.621^{* * *}$ & $4.970^{* * *}$ & $4.873^{* * *}$ & $5.070^{* * *}$ & $2.522^{* *}$ & $2.958^{* * *}$ \\
& $(0.837)$ & $(0.919)$ & $(0.782)$ & $(0.805)$ & $(0.715)$ & $(1.017)$ & $(0.901)$ \\
Sat. MSNBC Minutes & & & & & $0.185^{* * *}$ & & $0.162^{* * *}$ \\
& & & & & $(0.018)$ & $(0.018)$ \\
Fixed Effects: & Year & State-Year & State-Year & State-Year & State-Year & County-Year & County-Year \\
Cable Controls: & $\mathrm{Y}$ & $\mathrm{Y}$ & $\mathrm{Y}$ & $\mathrm{Y}$ & $\mathrm{Y}$ & $\mathrm{Y}$ & Extended \\
Demographics: & None & None & Basic & Extended & Extended & Extended & Exted \\
Robust F-Stat & 49.4 & 15.8 & 28.4 & 34.6 & 38.2 & 3.9 & 5.4 \\
Number of Clusters & 5633 & 5633 & 5632 & 4701 & 4632 & 4710 & 4641 \\
$\mathrm{~N}$ & 69,731 & 69,731 & 69,683 & 58,394 & 50,970 & 58,537 & 51,082 \\
$\mathrm{R}^{2}$ & 0.095 & 0.126 & 0.164 & 0.178 & 0.323 & 0.370 & 0.488 \\
\hline
\end{tabular}

${ }^{*} \mathrm{p}<.1 ;{ }^{* *} \mathrm{p}<.05 ;{ }^{* * *} \mathrm{p}<.01$

Notes: Cluster-robust standard errors in parentheses (clustered by cable system). Instrument is the ordinal position of MSNBC on the local system. The omitted category for the availability dummies is systems where neither FNC nor MSNBC is available. In Column (5), the specification conditions on the average MSNBC ratings among satellite subscribers in the same zip code. Cable system controls include the total number of channels on the system and the number of broadcast channels on the system, as well as an indicator for Nielsen collection mode (diary vs. settop). "Basic" demographics include the racial, gender, age, income, educational, and urban/rural makeup of the zip code. "Extended" demographics adds information on the percentage of homeowners; median housing values, sizes, ages, and property tax rates; the fraction of the population receiving food stamps; median social security income; the fraction of veterans; the fractions of married, unmarried, and same-sex couples; the share of federal campaign contributions that went to Republican candidates in 1996; the Republican presidential share of the county in 1996; and the religious composition of the county. Observations are weighted by the number of survey individuals in the zipcode according to Nielsen. 
Table A17: First Stage Regressions: Mediamark / Simmons Data

\begin{tabular}{|c|c|c|c|c|c|c|}
\hline & \multicolumn{6}{|c|}{ MSNBC Minutes } \\
\hline & $(1)$ & $(2)$ & $(3)$ & $(4)$ & $(5)$ & $(6)$ \\
\hline MSNBC Cable Position & $\begin{array}{c}-0.179^{* * *} \\
(0.030)\end{array}$ & $\begin{array}{c}-0.158^{* * *} \\
(0.033)\end{array}$ & $\begin{array}{c}-0.165^{* * *} \\
(0.032)\end{array}$ & $\begin{array}{c}-0.161^{* * *} \\
(0.029)\end{array}$ & $\begin{array}{c}-0.152^{* * *} \\
(0.033)\end{array}$ & $\begin{array}{c}-0.151^{* * *} \\
(0.033)\end{array}$ \\
\hline FNC Cable Position & $\begin{array}{c}0.085^{* * *} \\
(0.032)\end{array}$ & $\begin{array}{c}0.074^{* *} \\
(0.030)\end{array}$ & $\begin{array}{c}0.076^{* * *} \\
(0.029)\end{array}$ & $\begin{array}{c}0.077^{* * *} \\
(0.028)\end{array}$ & $\begin{array}{c}0.075^{* *} \\
(0.031)\end{array}$ & $\begin{array}{c}0.080^{* *} \\
(0.033)\end{array}$ \\
\hline HH Income & & & $\begin{array}{c}23.923^{* * *} \\
(1.717)\end{array}$ & $\begin{array}{c}22.761^{* * *} \\
(1.773)\end{array}$ & $\begin{array}{c}23.348^{* * *} \\
(1.696)\end{array}$ & $\begin{array}{c}22.253^{* * *} \\
(1.732)\end{array}$ \\
\hline HH Income ${ }^{2}$ & & & $\begin{array}{c}-8.825^{* * *} \\
(0.953)\end{array}$ & $\begin{array}{c}-8.555^{* * *} \\
(0.975)\end{array}$ & $\begin{array}{c}-8.642^{* * * *} \\
(0.943)\end{array}$ & $\begin{array}{c}-8.351^{* * * *} \\
(0.954)\end{array}$ \\
\hline HH Income ${ }^{3}$ & & & $\begin{array}{c}0.886^{* * *} \\
(0.119)\end{array}$ & $\begin{array}{c}0.867^{* * *} \\
(0.123)\end{array}$ & $\begin{array}{c}0.861^{* * *} \\
(0.119)\end{array}$ & $\begin{array}{c}0.836^{* * *} \\
(0.121)\end{array}$ \\
\hline Age Quintile 2 & & & $\begin{array}{c}5.583^{* * *} \\
(0.699)\end{array}$ & $\begin{array}{c}5.889^{* * *} \\
(0.714)\end{array}$ & $\begin{array}{c}5.796^{* * *} \\
(0.714)\end{array}$ & $\begin{array}{c}6.130^{* * *} \\
(0.735)\end{array}$ \\
\hline Age Quintile 3 & & & $\begin{array}{c}8.420^{* * *} \\
(0.743)\end{array}$ & $\begin{array}{c}8.888^{* * *} \\
(0.763)\end{array}$ & $\begin{array}{c}8.620^{* * *} \\
(0.772)\end{array}$ & $\begin{array}{c}8.949^{* * *} \\
(0.800)\end{array}$ \\
\hline Age Quintile 4 & & & $\begin{array}{c}12.385^{* * *} \\
(0.777)\end{array}$ & $\begin{array}{c}12.896^{* * *} \\
(0.808)\end{array}$ & $\begin{array}{c}12.854^{* * *} \\
(0.813)\end{array}$ & $\begin{array}{c}13.246^{* * *} \\
(0.841)\end{array}$ \\
\hline Age Quintile 5 & & & $\begin{array}{c}22.768^{* * *} \\
(0.854)\end{array}$ & $\begin{array}{c}23.013^{* * *} \\
(0.891)\end{array}$ & $\begin{array}{c}22.793^{* * *} \\
(0.892)\end{array}$ & $\begin{array}{c}22.871^{* * *} \\
(0.928)\end{array}$ \\
\hline White & & & $\begin{array}{l}-0.546 \\
(0.848)\end{array}$ & $\begin{array}{c}-0.549 \\
(0.863)\end{array}$ & $\begin{array}{l}-0.483 \\
(0.838)\end{array}$ & $\begin{array}{l}-0.421 \\
(0.866)\end{array}$ \\
\hline Black & & & $\begin{array}{c}3.042^{* *} \\
(1.188)\end{array}$ & $\begin{array}{c}3.864^{* * *} \\
(1.227)\end{array}$ & $\begin{array}{l}2.824^{* *} \\
(1.252)\end{array}$ & $\begin{array}{c}4.138^{* * *} \\
(1.269)\end{array}$ \\
\hline Hispanic & & & $\begin{array}{c}-5.515^{* * *} \\
(0.843)\end{array}$ & $\begin{array}{c}-3.549^{* * *} \\
(0.791)\end{array}$ & $\begin{array}{c}-4.817^{* * *} \\
(0.775)\end{array}$ & $\begin{array}{c}-3.529^{* * *} \\
(0.816)\end{array}$ \\
\hline College Degree & & & $\begin{array}{c}3.838^{* * *} \\
(0.528)\end{array}$ & $\begin{array}{c}3.012^{* * *} \\
(0.565)\end{array}$ & $\begin{array}{c}3.611^{* * *} \\
(0.543)\end{array}$ & $\begin{array}{c}2.963^{* * *} \\
(0.573)\end{array}$ \\
\hline Man & & & $\begin{array}{c}5.356^{* * *} \\
(0.486)\end{array}$ & $\begin{array}{c}5.372^{* * *} \\
(0.491)\end{array}$ & $\begin{array}{c}5.461^{* * *} \\
(0.481)\end{array}$ & $\begin{array}{c}5.515^{* * *} \\
(0.491)\end{array}$ \\
\hline Fixed Effects: & Year & State-Year & State-Year & State-Year & County-Year & County-Year \\
\hline Cable Controls: & $\mathrm{Y}$ & $\mathrm{Y}$ & $\mathrm{Y}$ & $\mathrm{Y}$ & $\mathrm{Y}$ & $\mathrm{Y}$ \\
\hline Demographics: & None & None & Individual & Extensive & Individual & Extensive \\
\hline Robust F-Stat & 36.7 & 22.8 & 27.3 & 29.7 & 21.9 & 20.2 \\
\hline Number of Clusters & 2589 & 2589 & 2589 & 2379 & 2589 & 2381 \\
\hline $\mathrm{N}$ & 207,950 & 207,950 & 207,860 & 197,551 & 207,860 & 198,300 \\
\hline $\mathrm{R}^{2}$ & 0.004 & 0.009 & 0.020 & 0.022 & 0.052 & 0.054 \\
\hline
\end{tabular}

${ }^{*} \mathrm{p}<.1 ;{ }^{* *} \mathrm{p}<.05 ;{ }^{* * *} \mathrm{p}<.01$

Cluster-robust standard errors in parentheses (clustered by cable system). Instrument is the ordinal position of MSNBC on the local system. The omitted category for the availability dummies is systems where neither FNC nor MSNBC is available. Cable system controls include the total number of channels on the system and the number of broadcast channels on the system. "Individual" demographics are measured at the level of the individual respondent. "Extensive" demographics include all of the same individual-level measures plus all of the zip-code-level demographics included in the zip-code-level analysis. 
Table A18: Second Stage Regressions: Precinct Voting Data

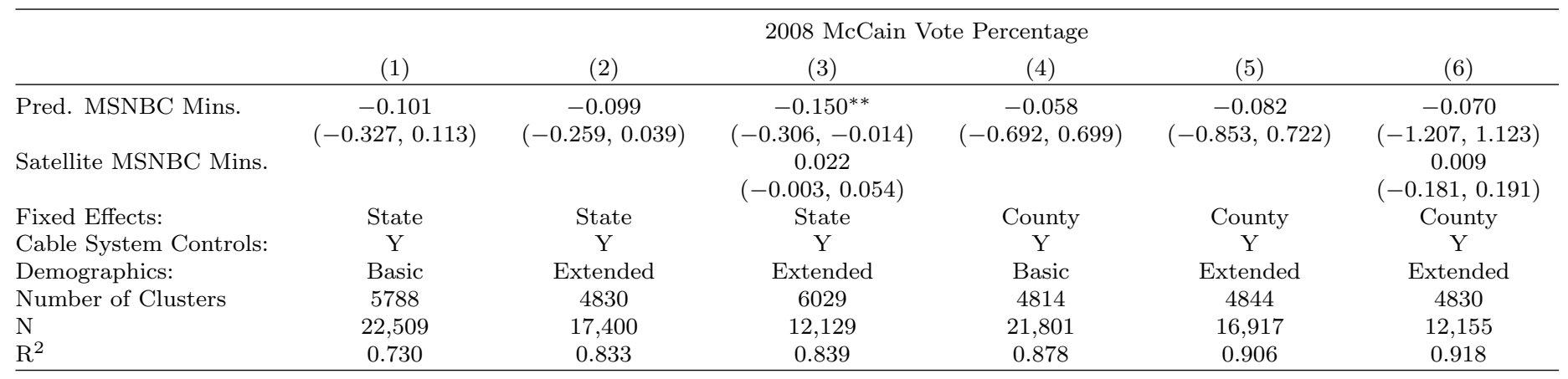

The first stage is estimated using viewership data for all Nielsen TV households. See first stage tables for description of instruments and control variables. Observations in the first stage are weighted by the number of survey individuals in the zipcode according to Nielsen. Confidence intervals are generated from 1000 independent STID-block-bootstraps of the first and second stage datasets. Reported lower and upper bounds give the central 95 percent interval of the relevant bootstrapped statistic.

\section{F.3 Turnout}

In Table A27, we check whether Fox News position correlates with a measure of turnout. We sum the zip code level votes cast across parties in the precinct level data, and divide this number by the age eighteen and over population from the Census at the zip code level. ${ }^{43}$ The coefficients on Fox News position tend to be small and noisy except with county fixed effects, where we see a significant negative coefficient on Fox News position. The results suggest that the persuasion estimates in our main specifications could be coming from both the conversion of swing voters and some additional turnout, though it is difficult to say with any precision.

\footnotetext{
${ }^{43}$ We dropped any zip code whose implied turnout exceeded 1.
} 
Table A19: Second Stage Regressions: NAES / CCES Data (MSNBC)

\begin{tabular}{|c|c|c|c|}
\hline & \multicolumn{3}{|c|}{ P(Vote for Republican Presidential Candidate) } \\
\hline & $(1)$ & $(2)$ & $(3)$ \\
\hline Pred. MSNBC Mins. & $\begin{array}{c}-0.0012 \\
(-0.0047,0.0018)\end{array}$ & $\begin{array}{c}-0.0006 \\
(-0.0028,0.0018)\end{array}$ & $\begin{array}{c}-0.0004 \\
(-0.0019,0.0012)\end{array}$ \\
\hline HH Income & & $\begin{array}{c}0.4976 \\
(0.4118,0.5742)\end{array}$ & $\begin{array}{c}0.4249 \\
(0.3594,0.4869)\end{array}$ \\
\hline HH Income ${ }^{2}$ & & $\begin{array}{c}-0.3775 \\
(-0.4394,-0.3071)\end{array}$ & $\begin{array}{c}-0.3189 \\
(-0.3830,-0.2563)\end{array}$ \\
\hline HH Income ${ }^{3}$ & & $\begin{array}{c}0.0908 \\
(0.0717,0.1084)\end{array}$ & $\begin{array}{c}0.0784 \\
(0.0598,0.0969)\end{array}$ \\
\hline Age Quintile 2 & & $\begin{array}{c}0.0332 \\
(0.0162,0.0497)\end{array}$ & $\begin{array}{c}0.0255 \\
(0.0107,0.0396)\end{array}$ \\
\hline Age Quintile 3 & & $\begin{array}{c}0.0364 \\
(0.0129,0.0579)\end{array}$ & $\begin{array}{c}0.0236 \\
(0.0052,0.0407)\end{array}$ \\
\hline Age Quintile 4 & & $\begin{array}{c}0.0114 \\
(-0.0207,0.0421)\end{array}$ & $\begin{array}{c}-0.0011 \\
(-0.0244,0.0220)\end{array}$ \\
\hline Age Quintile 5 & & $\begin{array}{c}0.0418 \\
(-0.0138,0.0926)\end{array}$ & $\begin{array}{c}0.0292 \\
(-0.0089,0.0658)\end{array}$ \\
\hline White & & $\begin{array}{c}0.0915 \\
(0.0790,0.1018)\end{array}$ & $\begin{array}{c}0.0781 \\
(0.0677,0.0897)\end{array}$ \\
\hline Black & & $\begin{array}{c}-0.3513 \\
(-0.3714,-0.3305)\end{array}$ & $\begin{array}{c}-0.3282 \\
(-0.3488,-0.3097)\end{array}$ \\
\hline Hispanic & & $\begin{array}{c}-0.0851 \\
(-0.1031,-0.0613)\end{array}$ & $\begin{array}{c}-0.0770 \\
(-0.0945,-0.0609)\end{array}$ \\
\hline College Degree & & $\begin{array}{c}-0.0819 \\
(-0.0925,-0.0699)\end{array}$ & $\begin{array}{c}-0.0608 \\
(-0.0688,-0.0519)\end{array}$ \\
\hline Man & & $\begin{array}{c}0.0776 \\
(0.0637,0.0917)\end{array}$ & $\begin{array}{c}0.0768 \\
(0.0659,0.0874)\end{array}$ \\
\hline Fixed Effects: & State-Year & State-Year & State-Year \\
\hline Cable Controls: & $\mathrm{Y}$ & $\mathrm{Y}$ & Y \\
\hline Demographics: & None & Individual & Extensive \\
\hline Number of Clusters & 6659 & 6523 & 5540 \\
\hline $\mathrm{N}$ & 134,970 & 122,738 & 116,009 \\
\hline $\mathrm{R}^{2}$ & 0.0286 & 0.1116 & 0.1365 \\
\hline
\end{tabular}

The first stage is estimated on all MediaMark/Simmons respondents. See first stage tables for description of instruments and control variables. Confidence intervals are generated from 500 independent STID-block-bootstraps of the first and second stage datasets. Reported lower and upper bounds give the central 95 percent interval of the relevant bootstrapped statistic. "Individual" demographics are measured at the level of the individual respondent. "Extensive" demographics include all of the same individual-level measures plus all of the zip-code-level demographics included in the zip-code-level analysis. 
Table A20: Second Stage Regressions: Precinct Voting Data

\begin{tabular}{|c|c|c|c|c|c|c|}
\hline & \multicolumn{6}{|c|}{2008 McCain Vote Percentage } \\
\hline & $(1)$ & $(2)$ & $(3)$ & $(4)$ & $(5)$ & $(6)$ \\
\hline Pred. Total FNC Mins. & $\begin{array}{c}0.078 \\
(-0.026,0.415)\end{array}$ & $\begin{array}{c}0.164 * * \\
(0.040,0.336)\end{array}$ & $\begin{array}{c}0.066 \\
(-0.024,0.246)\end{array}$ & $\begin{array}{c}-0.035 \\
(-0.533,1.435)\end{array}$ & $\begin{array}{c}-0.018 \\
(-0.417,1.176)\end{array}$ & $\begin{array}{c}-0.326 \\
(-0.192,0.632)\end{array}$ \\
\hline Pred. Total MSNBC Mins. & $\begin{array}{c}0.046 \\
(-0.261,0.462)\end{array}$ & $\begin{array}{c}0.077 \\
(-0.182,0.321)\end{array}$ & $\begin{array}{c}-0.129 \\
(-0.288,0.206)\end{array}$ & $\begin{array}{c}0.259 \\
(-1.489,3.366)\end{array}$ & $\begin{array}{c}0.535 \\
(-1.718,1.780)\end{array}$ & $\begin{array}{c}1.214 \\
(-0.944,1.603)\end{array}$ \\
\hline Satellite FNC Mins. & & & $\begin{array}{c}-0.011 \\
(-0.047,0.007)\end{array}$ & & & $\begin{array}{c}0.098 \\
(-0.110,0.035)\end{array}$ \\
\hline Satellite MSNBC Mins. & & & $\begin{array}{c}0.019 \\
(-0.043,0.051)\end{array}$ & & & $\begin{array}{c}-0.393 \\
(-0.254,0.149)\end{array}$ \\
\hline Fixed Effects: & State & State & State & County & County & County \\
\hline Cable System Controls: & Y & Y & Y & Y & Y & Y \\
\hline Demographics: & Basic & Extended & Extended & Basic & Extended & Extended \\
\hline Number of Clusters & 5788 & 4830 & 6029 & 4814 & 4844 & 4830 \\
\hline $\mathrm{N}$ & 22,509 & 17,400 & 12,128 & 21,801 & 16,917 & 12,154 \\
\hline $\mathrm{R}^{2}$ & 0.729 & 0.833 & 0.839 & 0.877 & 0.906 & 0.918 \\
\hline
\end{tabular}

The first stage is estimated using viewership data for all Nielsen TV households. See first stage tables for description of instruments and control variables. Observations in the first stage are weighted by the number of survey individuals in the zipcode according to Nielsen. Confidence intervals are generated from 1000 independent STID-block-bootstraps of the first and second stage datasets. Reported lower and upper bounds give the central 95 percent interval of the relevant bootstrapped statistic.

\section{G More on Channel Positions}

Our main arguments for the validity of channel positions as instrumental variables for the effect of watching cable news on voting Republican consisted over correlating channel positions with observable variables: demographics (aggregated in the manner they predict voting and viewership), pre-Fox News political variables, and satellite viewership of Fox News, together with the institutional narrative of the period 1992-2000 as leading to effective randomness in channel position assignment. Most of these tests were reassuring, aside from the satellite placebo test on zip code level data, where we find a significant negative correlation with Fox News cable position, albeit one-third the size of the coefficient for cable subscribers, and no such effect on the individual level data. In this section, we further probe the validity for the instrumental variables assumption. First, we show the first stage and satellite placebo for a variety of similarly positioned channels. Second, we show support for the satellite placebo test, by showing that cable and satellite subscribers have similar demographics. Third, we examine whether Fox News viewership is correlated with nearby or future Fox News positions. Fourth, we show that Fox News and MSNBC channel positions are highly correlated with the best available position on the system at the time they were added. 
Table A21: Second Stage Regressions: NAES / CCES Data (FNC and MSNBC)

\begin{tabular}{|c|c|c|c|}
\hline & \multicolumn{3}{|c|}{ P(Vote for Republican Presidential Candidate) } \\
\hline & $(1)$ & $(2)$ & $(3)$ \\
\hline Pred. FNC Mins. & $\begin{array}{c}0.0012 \\
(-0.0284,0.0191)\end{array}$ & $\begin{array}{c}0.0033 \\
(-0.0095,0.0364)\end{array}$ & $\begin{array}{c}0.0028 \\
(-0.0122,0.0246)\end{array}$ \\
\hline Pred. MSNBC Mins. & $\begin{array}{c}-0.0009 \\
(-0.8206,0.5313)\end{array}$ & $\begin{array}{c}-0.0001 \\
(-0.3737,0.5702)\end{array}$ & $\begin{array}{c}0.0007 \\
(-0.5754,1.0111)\end{array}$ \\
\hline HH Income & & $\begin{array}{c}0.3401 \\
(-1.0749,0.9888)\end{array}$ & $\begin{array}{c}0.2895 \\
(-0.9903,1.0518)\end{array}$ \\
\hline $\mathrm{HH}_{\text {Income }}^{2}$ & & $\begin{array}{c}-0.3107 \\
(-0.5910,0.2909)\end{array}$ & $\begin{array}{c}-0.2626 \\
(-0.5797,0.2786)\end{array}$ \\
\hline $\mathrm{HH}_{\text {Income }}^{3}$ & & $\begin{array}{c}0.0838 \\
(0.0201,0.1170)\end{array}$ & $\begin{array}{c}0.0725 \\
(0.0144,0.1067)\end{array}$ \\
\hline Age Quintile 2 & & $\begin{array}{c}-0.0062 \\
(-0.3703,0.1568)\end{array}$ & $\begin{array}{c}-0.0100 \\
(-0.3410,0.2123)\end{array}$ \\
\hline Age Quintile 3 & & $\begin{array}{c}-0.0407 \\
(-0.7482,0.2699)\end{array}$ & $\begin{array}{c}-0.0448 \\
(-0.6912,0.3513)\end{array}$ \\
\hline Age Quintile 4 & & $\begin{array}{c}-0.0999 \\
(-1.0900,0.3443)\end{array}$ & $\begin{array}{c}-0.1006 \\
(-1.0540,0.4832)\end{array}$ \\
\hline Age Quintile 5 & & $\begin{array}{c}-0.1839 \\
(-2.2494,0.7464)\end{array}$ & $\begin{array}{c}-0.1704 \\
(-1.9622,0.9913)\end{array}$ \\
\hline White & & $\begin{array}{c}0.0545 \\
(-0.2811,0.2014)\end{array}$ & $\begin{array}{c}0.0513 \\
(-0.1827,0.1886)\end{array}$ \\
\hline Black & & $\begin{array}{c}-0.3828 \\
(-0.6832,-0.2501)\end{array}$ & $\begin{array}{c}-0.3624 \\
(-0.6602,-0.1681)\end{array}$ \\
\hline Hispanic & & $\begin{array}{c}-0.0445 \\
(-0.2073,0.3334)\end{array}$ & $\begin{array}{c}-0.0494 \\
(-0.2063,0.2140)\end{array}$ \\
\hline College Degree & & $\begin{array}{c}-0.0585 \\
(-0.1398,0.1646)\end{array}$ & $\begin{array}{c}-0.0468 \\
(-0.1145,0.0733)\end{array}$ \\
\hline Man & & $\begin{array}{c}0.0398 \\
(-0.2973,0.1993)\end{array}$ & $\begin{array}{c}0.0415 \\
(-0.2918,0.2496)\end{array}$ \\
\hline Fixed Effects: & State-Year & State-Year & State-Year \\
\hline Cable Controls: & $\mathrm{Y}$ & $\mathrm{Y}$ & $\mathrm{Y}$ \\
\hline Demographics: & None & Individual & Extensive \\
\hline Number of Clusters & 6659 & 6523 & 5540 \\
\hline $\mathrm{N}$ & 134,970 & 122,738 & 116,009 \\
\hline $\mathrm{R}^{2}$ & 0.0286 & 0.1116 & 0.1365 \\
\hline
\end{tabular}

The first stage is estimated on all MediaMark/Simmons respondents. See first stage tables for description of instruments and control variables. Confidence intervals are generated from 500 independent STID-block-bootstraps of the first and second stage datasets. Reported lower and upper bounds give the central 95 percent interval of the relevant bootstrapped statistic. "Individual" demographics are measured at the level of the individual respondent. "Extensive" demographics include all of the same individual-level measures plus all of the zip-code-level demographics included in the zip-code-level analysis. 
Table A22: First Stage Regressions: Nielsen Data, Satellite and Cable Subscribers

\begin{tabular}{lcccccc}
\hline & \multicolumn{5}{c}{ MSNBC Minutes Per Week } \\
& $(1)$ & $(2)$ & $(3)$ & $(4)$ & $(5)$ & $(6)$ \\
\hline FNC Position $\times$ cable & $0.064^{* * *}$ & $0.057^{* * *}$ & $0.053^{* * *}$ & $0.050^{* *}$ & $0.051^{* *}$ & $0.048^{* *}$ \\
& $(0.017)$ & $(0.014)$ & $(0.014)$ & $(0.023)$ & $(0.021)$ & $(0.024)$ \\
FNC Position $\times$ sat & 0.017 & 0.009 & 0.012 & -0.011 & -0.009 & -0.014 \\
& $(0.014)$ & $(0.014)$ & $(0.014)$ & $(0.026)$ & $(0.027)$ & $(0.032)$ \\
MSNBC Position $\times$ cable & $-0.135^{* * *}$ & $-0.136^{* * *}$ & $-0.128^{* * *}$ & $-0.087^{* * *}$ & $-0.097^{* * *}$ & $-0.094^{* * *}$ \\
& $(0.025)$ & $(0.019)$ & $(0.017)$ & $(0.026)$ & $(0.026)$ & $(0.030)$ \\
MSNBC Position $\times$ sat & -0.007 & -0.004 & 0.003 & 0.019 & 0.011 & 0.021 \\
& $(0.017)$ & $(0.015)$ & $(0.015)$ & $(0.047)$ & $(0.047)$ & $(0.054)$ \\
Fixed Effects: & State-Year & State-Year & State-Year & County-Year & County-Year & County-Year \\
Cable Controls: & $\mathrm{Y}$ & $\mathrm{Y}$ & $\mathrm{Y}$ & $\mathrm{Y}$ & $\mathrm{Y}$ & $\mathrm{Y}$ \\
Demographics: & None & Basic & Extensive & None & Basic & Extensive \\
Chow Test p-value & 0 & 0 & 0 & 0.022 & 0.02 & 0.031 \\
Number of Clusters & 5630 & 5629 & 4701 & 5630 & 5629 & 4701 \\
$\mathrm{~N}$ & 124,442 & 124,386 & 105,654 & 124,442 & 124,386 & 105,654 \\
$\mathrm{R}^{2}$ & 0.053 & 0.063 & 0.068 & 0.203 & 0.209 & 0.223 \\
\hline
\end{tabular}

${ }^{*} \mathrm{p}<.1 ;{ }^{* *} \mathrm{p}<.05 ;{ }^{* * *} \mathrm{p}<.01$

Cluster-robust standard errors in parentheses (clustered by cable system). Positions are the ordinal position of FNC/MSNBC on the local cable system. The omitted category for the availability dummies is systems where neither FNC nor MSNBC is available. Cable system controls include the total number of channels on the system and the number of broadcast channels on the system. All controls (including fixed effects) are interacted with a dummy for the observation corresponding to satellite viewership. Observations are weighted by the number of survey individuals in the zipcode according to Nielsen.

Table A23: MSNBC cable position coefficients on predicted viewing / voting, and 1996 Republican voting and contributions.

\begin{tabular}{|c|c|c|c|c|c|c|c|c|}
\hline & \multicolumn{2}{|c|}{ Predicted Viewing } & \multicolumn{2}{|c|}{ Predicted Voting } & \multicolumn{2}{|c|}{1996 Contributions } & \multicolumn{2}{|c|}{1996 Vote } \\
\hline & $(1)$ & $(2)$ & $(3)$ & $(4)$ & $(5)$ & $(6)$ & $(7)$ & $(8)$ \\
\hline MSNBC Position & $\begin{array}{l}-0.001 \\
(0.007)\end{array}$ & $\begin{array}{l}-0.008 \\
(0.010)\end{array}$ & $\begin{array}{c}0.036^{* * *} \\
(0.013)\end{array}$ & $\begin{array}{c}0.034^{* *} \\
(0.016)\end{array}$ & $\begin{array}{c}0.0002 \\
(0.0002)\end{array}$ & $\begin{array}{l}0.00003 \\
(0.0002)\end{array}$ & $\begin{array}{c}0.0002 \\
(0.0001)\end{array}$ & $\begin{array}{c}0.00004 \\
(0.0001)\end{array}$ \\
\hline Fixed Effects: & State-Year & State-Year & State-Year & State-Year & State-Year & State-Year & State-Year & State-Year \\
\hline Demographics: & Basic & Extended & Basic & Extended & Basic & Extended & Basic & Extended \\
\hline Number of Clusters & 5788 & 4830 & 6029 & 4814 & 4844 & 4830 & 5779 & 4830 \\
\hline $\mathrm{N}$ & 71,129 & 59,551 & 22,509 & 17,400 & 59,843 & 59,551 & 70,971 & 59,551 \\
\hline $\mathrm{R}^{2}$ & 0.757 & 0.734 & 0.403 & 0.340 & 0.146 & 0.176 & 0.464 & 0.571 \\
\hline
\end{tabular}

${ }^{*} \mathrm{p}<.1 ;{ }^{* *} \mathrm{p}<.05 ;{ }^{* * *} \mathrm{p}<.01$

Cluster-robust standard errors in parentheses (clustered by cable system). Columns 1-4 regress predicted hours of MSNBC and predicted Republican vote share, respectively, on MSNBC cable position. The predicting regressions exclude MSNBC position but include the indicated set of demographic controls. Columns 5-8 regress indicators of pre-treatment political attitudes (1996 county-level Republican presidential vote share and 1996 zipcode-level Republican campaign contribution share) on MSNBC cable position. 
Table A24: Reduced Form Regressions: NAES / CCES Data, by Year

\begin{tabular}{lcccc}
\hline & \multicolumn{4}{c}{$\mathrm{P}$ (Vote for Republican Presidential Candidate) } \\
& 2000 & 2004 & 2008 & Interacted \\
\hline FNC Cable Position & -0.0003 & $-0.0003^{*}$ & -0.0003 & $-0.0003^{* * *}$ \\
& $(0.0002)$ & $(0.0002)$ & $(0.0002)$ & $(0.0001)$ \\
MSNBC Cable Position & -0.0003 & $0.0004^{*}$ & -0.00001 & 0.0001 \\
& $(0.0002)$ & $(0.0002)$ & $(0.0001)$ & $(0.0001)$ \\
Fixed Effects: & State & State & State & State \\
Cable Controls: & $\mathrm{Y}$ & $\mathrm{Y}$ & $\mathrm{Y}$ & $\mathrm{Y}$ \\
Demographics: & Extensive & Extensive & Extensive & Interacted \\
Number of Clusters & 4404 & 3829 & 3194 & 5582 \\
$\mathrm{~N}$ & 40,559 & 41,607 & 34,299 & 116,465 \\
$\mathrm{R}^{2}$ & 0.126 & 0.144 & 0.159 & 0.141 \\
\hline
\end{tabular}

${ }^{*} \mathrm{p}<.1 ;{ }^{* *} \mathrm{p}<.05 ;{ }^{* * *} \mathrm{p}<.01$

Cluster-robust standard errors in parentheses (clustered by cable system). Columns (1)-(3) show the position coefficients when the model is run separately for each year. In column (4), the extensive demographic set is interacted with dummy variables for each year, allowing the demographic effects on voting to vary flexibly by year.

\section{G.1 First Stage for other Cable Channels}

In Table A28, we display the coefficients on own-channel position for a variety of other cable channels. For each channel, we run a stacked regression where we interact cable channel position with dummy variables for whether the individual subscribers to cable or to satellite. As with the other checks on instrument validity, the results are mostly reassuring but not perfect. 26 out of 32 channels have a significantly negative position effect on cable subscribers at $99 \%$ confidence ( 2 more, for a total of 28 out of 32 at $95 \%$ confidence). 9 out of 32 have a significantly negative cable channel position effect on satellite subscribers at $90 \%$ confidence (only 2 at 99\%), suggesting some degree of endogenous positioning for these channels.

Figure A2 plots the growth in subscribers for a group of peer channels during this time period. The top line shows ESPN, which was available on virtually every cable system. The other channels in the graph all experienced substantial growth during this time period. Idiosyncracies in the timing of contracts and system upgrades created variation in channel positions for a given channel across locations. In some cases, if Fox News was being added to a system facing capacity constraints, its channel position was determined by the position of the channel it was replacing. 
Table A25: First Stage Regressions: Nielsen Data, All Households, by Year

\begin{tabular}{lccccc}
\hline & & \multicolumn{3}{c}{ FNC Minutes Per Week } & Interacted \\
\hline FNC Cable Position & 2005 & 2006 & 2007 & 2008 & $-0.177^{* * *}$ \\
& $-0.180^{* * *}$ & $-0.163^{* * *}$ & $-0.187^{* * *}$ & $-0.168^{* * *}$ & $(0.028)$ \\
MSNBC Cable Position & $(0.040)$ & $(0.039)$ & $(0.038)$ & $(0.040)$ & $0.064^{* * *}$ \\
& $0.087^{* *}$ & $0.088^{* *}$ & 0.011 & $0.055^{*}$ & $(0.024)$ \\
System has MSNBC Only & $(0.037)$ & $(0.035)$ & $(0.032)$ & $(0.033)$ & -3.832 \\
& -3.041 & -6.044 & -6.526 & -0.421 & $(4.246)$ \\
System has FNC Only & $(7.221)$ & $(5.404)$ & $(5.458)$ & $(12.119)$ & $23.487^{* * *}$ \\
& $24.566^{* * *}$ & $19.842^{* * *}$ & $23.859^{* * *}$ & $25.265^{* * *}$ & $18.175^{* * *}$ \\
System has Both & $(4.259)$ & $(3.548)$ & $(3.545)$ & $(4.376)$ & $(2.360)$ \\
& $16.855^{* * *}$ & $12.505^{* * *}$ & $23.021^{* * *}$ & $21.783^{* * *}$ & State \\
Fixed Effects: & $(4.431)$ & $(3.711)$ & $(3.686)$ & $(4.740)$ & $\mathrm{Y}$ \\
Cable System Controls: & State & State & State & State & Y \\
Demographics: & $\mathrm{Y}$ & $\mathrm{Y}$ & $\mathrm{Y}$ & Extended x Year \\
Robust F-Stat & Extended & Extended & Extended & Extended & 40.1 \\
Number of Clusters & 20.7 & 17.4 & 24.4 & 18 & 4830 \\
$\mathrm{~N}$ & 4640 & 4517 & 4394 & 4233 & 59,541 \\
$\mathrm{R}^{2}$ & 14,872 & 14,840 & 14,933 & 14,896 & 0.213 \\
\hline
\end{tabular}

${ }^{*} \mathrm{p}<.1 ;{ }^{* *} \mathrm{p}<.05 ;{ }^{* * *} \mathrm{p}<.01$

Cluster-robust standard errors in parentheses (clustered by cable system). Instrument is the ordinal position of FNC on the local system. The omitted category for the availability dummies is systems where neither FNC nor MSNBC is available. Columns (1)-(4) give the FNC position coefficient when the first stage model is run separately by year. In Column (5), the extensive demographic set is interacted with dummy variables for each year, allowing the demographic effects on viewership to vary flexibly by year. Observations are weighted by the number of survey individuals in the zipcode according to Nielsen. 


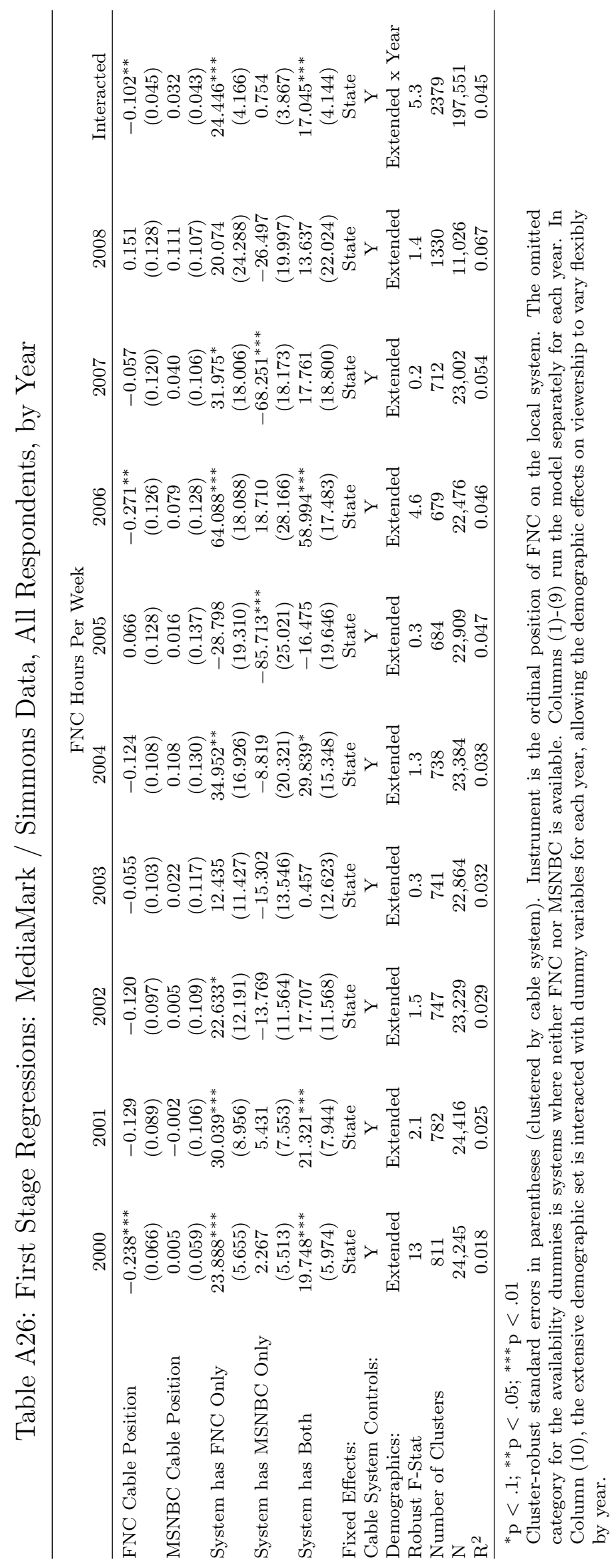


Table A27: Reduced Form Regressions: Precinct Voting Data, Turnout

\begin{tabular}{lcccccc}
\hline & \multicolumn{5}{c}{2008 Presidential Turnout } \\
& $(1)$ & $(2)$ & $(3)$ & $(4)$ & $(5)$ & $(6)$ \\
\hline FNC Cable Position & $0.036^{*}$ & -0.012 & -0.008 & -0.008 & -0.020 & $-0.031^{* *}$ \\
& $(0.020)$ & $(0.014)$ & $(0.010)$ & $(0.011)$ & $(0.013)$ & $(0.014)$ \\
MSNBC Cable Position & -0.006 & 0.010 & -0.006 & -0.002 & -0.003 & 0.003 \\
& $(0.018)$ & $(0.010)$ & $(0.008)$ & $(0.008)$ & $(0.009)$ & $(0.010)$ \\
Fixed Effects: & None & State & State & State & County & County \\
Cable System Controls: & $\mathrm{Y}$ & $\mathrm{Y}$ & $\mathrm{Y}$ & $\mathrm{Y}$ & $\mathrm{Y}$ & $\mathrm{Y}$ \\
Demographics: & None & None & Basic & Extended & Basic & Extended \\
Number of Clusters & 5516 & 5516 & 5513 & 4508 & 5513 & 4508 \\
$\mathrm{~N}$ & 20,390 & 20,390 & 20,353 & 16,274 & 20,353 & 16,274 \\
$\mathrm{R}^{2}$ & 0.020 & 0.196 & 0.404 & 0.465 & 0.522 & 0.596 \\
\hline
\end{tabular}

${ }^{*} \mathrm{p}<.1 ;{ }^{* *} \mathrm{p}<.05 ;{ }^{* * *} \mathrm{p}<.01$

The dependent variable is turnout in the presidential election, measured as number of presidential votes cast divided by the voting-age population in the zip code. Cluster-robust standard errors in parentheses (clustered by cable system).

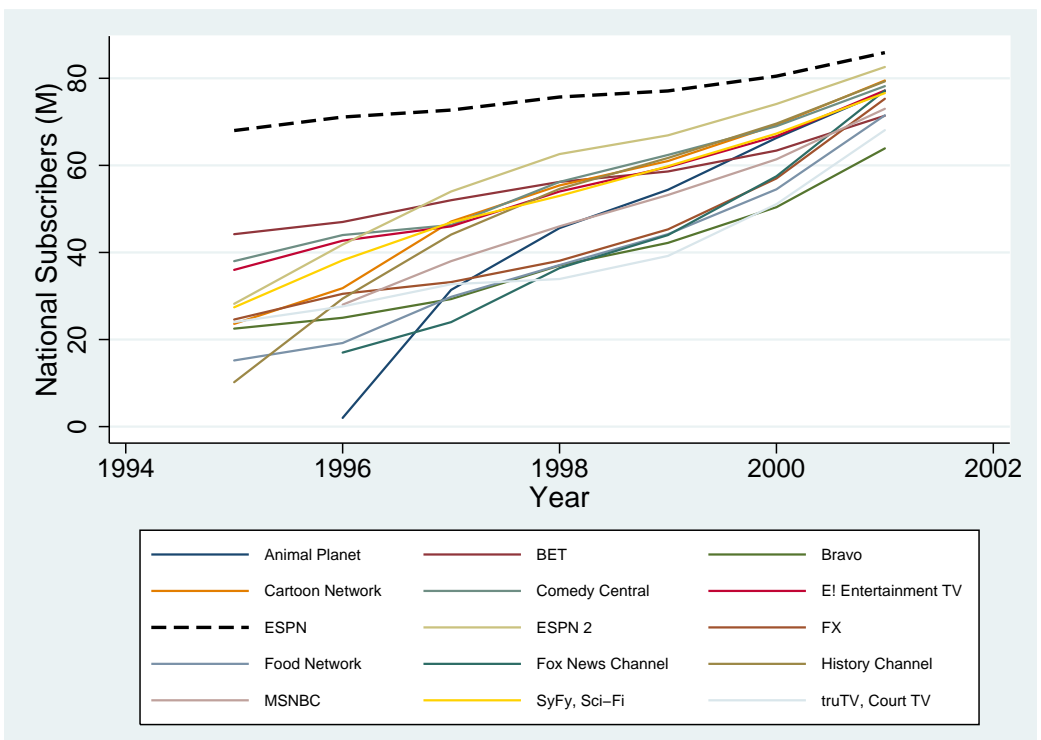

Figure A2: Number of subscribers for a group of peer channels by year for the period 1994-2001. National subscriber numbers according to SNL Kagan data. 
Table A28: First Stage Regressions for Other Channels: MediaMark / Simmons Data, All Respondents

\begin{tabular}{|c|c|c|c|c|c|}
\hline \multirow[b]{2}{*}{ Channel } & \multicolumn{2}{|c|}{ Own Position Effect } & \multirow[b]{2}{*}{ Channel } & \multicolumn{2}{|c|}{ Own Position Effect } \\
\hline & Cable Subscribers & Satellite Subscribers & & Cable Subscribers & Satellite Subscribers \\
\hline ABC Family & $\begin{array}{c}-0.0033^{* * *} \\
(0.0007)\end{array}$ & $\begin{array}{c}0.0001 \\
(0.0008)\end{array}$ & FX & $\begin{array}{c}-0.0024^{* * *} \\
(0.0004)\end{array}$ & $\begin{array}{l}-0.0009 \\
(0.0006)\end{array}$ \\
\hline $\mathrm{AMC}$ & $\begin{array}{l}-0.0003 \\
(0.0006)\end{array}$ & $\begin{array}{c}0.0008 \\
(0.0007)\end{array}$ & History Channel & $\begin{array}{c}-0.0048^{* * *} \\
(0.0007)\end{array}$ & $\begin{array}{c}-0.0032^{* * *} \\
(0.0011)\end{array}$ \\
\hline BET & $\begin{array}{c}-0.0015^{* * *} \\
(0.0004)\end{array}$ & $\begin{array}{l}-0.0001 \\
(0.0008)\end{array}$ & MSNBC & $\begin{array}{c}-0.0034^{* * *} \\
(0.0006)\end{array}$ & $\begin{array}{l}-0.0005 \\
(0.0008)\end{array}$ \\
\hline Bravo & $\begin{array}{c}-0.0038^{* * *} \\
(0.0003)\end{array}$ & $\begin{array}{l}-0.0003 \\
(0.0004)\end{array}$ & MTV & $\begin{array}{c}-0.0009^{* * *} \\
(0.0003)\end{array}$ & $\begin{array}{c}-0.0011^{* *} \\
(0.0005)\end{array}$ \\
\hline Cartoon Network & $\begin{array}{l}-0.0008 \\
(0.0005)\end{array}$ & $\begin{array}{c}-0.0018^{* *} \\
(0.0008)\end{array}$ & Nickelodeon & $\begin{array}{c}-0.0014^{* * *} \\
(0.0003)\end{array}$ & $\begin{array}{c}0.0005 \\
(0.0006)\end{array}$ \\
\hline CMT & $\begin{array}{c}-0.0012^{* * *} \\
(0.0002)\end{array}$ & $\begin{array}{c}-0.0007^{* *} \\
(0.0003)\end{array}$ & SyFy & $\begin{array}{c}-0.0039^{* * *} \\
(0.0005)\end{array}$ & $\begin{array}{l}-0.0005 \\
(0.0008)\end{array}$ \\
\hline Court TV & $\begin{array}{c}-0.0026^{* * *} \\
(0.0004)\end{array}$ & $\begin{array}{c}0.0003 \\
(0.0007)\end{array}$ & TNT & $\begin{array}{c}-0.0043^{* * *} \\
(0.0009)\end{array}$ & $\begin{array}{c}-0.0021^{*} \\
(0.0012)\end{array}$ \\
\hline Discovery Channel & $\begin{array}{c}-0.0027^{* * *} \\
(0.0008)\end{array}$ & $\begin{array}{l}-0.0012 \\
(0.0012)\end{array}$ & Travel Channel & $\begin{array}{c}-0.0022^{* * *} \\
(0.0003)\end{array}$ & $\begin{array}{c}-0.000004 \\
(0.0003)\end{array}$ \\
\hline Disney & $\begin{array}{c}-0.0027^{* * *} \\
(0.0003)\end{array}$ & $\begin{array}{l}-0.0006 \\
(0.0006)\end{array}$ & TV Land & $\begin{array}{c}-0.0015^{* * *} \\
(0.0003)\end{array}$ & $\begin{array}{c}-0.0014^{* * *} \\
(0.0004)\end{array}$ \\
\hline $\mathrm{E} !$ & $\begin{array}{c}-0.0020^{* * *} \\
(0.0004)\end{array}$ & $\begin{array}{l}-0.0004 \\
(0.0005)\end{array}$ & USA & $\begin{array}{c}-0.0022^{* * *} \\
(0.0007)\end{array}$ & $\begin{array}{l}-0.0016 \\
(0.0011)\end{array}$ \\
\hline ESPN2 & $\begin{array}{c}-0.0021^{* * *} \\
(0.0005)\end{array}$ & $\begin{array}{c}0.0008 \\
(0.0009)\end{array}$ & VH1 & $\begin{array}{c}-0.0011^{* * *} \\
(0.0003)\end{array}$ & $\begin{array}{c}0.0001 \\
(0.0004)\end{array}$ \\
\hline Food Network & $\begin{array}{c}-0.0035^{* * *} \\
(0.0006) \\
\end{array}$ & $\begin{array}{l}-0.0015 \\
(0.0010)\end{array}$ & Weather Channel & $\begin{array}{l}-0.0006 \\
(0.0012) \\
\end{array}$ & $\begin{array}{c}0.0025 \\
(0.0017) \\
\end{array}$ \\
\hline
\end{tabular}

${ }^{*} \mathrm{p}<.1 ;{ }^{* *} \mathrm{p}<.05 ;{ }^{* * *} \mathrm{p}<.01$

Cluster-robust standard errors in parentheses (clustered by cable system). The main regressors are the ordinal position and availability of the indicated channel on the local cable system. All regressions include controls for individual and zipcode level demographics as well as cable system characteristics, and state-year fixed effects. 


\section{G.2 Cable and Satellite Subscriber Observable Correlations}

Across locations, satellite subscriber characteristics correlate strongly with cable subscriber characteristics. Table A29 shows the regression coefficients of mean satellite subscriber characteristics on mean cable subscriber characteristics in the same cable system territory, nearly all of which are positive and large. Since the means of these characteristics are measured with sampling error - as they are constructed from the television viewership survey samples - the OLS coefficients are attenuated. In the table, we address this measurement error problem in two ways. ${ }^{44}$ First, we progressively restrict the regression to markets with more and more survey respondents as these markets will have less sampling error. Second, we instrument for the mean cable characteristic with lead and lagged mean cable characteristic. Survey respondents are sampled independently from year to year. Consistent with measurement error, the coefficients generally tend upwards to one when we restrict to system-years with more respondents. Furthermore, the IV coefficients are generally very close to one.

In the same vein, we can look directly at viewership patterns. Satellite viewers watch 1.2 fewer minutes per week of Fox News Channel on average relative to cable viewers (on an overall mean of 90 minutes). At the bottom of Table A29, we regress predicted mean viewership of satellite subscribers (predicted from demographics) on that of cable subscribers. We also regress the cable system territory mean residual viewership of satellite subscribers (net of demographics) on the cable system territory mean residual viewership of cable subscribers. Across the board, cable and satellite subscribers within the same cable system territory display strong correlations of both demographics and viewing behavior.

\section{G.3 Future and Nearby Channel Positions}

We examine whether future cable news channel position predicts current viewership conditional on current position. If political tastes are shifting over time, and channel positions are endogenous but sticky, then future position should predict current viewership. A location which has become more Republican would watch more Fox News, but, if channel positions were endogenously tailored and sticky, their channel position may not have adjusted yet, so future position, after adjustment, would be informative about current ideology. The zip-level results for Fox News are in Table A30. Position in 2008 does not predict viewership in 2005 conditional on position in 2005.

\footnotetext{
${ }^{44}$ One could also dis-attenuate the coefficients as the variance induced by sampling is known. This exercise is complicated because each cable system-year has different sampling variance.
} 


\begin{tabular}{|c|c|c|c|c|c|}
\hline Characteristic & $\mathrm{N}>0$ & $\mathrm{~N}>10$ & $\mathrm{~N}>50$ & $\mathrm{~N}>100$ & IV \\
\hline \multirow[t]{2}{*}{ Black } & $0.649^{* * *}$ & $0.733^{* * *}$ & $0.836^{* * *}$ & $0.978^{* * *}$ & $1.043^{* * *}$ \\
\hline & $(0.0129)$ & $(0.0141)$ & $(0.0242)$ & $(0.0405)$ & $(0.0348)$ \\
\hline \multirow{3}{*}{$\begin{array}{r}\text { Num Zips } \\
\text { College }\end{array}$} & 5,843 & $4,685)$ & 1,252 & 342 & 2,436 \\
\hline & $0.454^{* * *}$ & $0.576^{* * *}$ & $0.728^{* * *}$ & $0.793^{* * *}$ & $1.013^{* * *}$ \\
\hline & $(0.0165)$ & $(0.0193)$ & $(0.0371)$ & $(0.0633)$ & $(0.0707)$ \\
\hline Num Zips & 5,843 & $4,685)$ & 1,252 & 342 & 2,436 \\
\hline \multirow{2}{*}{ HH Income } & $0.448^{* * *}$ & $0.603^{* * *}$ & $0.781^{* * *}$ & $0.870^{* * *}$ & $0.973^{* * *}$ \\
\hline & $(0.0150)$ & $(0.0164)$ & $(0.0287)$ & $(0.0646)$ & $(0.0656)$ \\
\hline \multirow{3}{*}{$\begin{array}{r}\text { Num Zips } \\
\text { Age }\end{array}$} & 5,843 & $4,685)$ & 1,252 & 342 & 2,436 \\
\hline & $0.264^{* * *}$ & $0.350^{* * *}$ & $0.414^{* * *}$ & $0.449^{* * *}$ & $0.812^{* * *}$ \\
\hline & $(0.0162)$ & $(0.0197)$ & $(0.0411)$ & $(0.0704)$ & $(0.147)$ \\
\hline \multirow{3}{*}{$\begin{array}{r}\text { Num Zips } \\
\text { Hispanic }\end{array}$} & 5,843 & $4,685)$ & 1,252 & 342 & 2,436 \\
\hline & $0.618^{* * *}$ & $0.758^{* * *}$ & $0.850^{* * *}$ & $0.842^{* * *}$ & $0.966^{* * *}$ \\
\hline & $(0.0143)$ & $(0.0157)$ & $(0.0250)$ & $(0.0365)$ & $(0.0380)$ \\
\hline Num Zips & 5,843 & $4,685)$ & 1,252 & 342 & 2,436 \\
\hline \multirow[t]{2}{*}{ Party ID R } & $0.104^{* * *}$ & $0.285^{* * *}$ & $0.448 * * *$ & $0.588^{* * *}$ & $1.348^{* * *}$ \\
\hline & $(0.0364)$ & $(0.0567)$ & $(0.127)$ & $(0.215)$ & $(0.626)$ \\
\hline \multirow{3}{*}{$\begin{array}{l}\text { Num Zips } \\
\text { Party ID D }\end{array}$} & 896 & 453) & 78 & 25 & 361 \\
\hline & $0.165^{* * *}$ & $0.274^{* * *}$ & $0.341^{* * *}$ & $0.548^{* * *}$ & $1.348^{*}$ \\
\hline & $(0.0359)$ & $(0.0583)$ & $(0.126)$ & $(0.215)$ & $(0.626)$ \\
\hline Num Zips & 896 & 453) & 78 & 25 & 361 \\
\hline \multirow[t]{2}{*}{ Predicted Fox News } & $0.737^{* * *}$ & $0.833^{* * *}$ & $0.961^{* * *}$ & $0.967^{* * *}$ & $1.004^{* * *}$ \\
\hline & $(0.0133)$ & $(0.0137)$ & $(0.0202)$ & $(0.0291)$ & $(0.0436)$ \\
\hline Num Zips & 5,843 & $4,685)$ & 1,252 & 342 & 2,436 \\
\hline \multirow[t]{2}{*}{ Predicted MSNBC Viewing } & $0.498^{* * *}$ & $0.505^{* * *}$ & $0.581^{* * *}$ & $0.679 * * *$ & $0.725^{* * *}$ \\
\hline & $(0.0118)$ & $(0.0130)$ & $(0.0254)$ & $(0.0436)$ & $(0.0563)$ \\
\hline Num Zips & 5,843 & $4,685)$ & 1,252 & 342 & 2,436 \\
\hline \multirow{2}{*}{ Fox News Residual } & $0.0977^{* * *}$ & $0.165^{* * *}$ & $0.392^{* * *}$ & $0.424^{* * *}$ & $0.688^{* *}$ \\
\hline & $(0.0195)$ & $(0.0253)$ & $(0.0510)$ & $(0.0814)$ & $(0.254)$ \\
\hline \multirow[t]{2}{*}{ MSNBC Residual } & $0.0814^{* * *}$ & $0.117^{* * *}$ & $0.381^{* * *}$ & $0.567^{* * *}$ & $0.320 * *$ \\
\hline & $(0.0158)$ & $(0.0190)$ & $(0.0504)$ & $(0.0873)$ & $(0.129)$ \\
\hline
\end{tabular}

Note: The first column of coefficients uses all cable system territory-years. These coefficients are attenuated because the mean cable is constructed from samples of survey respondents which can be as few as 2 per cable system territory-year. The second column of coefficients restricts to those with more than ten surveyed respondents. The third column of coefficients restricts to those with more than fifty survey respondents. The fourth column of coefficients restricts to those with more than 100 survey respondents. The final column of coefficients are uses lead and lagged means of cable subscribers as instrumental variables, as respondents are sampled independently from year to year.

Table A29: Regression coefficients of demographic characteristics and cable news viewership of satellite subscribers on the characteristics of cable subscribers in the same cable territory-year in MediaMark / Simmons viewership data. 
Table A30: First Stage Regressions: Nielsen Data, Future Position Placebo

\begin{tabular}{lcccccc}
\hline & \multicolumn{2}{c}{ Cable Subscribers } & \multicolumn{2}{c}{ All Households } & \multicolumn{2}{c}{ Satellite Subscribers } \\
\hline FNC Position in 2005 & $-0.2574^{* * *}$ & $-0.2153^{*}$ & $-0.1285^{* *}$ & -0.0829 & 0.0661 & -0.0142 \\
& $(0.0737)$ & $(0.1253)$ & $(0.0574)$ & $(0.0857)$ & $(0.1231)$ & $(0.1805)$ \\
FNC Position in 2008 & -0.0569 & 0.0193 & -0.0669 & 0.0045 & -0.1487 & 0.0267 \\
& $(0.0754)$ & $(0.1127)$ & $(0.0597)$ & $(0.0813)$ & $(0.1139)$ & $(0.1726)$ \\
Fixed Effects: & State-Year & County-Year & State-Year & County-Year & State-Year & County-Year \\
Cable System Controls: & Y & Y & Y & Y & Y & Y \\
Demographics: & Basic & Extended & Basic & Extended & Basic & Extended \\
Number of Clusters & 3836 & 3836 & 3968 & 3968 & 3784 & 3784 \\
$\mathrm{~N}$ & 13,372 & 13,372 & 13,918 & 13,918 & 12,240 & 12,240 \\
$\mathrm{R}^{2}$ & 0.0962 & 0.3890 & 0.2128 & 0.4421 & 0.0522 & 0.2056 \\
\hline
\end{tabular}

${ }^{*} \mathrm{p}<.1 ;{ }^{* *} \mathrm{p}<.05 ;{ }^{* * *} \mathrm{p}<.01$

Cluster-robust standard errors in parentheses (clustered by cable system). The outcome is Fox News minutes per week in 2005 among cable subscribers, all households, and satellite subscribers, respectively in columns (1)-(2), (3)(4), and (5)-(6). We include only zip codes that had access to Fox News in 2005, and regress hours per week on both the actual position in 2005, and the future position in the same zip code in 2008. Observations are weighted by the number of survey individuals in the zipcode according to Nielsen.

We also examine whether Fox News position in nearby systems predicts local viewership. If unobserved political tastes were uncorrelated with local positions, then they should also be uncorrelated with nearby positions even though ideology and demographics are correlated nearby. For each zip code-year in the data, we found the nearest zip code in the data for that year which wasn't in the same cable system. The results are in Table A31. We do not see a significant correlation of nearby position on local viewership in our preferred specifications. In Table A32, we see that nearby positions also do not correlate with 2008 McCain vote share.

\section{G.4 Best Available Channel Position}

We demonstrate one example of this historical influence in Table A33. We regress the ordinal positions of Fox News and MSNBC on the system's best available ordinal position in 1998, along with a control for the overall size of the system - its total number of channels. ${ }^{45}$ The best available position in 1998 is a strong predictor of the current position, even though the positioning data here extends through 2008. A system's channel configuration prior to the

\footnotetext{
${ }^{45}$ Our lineup data begins in 1998, and hence we restrict the sample for this regression to cable systems that did not have Fox/MSNBC in 1998. "Best available" is defined as the lowest open slot (unoccupied by an existing channel) in the region of the lineup dedicated to cable (i.e. non-network and non-local-access) channels. We define the cable region by locating the positions of CNN, ESPN, TNT, and The Discovery Channel, and consider any open slot above at least one of those channels to be available.
} 
Table A31: First Stage Regressions: Nielsen Data, All Households, Nearby Position

\begin{tabular}{lcccccc}
\hline & \multicolumn{5}{c}{ FNC Minutes per Week } \\
& $(1)$ & $(2)$ & $(3)$ & $(4)$ & $(5)$ & $(6)$ \\
\hline FNC Position & $-0.1311^{* * *}$ & $-0.0710^{*}$ & $-0.1496^{* * *}$ & $-0.1698^{* * *}$ & $-0.1016^{* * *}$ & $-0.1651^{* * *}$ \\
& $(0.0420)$ & $(0.0384)$ & $(0.0286)$ & $(0.0281)$ & $(0.0333)$ & $(0.0252)$ \\
FNC Position in Nearby Zip & $-0.0420^{*}$ & -0.0185 & -0.0205 & -0.0166 & -0.0022 & -0.0110 \\
& $(0.0223)$ & $(0.0216)$ & $(0.0155)$ & $(0.0159)$ & $(0.0197)$ & $(0.0139)$ \\
Fixed Effects: & Year & State-Year & State-Year & State-Year & County-Year & State-Year \\
Cable System Controls: & $\mathrm{Y}$ & $\mathrm{Y}$ & $\mathrm{Y}$ & $\mathrm{Y}$ & $\mathrm{Y}$ & Y \\
Demographics: & None & None & Basic & Extended & Extended & Extended+Sat.Hrs. \\
Number of Clusters & 5796 & 5796 & 5787 & 4829 & 4829 & 4757 \\
$\mathrm{~N}$ & 70,743 & 70,743 & 70,622 & 59,073 & 59,073 & 51,695 \\
$\mathrm{R}^{2}$ & 0.0299 & 0.0731 & 0.1903 & 0.2130 & 0.4292 & 0.3769 \\
\hline
\end{tabular}

${ }^{*} \mathrm{p}<.1 ;{ }^{* *} \mathrm{p}<.05 ;{ }^{* * *} \mathrm{p}<.01$

Cluster-robust standard errors in parentheses (clustered by cable system). FNC hours per week (among all Nielsen households) are regressed on both the actual position and the position on a neighboring system. Regressions include controls for availability on both the actual and neighboring system. Observations are weighted by the number of survey individuals in the zipcode according to Nielsen.

Table A32: Reduced Form Regressions: Zip Code Data, All Households, Nearby Position

\begin{tabular}{lcccc}
\hline & \multicolumn{4}{c}{2008 McCain Vote Share } \\
& $(1)$ & $(2)$ & $(3)$ & $(4)$ \\
\hline FNC Position & 0.0002 & 0.0002 & $-0.0002^{* * *}$ & -0.0001 \\
& $(0.0002)$ & $(0.0002)$ & $(0.0001)$ & $(0.0001)$ \\
FNC Position in Nearby Zip & 0.00005 & 0.00005 & -0.0001 & 0.00004 \\
& $(0.0001)$ & $(0.0001)$ & $(0.0001)$ & $(0.0001)$ \\
Fixed Effects: & State-Year & State-Year & State-Year & County-Year \\
Cable System Controls: & $\mathrm{Y}$ & $\mathrm{Y}$ & $\mathrm{Y}$ & $\mathrm{Y}$ \\
Demographics: & None & Basic & Extended & Extended \\
Number of Clusters & 4996 & 4996 & 4222 & 4222 \\
$\mathrm{~N}$ & 17,588 & 17,588 & 14,719 & 14,719 \\
$\mathrm{R}^{2}$ & 0.2927 & 0.2927 & 0.8435 & 0.9171 \\
\hline${ }^{*} \mathrm{p}<.1 ;{ }^{* *} \mathrm{p}<.05 ;{ }^{* * *} \mathrm{p}<.01$ & \multicolumn{4}{c}{} \\
Cluster-robust standard errors in parentheses (clustered by cable system). FNC hours per \\
week (among all Nielsen households) are regressed on both the actual position and the position \\
on a neighboring system. Regressions include controls for availability on both the actual and \\
neighboring system.
\end{tabular}


addition of Fox or MSNBC exerts a lasting influence on the positioning of Fox and MSNBC today.

\begin{tabular}{lcc}
\hline \hline Coefficient & MSNBC & Fox \\
\hline (Intercept) & 33.8 & 30.7 \\
& $(0.573)$ & $(0.432)$ \\
Number of Channels & 0.032 & 0.032 \\
& $(0.003)$ & $(0.002)$ \\
Best Available & 0.181 & 0.148 \\
& $(0.014)$ & $(0.012)$ \\
\hline $\mathrm{R}^{2}$ & 0.066 & 0.077 \\
$\mathrm{~N}$ & 29,337 & 38,328 \\
\hline \hline
\end{tabular}

Table A33: Ordinal channel position vs. best available ordinal channel position, among systems where the channel (MSNBC or Fox News) was added in 1998 or later. Standard errors clustered by cable system. 


\section{H Solution Algorithm for Viewership Problem}

Define $\rho_{i c t}$ as the Lagrange multipliers associated with the non-negativity constraints on $T_{i c t}$. By complementary slackness, if $\rho_{i c t}>0$ then $T_{i c t}=0$. From the first order condition, $\rho_{i c t}=$ $\lambda_{i t}-\gamma_{i c t}$ where $\lambda_{i t}$ is the Lagrange multiplier on consumer $i$ 's budget constraint. Therefore, $T_{i c t}$ can be zero if and only if $\gamma_{i c t}<\lambda_{i t}$.

For all the channels with $T_{i c t}>0, \lambda_{i t}=\gamma_{i c t} /\left(1+T_{i c t}\right)$. Additionally, each consumer faces a time-budget constraint, $\sum_{c} T_{i c t}=B$, where $\mathrm{B}$ is the total time available (in our scaling, the number of hours in a week: 168). This gives a system of equations with solution:

$$
\lambda_{i t}=\frac{1+\sum_{c^{+}} \gamma_{i c^{+} t}}{B+C^{+}}
$$

where $c^{+}$are the indices of the channels that $i$ watches a positive amount, and $C^{+}$is the total number of such channels. Given this result, the iterative solution is to replace the $\gamma_{i c t}$ 's below the cutoff $\left(1+\sum_{c} \gamma_{c}\right) /(B+C)$ with zero. If there were any $\gamma_{i c t}$ 's below this threshold, we now have a new cutoff defined by the remaining positive $\gamma_{i c t}$ 's, and we repeat the process again. There are at most $\mathrm{C}$ steps of this until we hit the final set of positive $\gamma_{i c t}$ 's, at which point we compute the times watched as:

$$
T_{i c t}=\left(T+C^{+}\right) \frac{\gamma_{i c t}}{\sum_{c^{+}} \gamma_{i c^{+} t}}-\mathbf{1}\left(\gamma_{i c t}>0\right)
$$




\section{Comparison of Regression Coefficients in Real and Simulated Data}

\begin{tabular}{|c|c|c|c|c|c|c|}
\hline \multirow[b]{2}{*}{ Regressor } & \multicolumn{2}{|c|}{ CNN Hours } & \multicolumn{2}{|c|}{ FNC Hours } & \multicolumn{2}{|c|}{ MSNBC Hours } \\
\hline & Real & Simulated & Real & Simulated & Real & Simulated \\
\hline CNN Position & -0.0038 & -0.0084 & -0.0009 & 0.0008 & -0.0007 & 0.0003 \\
\hline FOX Position & 0.0015 & -0.0001 & -0.0015 & -0.0067 & 0.0014 & -0.0003 \\
\hline MSN Position & 0.0001 & -0.0001 & 0.0006 & 0.0003 & -0.0027 & -0.0035 \\
\hline FOX Only & 0.0389 & -0.0084 & 0.3844 & 1.3971 & -0.0476 & 0.0487 \\
\hline MSN Only & -0.0057 & -0.0146 & 0.0165 & 0.1491 & 0.3546 & 0.7967 \\
\hline Both Available & 0.0064 & -0.0252 & 0.2806 & 1.3316 & 0.2769 & 0.7760 \\
\hline Number of Channels & 0.0007 & 0.0001 & 0.0002 & 0.0003 & -0.0003 & -0.0003 \\
\hline Number of Broadcast Channels & -0.0079 & -0.0044 & -0.0060 & -0.0032 & 0.0004 & -0.0016 \\
\hline Age Quintile 2 & 0.2560 & 0.2859 & 0.1799 & 0.2885 & 0.0915 & 0.1503 \\
\hline Age Quintile 3 & 0.4167 & 0.4002 & 0.3610 & 0.2521 & 0.1395 & 0.1383 \\
\hline Age Quintile 4 & 0.6060 & 0.5935 & 0.5227 & 0.4636 & 0.2059 & 0.1925 \\
\hline Age Quintile 5 & 1.2475 & 1.1083 & 1.0711 & 1.1149 & 0.3790 & 0.4104 \\
\hline Income & 0.6725 & 0.3916 & 0.7089 & -0.0500 & 0.3998 & 0.1508 \\
\hline Income $^{2}$ & -0.2374 & -0.0971 & -0.3055 & -0.3782 & -0.1482 & -0.2310 \\
\hline Income $^{3}$ & 0.0227 & 0.0100 & 0.0324 & 0.0706 & 0.0149 & 0.0383 \\
\hline White & -0.1579 & -0.1960 & 0.1774 & 0.3106 & -0.0098 & 0.0229 \\
\hline Black & 0.0444 & -0.0012 & 0.1722 & -0.1412 & 0.0497 & -0.0160 \\
\hline Hispanic & -0.1756 & -0.1687 & -0.1728 & -0.1591 & -0.0938 & 0.0106 \\
\hline College Graduate & 0.1865 & 0.1524 & -0.1195 & -0.0883 & 0.0632 & 0.1168 \\
\hline Man & 0.1394 & 0.1312 & 0.1750 & 0.1325 & 0.0884 & 0.0986 \\
\hline 1996 County R Share & -0.1976 & 0.0011 & 0.6419 & -0.0310 & -0.0223 & 0.0059 \\
\hline
\end{tabular}

Table A34: Comparison of regression coefficients in real data and simulations: first stage regression at the individual level. Dependent variable is individual-level hours watched of each channel.

This section reports the fit of the indirect inference estimation routine. Tables A34 and A35 report the individual and zip-code level first stage regression coefficients, respectively. Table A36 reports the auxiliary regression of an indicator for watching any of the channel on individual demographics and cable positions. Tables A37 and A38 report the second stage IV and OLS regressions at the individual and zip levels.. 


\begin{tabular}{|c|c|c|c|c|c|c|}
\hline \multirow[b]{2}{*}{ Regressor } & \multicolumn{2}{|c|}{ CNN Hours } & \multicolumn{2}{|c|}{ FNC Hours } & \multicolumn{2}{|c|}{ MSNBC Hours } \\
\hline & Real & Simulated & Real & Simulated & Real & Simulated \\
\hline CNN pos & -0.0027 & -0.0054 & 0.0019 & 0.0010 & 0.0002 & 0.0001 \\
\hline FOX pos & 0.0009 & 0.0003 & -0.0033 & -0.0043 & 0.0006 & 0.0000 \\
\hline MSN pos & 0.0003 & -0.0001 & 0.0009 & 0.0001 & -0.0014 & -0.0021 \\
\hline FOX Only & -0.0670 & -0.0930 & 0.3723 & 0.8305 & -0.0620 & -0.0135 \\
\hline MSN Only & -0.0050 & -0.0178 & -0.0202 & 0.0103 & 0.1278 & 0.4004 \\
\hline Both Available & -0.1280 & -0.0927 & 0.2780 & 0.8220 & 0.0821 & 0.3688 \\
\hline Number of Channels & -0.0001 & -0.0002 & -0.0004 & -0.0004 & -0.0002 & 0.0000 \\
\hline Number of Broadcast Channels & -0.0011 & 0.0042 & -0.0051 & 0.0035 & 0.0008 & 0.0008 \\
\hline Nielsen Diary Market & -0.0559 & 0.0168 & -0.1067 & 0.0029 & -0.0356 & 0.0094 \\
\hline Log Population Density & -0.0066 & -0.0046 & -0.0177 & -0.0073 & 0.0012 & -0.0017 \\
\hline Percent Black & 0.2616 & 0.2061 & -0.4682 & -0.2786 & 0.0475 & 0.1434 \\
\hline Percent Asian & 0.0679 & 0.5497 & -0.2136 & 0.0250 & -0.1004 & 0.0310 \\
\hline Percent Other & 0.3632 & 0.3221 & 0.5660 & -0.3146 & 0.2717 & 0.1272 \\
\hline Percent Hispanic & -0.0414 & -0.1372 & -0.4037 & -0.0934 & -0.0753 & -0.0444 \\
\hline Percent Male & 0.2960 & 0.4305 & 2.1267 & 0.3432 & 0.3573 & -0.0822 \\
\hline Percent Age 10-20 & 0.1428 & -0.3086 & -1.2863 & -0.7501 & 0.3658 & 0.8269 \\
\hline Percent Age 20-30 & 0.4524 & -0.1326 & -1.6617 & -0.2846 & 0.2384 & 0.6719 \\
\hline Percent Age 30-40 & 0.6939 & -0.4529 & -2.4931 & -0.1636 & 0.4895 & 1.0751 \\
\hline Percent Age 40-50 & 0.3961 & 0.4848 & -2.9705 & -0.5794 & -0.0944 & 0.4682 \\
\hline Percent Age 50-60 & -0.0249 & 0.4462 & -1.4036 & -0.5868 & 0.3974 & 0.7346 \\
\hline Percent Age 60-70 & 1.6054 & -0.1694 & 1.9905 & -0.6619 & 0.8937 & 0.3962 \\
\hline Percent Age 70-80 & 1.8094 & 1.2224 & 3.4916 & 2.1240 & 0.8530 & 1.7386 \\
\hline Percent Age 80+ & 2.4572 & 0.3938 & -1.0987 & 0.2538 & 1.0178 & 0.7552 \\
\hline Income Decile 2 & 0.0066 & -0.0227 & 0.0439 & -0.0830 & 0.0050 & -0.0103 \\
\hline Income Decile 3 & 0.0129 & -0.0071 & 0.0369 & -0.0680 & -0.0054 & 0.0040 \\
\hline Income Decile 4 & -0.0114 & -0.0078 & 0.0656 & -0.0859 & -0.0086 & -0.0158 \\
\hline Income Decile 5 & -0.0190 & 0.0081 & 0.0295 & -0.0497 & -0.0186 & 0.0037 \\
\hline Income Decile 6 & -0.0400 & 0.0031 & 0.0182 & -0.0917 & -0.0250 & 0.0086 \\
\hline Income Decile 7 & -0.0464 & 0.0235 & 0.0113 & -0.0997 & -0.0288 & 0.0144 \\
\hline Income Decile 8 & -0.0480 & 0.0328 & 0.0228 & -0.0840 & -0.0330 & 0.0006 \\
\hline Income Decile 9 & -0.0550 & 0.0702 & -0.0079 & -0.1217 & -0.0426 & -0.0014 \\
\hline Income Decile 10 & -0.0590 & 0.0965 & 0.0193 & -0.1018 & -0.0435 & 0.0114 \\
\hline Percent HS Grad & 0.2279 & 0.2207 & 0.0923 & 0.4498 & 0.1484 & 0.1515 \\
\hline Percent Some College & 0.4931 & -0.0068 & 0.9744 & -0.1557 & 0.2755 & 0.0096 \\
\hline Percent Bachelors' & 0.3295 & -0.0267 & 1.4768 & -0.1671 & 0.2556 & 0.0551 \\
\hline Percent Post-Grad & 0.8696 & 0.5791 & 0.0432 & -0.2022 & 0.5092 & -0.0535 \\
\hline Percent Suburban & 0.0767 & -0.1377 & 0.2993 & -0.1306 & 0.0498 & -0.0511 \\
\hline Percent Urban & 0.0475 & -0.1187 & 0.2100 & -0.1009 & 0.0556 & -0.0502 \\
\hline 1996 County R Share & -0.2069 & -0.0893 & 0.5183 & -0.0683 & -0.1123 & -0.0214 \\
\hline
\end{tabular}

Table A35: Comparison of regression coefficients in real data and simulations: first stage regression at the zipcode level. Dependent variable is zipcode-level average hours watched of each channel. 


\begin{tabular}{|c|c|c|c|c|c|c|}
\hline \multirow[b]{2}{*}{ Regressor } & \multicolumn{2}{|c|}{ CNN-Zero } & \multicolumn{2}{|c|}{ FNC-Zero } & \multicolumn{2}{|c|}{ MSNBC-Zero } \\
\hline & Real & Simulated & Real & Simulated & Real & Simulated \\
\hline CNN Position & -0.0008 & -0.0001 & -0.0002 & 0.0003 & -0.0002 & 0.0002 \\
\hline FOX Position & 0.0003 & -0.0001 & -0.0005 & -0.0004 & 0.0004 & -0.0001 \\
\hline MSN Position & 0.0000 & 0.0000 & 0.0002 & 0.0000 & -0.0009 & -0.0003 \\
\hline FOX Only & 0.0160 & 0.0038 & 0.0824 & 0.2340 & -0.0067 & 0.0038 \\
\hline MSN Only & 0.0294 & 0.0021 & 0.0067 & 0.0002 & 0.1227 & 0.1870 \\
\hline Both Available & 0.0171 & 0.0049 & 0.0654 & 0.2307 & 0.0993 & 0.1840 \\
\hline Number of Channels & 0.0003 & 0.0000 & 0.0003 & 0.0000 & 0.0001 & -0.0001 \\
\hline Number of Broadcast Channels & -0.0019 & -0.0009 & -0.0019 & -0.0007 & -0.0007 & -0.0004 \\
\hline Age Quintile 2 & 0.0568 & -0.0025 & 0.0395 & -0.0244 & 0.0306 & -0.0027 \\
\hline Age Quintile 3 & 0.0967 & 0.1241 & 0.0842 & 0.1143 & 0.0435 & 0.0512 \\
\hline Age Quintile 4 & 0.1321 & 0.1685 & 0.1080 & 0.1469 & 0.0588 & 0.0771 \\
\hline Age Quintile 5 & 0.2199 & 0.2416 & 0.1687 & 0.1439 & 0.0835 & 0.0082 \\
\hline Income & 0.3180 & 0.3405 & 0.2443 & 0.3408 & 0.2102 & 0.2630 \\
\hline Income $^{2}$ & -0.1175 & -0.1394 & -0.0983 & -0.0738 & -0.0795 & -0.0252 \\
\hline Income $^{3}$ & 0.0115 & 0.0129 & 0.0100 & 0.0066 & 0.0079 & 0.0002 \\
\hline White & -0.0257 & -0.0060 & 0.0197 & -0.0469 & -0.0004 & -0.0207 \\
\hline Black & 0.0119 & 0.0260 & 0.0490 & 0.1034 & 0.0091 & 0.0549 \\
\hline Hispanic & -0.0436 & -0.0482 & -0.0382 & -0.0226 & -0.0350 & -0.1113 \\
\hline College Graduate & 0.0610 & 0.0772 & -0.0181 & -0.0175 & 0.0385 & 0.0343 \\
\hline Man & 0.0432 & 0.0429 & 0.0475 & 0.0634 & 0.0371 & 0.0400 \\
\hline 1996 County R Share & 0.0200 & -0.0094 & 0.1487 & -0.0071 & 0.0327 & -0.0049 \\
\hline
\end{tabular}

Table A36: Comparison of regression coefficients in real data and simulations. Dependent variable is an (individual-level) indicator for watching any of the channel. 


\begin{tabular}{l|rr|rr}
\hline \hline & \multicolumn{3}{|c}{ Vote Intention - IV } & \multicolumn{2}{c}{ Vote Intention - OLS } \\
Regressor & Real & Simulated & Real & Simulated \\
\hline FOX Predicted Hours & 0.2127 & 0.0445 & & \\
CNN pos & 0.0000 & 0.0002 & & \\
MSN pos & -0.0001 & 0.0000 & & \\
CNN Most-Watched & & & -0.0912 & -0.0578 \\
FOX Most-Watched & & & 0.3073 & 0.2533 \\
MSN Most-Watched & & & -0.0971 & -0.0218 \\
FOX Only & -0.0697 & -0.0199 & -0.0215 & 0.0224 \\
MSN Only & -0.0017 & 0.0002 & 0.0163 & 0.0041 \\
Both Available & -0.0522 & -0.0212 & -0.0066 & 0.0264 \\
Number of Channels & -0.0006 & 0.0001 & -0.0007 & 0.0000 \\
Number of Broadcast Channels & 0.0006 & 0.0000 & -0.0005 & 0.0001 \\
Age Quintile 2 & -0.0103 & 0.0733 & 0.0467 & 0.0804 \\
Age Quintile 3 & -0.0489 & 0.0420 & 0.0658 & 0.0449 \\
Age Quintile 4 & -0.1096 & -0.0143 & 0.0136 & 0.0068 \\
Age Quintile 5 & -0.2018 & 0.0044 & 0.0310 & 0.0580 \\
Income & 0.3104 & 0.5407 & 0.4242 & 0.4246 \\
Income ${ }^{2}$ & -0.2918 & -0.1149 & -0.3043 & -0.1010 \\
Income ${ }^{3}$ & 0.0803 & 0.0075 & 0.0707 & 0.0073 \\
White & 0.0443 & 0.1115 & 0.0899 & 0.1182 \\
Black & -0.3662 & -0.2804 & -0.2920 & -0.2697 \\
Hispanic & -0.0277 & -0.0772 & -0.0859 & -0.0797 \\
College Graduate & -0.0522 & -0.0940 & -0.0508 & -0.0759 \\
Man & 0.0367 & 0.0518 & 0.0427 & 0.0466 \\
1996 County R Share & 0.4810 & 0.0257 & 0.4894 & 0.0190 \\
\hline \hline
\end{tabular}

Table A37: Comparison of regression coefficients in real data and simulations. Dependent variable is individual-level Republican vote intention. 


\begin{tabular}{|c|c|c|c|c|}
\hline \multirow[b]{2}{*}{ Regressor } & \multicolumn{2}{|c|}{ Vote Intention - IV } & \multicolumn{2}{|c|}{ Vote Intention - OLS } \\
\hline & Real & Simulated & Real & Simulated \\
\hline FOX Predicted Hours & 0.0783 & 0.1002 & & \\
\hline CNN pos & -0.0001 & 0.0003 & & \\
\hline MSN pos & 0.0000 & 0.0000 & & \\
\hline CNN Hours & & & -0.0052 & -0.0227 \\
\hline FOX Hours & & & 0.0105 & 0.0240 \\
\hline MSN Hours & & & -0.0111 & -0.0190 \\
\hline FOX Only & 0.0007 & 0.0096 & 0.0306 & 0.0611 \\
\hline MSN Only & -0.0050 & -0.0103 & 0.0073 & -0.0199 \\
\hline Both Available & -0.0039 & -0.0023 & 0.0143 & 0.0616 \\
\hline Number of Channels & -0.0001 & 0.0001 & -0.0002 & 0.0000 \\
\hline Number of Broadcast Channels & 0.0008 & 0.0000 & 0.0019 & 0.0002 \\
\hline Nielsen Diary Market & 0.0090 & 0.0012 & 0.0151 & -0.0052 \\
\hline Log Population Density & -0.0075 & 0.0020 & -0.0086 & 0.0006 \\
\hline Percent Black & -0.4687 & -0.3122 & -0.5090 & -0.3255 \\
\hline Percent Asian & -0.0133 & -0.1085 & -0.0337 & -0.0945 \\
\hline Percent Other & -0.2625 & -0.0986 & -0.1716 & -0.1677 \\
\hline Percent Hispanic & -0.1593 & -0.0731 & -0.2092 & -0.0781 \\
\hline Percent Male & 0.1447 & 0.1176 & 0.3167 & 0.2454 \\
\hline Percent Age 10-20 & -0.0945 & -0.1251 & -0.6868 & -0.2507 \\
\hline Percent Age 20-30 & -0.4102 & -0.2713 & -0.8117 & -0.4524 \\
\hline Percent Age 30-40 & -0.4059 & -0.3194 & -1.2890 & -0.4273 \\
\hline Percent Age 40-50 & -0.0597 & 0.0332 & -0.4025 & -0.3862 \\
\hline Percent Age 50-60 & -0.5314 & -0.0808 & -0.8885 & -0.1065 \\
\hline Percent Age $60-70$ & -0.8083 & -0.1636 & -1.1453 & -0.5558 \\
\hline Percent Age 70-80 & -0.0943 & -0.3253 & 0.0176 & 0.0176 \\
\hline Percent Age 80+ & -0.2447 & -0.2336 & -0.7991 & -0.3938 \\
\hline Income Decile 2 & 0.0253 & 0.0205 & 0.0500 & 0.0139 \\
\hline Income Decile 3 & 0.0354 & 0.0296 & 0.0625 & 0.0204 \\
\hline Income Decile 4 & 0.0374 & 0.0429 & 0.0687 & 0.0337 \\
\hline Income Decile 5 & 0.0416 & 0.0432 & 0.0702 & 0.0363 \\
\hline Income Decile 6 & 0.0450 & 0.0554 & 0.0773 & 0.0467 \\
\hline Income Decile 7 & 0.0578 & 0.0671 & 0.0941 & 0.0584 \\
\hline Income Decile 8 & 0.0670 & 0.0761 & 0.1010 & 0.0655 \\
\hline Income Decile 9 & 0.0815 & 0.1020 & 0.1074 & 0.0861 \\
\hline Income Decile 10 & 0.1001 & 0.1438 & 0.1197 & 0.1183 \\
\hline Percent HS Grad & -0.0425 & 0.0058 & -0.0692 & 0.0690 \\
\hline Percent Some College & -0.0766 & 0.0244 & 0.0744 & 0.0225 \\
\hline Percent Bachelors' & -0.1721 & 0.0334 & 0.0001 & 0.0859 \\
\hline Percent Post-Grad & -0.4056 & 0.1130 & -0.3799 & 0.0593 \\
\hline Percent Suburban & -0.0119 & 0.0205 & 0.0046 & 0.0117 \\
\hline Percent Urban & -0.0218 & 0.0109 & -0.0064 & 0.0053 \\
\hline 1996 County R Share & 0.4572 & 0.0318 & 0.5034 & 0.0301 \\
\hline
\end{tabular}

Table A38: Comparison of regression coefficients in real data and simulations. Dependent variable is individual-level Republican vote intention. 